\title{
Cell therapy for spinal cord injury with Olfactory Ensheathing Glia Cells (OECs)
}

\section{Running Title: Cell Therapy with OECS}

Rosa M. Gómez ${ }^{*, 1}$, Magdy Y. Sánchez ${ }^{\ddagger 1,2}$, Maria Portela-Lomba ${ }^{\ddagger, 3}$, Kemel Ghotme ${ }^{4}$, George E. Barreto ${ }^{5,6}$, Javier Sierra ${ }^{\&, 3}$, M. Teresa Moreno-Flores ${ }^{*, \&, 7}$

1. Fundación de Neuroregeneración en Colombia, Grupo de investigación NeuroRec.

2. Maestría en Neurociencias, Universidad Nacional de Colombia, Bogota D.C., Colombia.

3. Facultad de CC Experimentales, Universidad Francisco de Vitoria, Pozuelo de Alarcón (Madrid), Spain.

4. Facultad de Medicina, Universidad de la Sabana, Chía, Colombia.

5. Departamento de Nutrición y Bioquímica, Facultad de Ciencias, Pontificia Universidad Javeriana, Bogota D.C., Colombia.

6. Instituto de Ciencias Biomédicas, Universidad Autónoma de Chile, Santiago, Chile.

7. Facultad de Medicina, Universidad Autónoma de Madrid, Madrid, Spain.

$\ddagger$ \&: These authors contributed equally to this review.

\section{*Corresponding authors:}

Rosa Margarita Gomez-Bello PhD., Fundación de Neuroregeneracion en Colombia.

rosa.gomez.b1@gmail.com

neurorecolombia@gmail.com
M. Teresa Moreno-Flores PhD, Facultad de Medicina, C/Arzobispo Morcillo 2, Universidad Autónoma de Madrid, 28029 Madrid, Spain. mteresa.moreno@uam.es

\section{ACKNOWLEDGMENTS}

We would like to thank: i) the Fundación de Neuroregeneración de Colombia, Grupo NeuroRec for their contributions in preparing this manuscript; and ii) to Candelas Gil from the Library and Documentation Service of the Facultad of Medicina from Universidad Autónoma de Madrid, for her valuable help with the preparation of the references.

\section{CONFLICTS OF INTEREST STATEMENT}

The authors have no conflicts of interest to declare in relation to this systematic review or the preparation of the manuscript.

WORD COUNT: Abstract, 250; Section 1 (Introduction), 1073; Section 2, 603; Section 3, 1454; Section 4, 1511; Section 5, 5981; Section 6, 2536; Section 7, $\underline{309}$; References, 12108; Figure legends, 442; Table 1, 294; Table 2, 푸; Table 3, 1913; TOTAL 28531 Words. 
Table of Contents: Main Points

1. Current status of research in OECs: ontogeny, morphological aspects, physiological functions, and molecular characteristics.

2. Properties of OECs that make them suitable to achieve neuroplasticity/neuroregeneration in SCI: OECs can interact with the glial scar; stimulate angiogenesis, axon outgrowth and remyelination.

3. Promising results of cell therapy with $\mathrm{OECs}$ to treat $\mathrm{SCl}$ for future treatments, both from animal models and clinical studies performed on $\mathrm{SCl}$ patients. 


\section{Abstract}

The prospects of achieving regeneration in the Central Nervous System (CNS) have changed, as most recent findings indicate that several species, including humans, can produce neurons in adulthood. Studies targeting this property may be considered as potential therapeutic strategies to respond to injury or the effects of demyelinating diseases in the CNS. While CNS trauma may interrupt the axonal tracts that connect neurons with their targets, some neurons remain alive, as seen in optic nerve and spinal cord (SC) injuries ( $\mathrm{SCls}$ ). The devastating consequences of $\mathrm{SCls}$ are due to the immediate and significant disruption of the ascending and descending spinal pathways, which result in varying degrees of motor and sensory impairment. Recent therapeutic studies for $\mathrm{SCl}$ have focused on cell transplantation in animal models, using cells capable of inducing axon regeneration like Schwann cells (SchCs), astrocytes, genetically modified fibroblasts and olfactory ensheathing glia cells (OECs). Nevertheless, and despite the improvements in such cell-based therapeutic strategies, there is still little information regarding the mechanisms underlying the success of transplantation and regarding any secondary effects. Therefore, further studies are needed to clarify these issues. In this review, we highlight the properties of OECs that make them suitable to achieve neuroplasticity/neuroregeneration in $\mathrm{SCl}$. OECs can interact with the glial scar, stimulate angiogenesis, axon outgrowth and remyelination, improving functional outcomes following lesion. Furthermore, we present evidence of the utility of cell therapy with $\mathrm{OECS}$ to treat $\mathrm{SCl}$, both from animal models and clinical studies performed on $\mathrm{SCl}$ patients, providing promising results for future treatments.

Keywords: Olfactory ensheathing glia cells, Cell therapies, Transplantation, Spinal cord injuries, Cell transplantation, Neuroregeneration. 


\section{I INTRODUCTION}

Spinal cord injury $(\mathrm{SCl})$ is a secondary outcome of a compression injury, bleeding and/or ischemia, which compromises the bone component of the spine, the spinal cord (SC) and its coverings. Several mechanisms can cause this type of damage, the most common bone injury being bone disruption produced by flexo-extension injuries associated with fracture (Ahuja, Martin, \& Fehlings, 2016; McDonald and Sadowsky, 2002; Rogers and Todd, 2016). The pathological features of traumatic SCl include axon demyelination, which is in part due to the loss of the glial substrate at the site of injury as a combined result of necrosis, apoptosis and autophagy (McDonald and Sadowsky, 2002; Plemel et al., 2014). In the days and weeks following SCl there is extensive oligodendrocyte loss and widespread demyelination, which can already be detected at 7 days post injury (DPI) (Plemel et al., 2014).

$\mathrm{SCl}$ generates a series of temporary anatomical and pathological changes. After the first pathological events associated with injury (see below), a secondary phase begins from 1 to $3 \mathrm{DPI}$, and a loss of blood vessels, neurons, glial cells and axonal tracts occurs in this phase. These events are responsible for the loss of function in most nervous system injuries (Botero, Gómez, \& Chaparro, 2013; McDonald and Sadowsky, 2002). As such, $\mathrm{SCl}$ can generally be divided into different clinical phases:

i) Acute $\mathrm{SCl}$ - with destruction of the blood-brain barrier, alterations to the microvasculature of the grey matter and induction of petechial haemorrhages, which has also been linked with the formation of oedema, thrombin production and erythrocyte lysis. Vascular changes and haemorrhages fulfil a crucial role in the initial pathological events leading to neuronal cell death and axonal damage (Gerzanich et al., 2009; Griffiths, Burns, \& Crawford, 1978; Losey and Anthony, 2014; Losey, Young, Krimholtz, Bordet, \& Anthony, 2014; Yu and Fehlings, 2011). The presence of inflammatory cells can also be observed, especially that of neutrophils, which have been detected as soon as three minutes after a contusion injury and that are related to the extent of injury (Griffiths et al., 1978; Taoka et al., 1997; Yu and Fehlings, 2011). In addition to the vascular changes, several pathophysiological events take place after $\mathrm{SCl}$. There is a loss of ionic regulation 
that leads to a loss of nerve impulses and oedema formation. An increase of free intracellular calcium also occurs, which activates the proteases and phospholipases that are involved in the destruction of myelin (Balentine, 1988). Glutamate and aspartate release also produces the excessive excitation of viable neurons and there is a disruption of redox homeostasis, with the consequent generation of free radicals (e.g., superoxide anions, hydrogen peroxide, hydroxyl anions, etc.: (Tator and Fehlings, 1991).

ii) Subacute $\mathrm{SCl}$ - in which glial cell activation occurs as a result of necrosis, haemorrhage and local ischemia, and in which neuronal and oligodendroglial apoptosis takes place (Spitzbarth et al., 2011; Tator and Koyanagi, 1997; Yu and Fehlings, 2011).

iii) Chronic $\mathrm{SCl}$ - in which the degenerative process continues and extends beyond the primary lesion (Gomez, 2009; McDonald and Sadowsky, 2002; Tator and Koyanagi, 1997).

Glial and neuronal degeneration, and demyelination is evident in each of these phases, with morphological and structural abnormalities in both the grey and white matter associated with complete SCI (Botero, 2015; McDonald and Sadowsky, 2002).

After $\mathrm{SCl}$, severe functional deficits generally appear as a result of the disconnection in the spinal tract, a condition that persists due to the poor capacity for spontaneous axonal regeneration of the neurons implicated. This is due to several problems: i) intrinsic neuronal deficits in the expression of genes implicated in axon regrowth/regeneration (Bomze, Bulsara, Iskandar, Caroni, \& Skene, 2001; Hannila and Filbin, 2008); ii) the presence of inhibitory factors in the glial scar that develops after trauma (Cregg et al., 2014; Silver and Miller, 2004; Yiu and He, 2006); and iii) a lack of trophic factors for neuroprotection and regeneration (Jones, Oudega, Bunge, \& Tuszynski, 2001; Sharma, 2007).

Functional recovery from the SCl depends on its pathophysiology (Tator, 1998) and different therapeutic strategies have been considered to achieve this, both individually and in combination. These strategies include approaches that involve the provision of neurotrophic factors, overcoming glial scar inhibitory factors and cell transplantation 
(Assinck, Duncan, Hilton, Plemel, \& Tetzlaff, 2017; Bunge, 2008; Jones et al., 2001; Moreno-Flores and Avila, 2006; Moreno-Flores and Avila, 2010). Glial cell transplantation aims to provide neuroprotection and/or promote the plasticity/myelination of spared fibres, and/or to foster axon regeneration. Stem cell transplantation aims to provide new glial cells for myelination or neuroprotection, or new neurons to replace the lost ones and/or to provide synaptic relays (Erceg et al., 2010; Lu et al., 2012; Moreno-Flores and Avila, 2006; Moreno-Flores and Avila, 2010; Moreno-Manzano et al., 2009; Okano, 2002; Zurita and Vaquero, 2006; Zurita et al., 2008). In animal SCI models of diverse severity, promising results have been obtained by transplanting different cell types, such as:

- Schwann cells (SchCs) or peripheral nerve grafts (Cheng, Cao, \& Olson, 1996; Kanno, Pearse, Ozawa, Itoi, \& Bunge, 2015);

- Olfactory ensheathing glia cells (OECs: (Li, Field, \& Raisman, 1997; Lopez-Vales, Fores, Verdu, \& Navarro, 2006; Lu, Feron, Ho, Mackay-Sim, \& Waite, 2001; RamonCueto and Nieto-Sampedro, 1994; Ramon-Cueto, Plant, Avila, \& Bunge, 1998; Ramon-Cueto, Cordero, Santos-Benito, \& Avila, 2000);

- Genetically modified OECs (Lim et al., 2010; Moreno-Flores et al., 2006);

- Olfactory mucosa (OM) grafts (Iwatsuki et al., 2008);

- Different types of stem cells (Assinck et al., 2017; Deshpande et al., 2006; Erceg et al., 2010; Lu et al., 2012; Okano, 2002), including ependymal stem cells (MorenoManzano et al., 2009), bone marrow mesenchymal stem cells (Laroni, Novi, Kerlero, \& Uccelli, 2013; Novikova, Brohlin, Kingham, Novikov, \& Wiberg, 2011; Urdzikova et al., 2006; Zurita and Vaquero, 2006; Zurita et al., 2008) and mesenchymal stem cells (MSCs) from the human mucosa lamina propria (OMMSCs: (Lindsay, Riddell, \& Barnett, 2010; Lindsay and Barnett, 2017; Lindsay et al., 2017).

- Fibroblasts and genetically modified fibroblasts (GMFs: (Franzen, Martin, Daloze, Moonen, \& Schoenen, 1999; Grill, Murai, Blesch, Gage, \& Tuszynski, 1997; Grill, Blesch, \& Tuszynski, 1997; Tuszynski, Murai, Blesch, Grill, \& Miller, 1997).

This review focuses on OECS due to their inherent ability to support the continuous renewal of olfactory neurons in the olfactory system, and their ability to stimulate axon repair/plasticity/sparing and functional recovery in the central nervous system 
(CNS: (Barnett and Riddell, 2007; Franssen, de Bree, \& Verhaagen, 2007; MorenoFlores, Diaz-Nido, Wandosell, \& Avila, 2002; Ramon-Cueto and Valverde, 1995).

\section{I ONTOGENY OF OLFACTORY ENSHEATHING GLIA CELLS (OECs)}

OECs are a type of macroglia located in the OM lamina propria (LP) of the peripheral nervous system (PNS) and in the CNS, in the external layer of the olfactory bulb (OB), the olfactory nerve layer (ONL). These cells are organized along the pathway from the $\mathrm{OM}$ to the $\mathrm{OB}$ and they are derived from the embryonic ectoderm in the olfactory placodes at the lateral-face of the embryo's head. It is from this region that the migratory mass that gives rise to the olfactory nerve originates. Finally, the cells and bundles of axons of this mass reach the prospective $O B$ in the telencephalic vesicle, which originates from the mantle of the forebrain (Chuah and $\mathrm{Au}, 1991$; Doucette, 1990; Doucette, 1993; Miller, Treloar, \& Greer, 2010; Ramon-Cueto and Valverde, 1995; Valverde, Santacana, \& Heredia, 1992).

Recent studies established a dual source of OECs, implicating the neural crest in their origin together with the ectodermal placodes (Katoh et al., 2011). Indeed, more recent studies using fate-mapping techniques and genetic lineage tracing suggest that OECS are exclusively derived from the neural crest (Fig. 1: (Barraud et al., 2010; Forni, TaylorBurds, Melvin, Williams, \& Wray, 2011). These neural crest cells would later contribute to the ectodermal derived cranial placodes (Forni et al., 2011) and therefore, OECs share a common developmental lineage with SchCs. This modifies the previous model of OEC development and it could explain the similarities between both types of cells (Barraud et al., 2010; Forni et al., 2011). Moreover, because stem cells from the neural crest persist in adult tissue, these cells could provide an accessible source of OECs for autologous SCl therapy (Barraud et al., 2010).

The normal physiology of OECs in the adult is not yet well understood. In the mature olfactory neuroepithelium (Fig. 2), sensory neurons renew with a turnover of around 28 days (Chuah and West, 2002). New olfactory neurons extend an apical dendrite and 
a basal axon, and these new axons fasciculate with other ones to grow in the right direction through the LP (connective tissue), cross the cribriform plate of the ethmoids, and finally reach the $\mathrm{OB}$ in the CNS to connect with their targets in the glomeruli (Chuah and West, 2002). Two types of neural stem cells coexist in the adult olfactory epithelium, the globose basal cells (GBCs) and the horizontal basal cells (HBCs, see Fig.2; (Carr, Farbman, Colletti, \& Morgan, 1991; Frisch, 1967; Graziadei and Graziadei, 1979; Holbrook, Szumowski, \& Schwob, 1995). The former are the main source of neurons that give rise to the main cell populations of the mucosa, whereas the second cell type (HBCS) are normally inactive, although they can be activated to generate new GBCs and reconstitute the population of the olfactory epithelium after extreme injury (Carter, MacDonald, \& Roskams, 2004; Leung, Coulombe, \& Reed, 2007). However, the true origin of new OECs in vivo has not yet been fully clarified and thus, it is still not clear how the turnover of OECs in the adult mucosa takes place. Some in vitro studies suggest that HBCs could give rise to new OECs, perhaps through intermediate steps involving precursor cells (Carter et al., 2004). Nevertheless this process might be very slow or rare in vivo. In this sense, it was shown that OECs do not divide or noticeably migrate within the olfactory system in response to a lesion of the OM (zinc sulphate irrigation). These studies suggest that regenerating olfactory nerve processes grow through conduits of remaining OECs, implying that these cells and their conduits persist as "pathways" for regenerating fibres (Williams, Franklin, \& Barnett, 2004).

\section{I OLFACTORY CELL CHARACTERISTICS AND THEIR ORIGINS IN THE OM OR OB}

OECs are elongated in shape with a thin laminar process that wraps around the olfactory nerves in situ, while they are characterized by their flat, bipolar or multipolar morphology in culture (Franceschini and Barnett, 1996; Vincent, West, \& Chuah, 2005). OECs are present in both the peripheral olfactory nerve and in the ONL of the OB in the CNS (Vincent et al., 2005). They express several recognized markers (Figs. 3A and B) that can be detected by immunostaining in vitro and in vivo (Alexander, Fitzgerald, \& 
Barnett, 2002; Franceschini and Barnett, 1996; Gomez et al., 2016; Vincent et al., 2005). However, the expression of these proteins depends on their state of differentiation and their location in the CNS or PNS (Vincent et al., 2005). In the adult $\mathrm{OB}$ in vivo (Fig. $3 \mathrm{~A}$ ), OECs express $\mathrm{S} 100 \beta$, an intracellular calcium binding protein, and the intermediate filament protein GFAP (glial fibrillary acidic protein), albeit more weakly. In addition, OECs located in the outer area of the ONL of the OB weakly express the low-affinity NGF receptor, p75NTR, and the embryonic form of the neural cell adhesion molecule, E-NCAM. By contrast, in the inner area of the ONL these cells express neuropeptide Y (NPY) but not p75NTR or E-NCAM (Barnett, Hutchins, \& Noble, 1993; Franceschini and Barnett, 1996; Ubink, Halasz, Zhang, Dagerlind, \& Hokfelt, 1994; Valverde et al., 1992; Vincent et al., 2005). In the adult mouse, cells containing S100 are distributed throughout the ONL, and p75NTR also appears to be restricted to the olfactory nerve and the outer ONL. While NPY positive OEC processes are located in the inner ONL, GFAP positive processes appear to be distributed in the inner ONL, at the ONL/glomerular layer boundary and in the glomerular layer, defining loosely aggregated axon fascicles that enter the glomeruli obliquely ( $\mathrm{Au}$, Treloar, \& Greer, 2002). However, a population of unidentified glial cells positive for GFAP but not S100 has also been detected (Au et al., 2002).

During the in vitro characterization of the OECs obtained from cultures of the neonatal rat $\mathrm{OB}$, subpopulations of cells have been found with morphological and proteomic features similar to those described above (Fig. 3B). These subpopulations were defined as: i) astrocyte-like, similar in morphology to flattened astrocytes, and characterized by the expression of E-NCAM and GFAP (fibrous appearance); and ii) SchC-like, spindle shaped, similar in morphology to SchCs, and characterized by the expression of p75NTR, weak (diffuse) GFAP expression and a lack of E-NCAM (Franceschini and Barnett, 1996).

Although these studies described the existence of these two populations of OECs in vitro and in vivo (Franceschini and Barnett, 1996; Pixley, 1992), it is not possible to accurately determine if these two populations exist in the $\mathrm{ONL}$ of the $\mathrm{OB}$, as variations in protein expression at different stages of development cannot be ruled out. In addition, the acquisition of different morphologies and markers by clonal OECs in 
response to the culture conditions must be considered (Alexander et al., 2002; Franceschini and Barnett, 1996; Moreno-Flores et al., 2003a; Moreno-Flores et al., 2003b; Moreno-Flores et al., 2006; Pixley, 1992; Vincent et al., 2005). Furthermore, OECs are migratory cells (Huang et al., 2008; Nocentini et al., 2012; Reginensi et al., 2015; Windus, Claxton, Allen, Key, \& St John, 2007) and dynamic lamellipodal waves are crucial for cell migration (Windus et al., 2007). Through the re-organization of the cytoskeleton, different phenotypes with flattened and spindle-shaped morphologies can be generated (the morphological characteristics of astrocytes and SchCs, respectively), producing unique OEC subpopulations that can spontaneously transform from one to the other (Huang et al., 2008).

Finally, other potential phenotypic OEC markers have been described, such as Calponin, an actin binding protein associated with smooth muscle contraction and smooth muscle $\alpha$-actin, and a marker that can help differentiate OECs from SchCs in vitro and in vivo (Boyd et al., 2006; Jahed et al., 2007; Rizek and Kawaja, 2006). However, conflicting results have been obtained when trying to test these markers (Ibanez, Ito, Zawadzka, Jeffery, \& Franklin, 2007), and calponin expression defined subpopulations of mucosal connective tissue cells rather than OECS in embryonic and neonatal tissue. In vitro punctate staining appears to be non-specific, seen also in astrocytes and fibroblasts (Tome, Siladzic, Santos-Silva, \& Barnett, 2007), and therefore, calponin seem not be a specific OEC marker.

A growing number of studies have been performed to obtain OECs in vitro from different sources of tissue: from the $\mathrm{OB}$ or $\mathrm{OM}$ of neonatal, early post-natal and young rodents (Au and Roskams, 2002; Au and Roskams, 2003; Barnett et al., 1993; Gomez et al., 2016; Pixley, 1992); from adult rodents (Jani and Raisman, 2004; Ramon-Cueto and Nieto-Sampedro, 1992); or from young and adult humans (Garcia-Escudero et al., 2010; Garcia-Escudero et al., 2012; Jani and Raisman, 2004; Lim et al., 2010). It has not been possible to extract accurate generalizations from these studies due to the difficulty in comparing results from such a variety of sources, and given the different culture techniques that have been employed and the distinct antigenic features have been used to define OECs in each. Moreover, while $O B$ and OM derived cells have been evaluated in vitro and in vivo, there is still no consensus regarding the "adequate" 
regenerative histological features or on the use of OECs derived from different sources. Nevertheless, the culture method (Garcia-Escudero et al., 2012) and composition of these cultures seems to be fundamental to the nature of the cells obtained (Ibrahim et al., 2014; Jani and Raisman, 2004; Mayeur et al., 2013). It was proposed that OM and $O B$ derived OECs both have the same potential, both reducing astrocyte reactivity and hindering the formation glial scar, as well as promoting axonal regrowth, and electrophysiological and functional recovery (Mayeur et al., 2013). Moreover, it was concluded that the accessibility of OM-OECs gave them the best benefit/risk ratio. OM and $\mathrm{OB} \mathrm{OECs}$ were also compared in a rat transplantation model of $\mathrm{SCl}$ and although they exhibit some distinct properties (see below "OEG transplantation in animal models of $\mathrm{SCl}^{\prime \prime}$ ), both reduced the size of the lesion and of the cavity in the $\mathrm{SC}$, and provoked differential sprouting of spinal axon tracts (Richter, Fletcher, Liu, Tetzlaff, \& Roskams, 2005). Despite the possible biological differences between these types of OECs, both have neuroregenerative properties, fostering axon outgrowth from adult CNS neurons in culture (Garcia-Escudero et al., 2012). Nevertheless, it should be noted that cultures from a dissected OM can contain a small proportion of p75NTR-positive cells, which could explain the lack of an effect of the OM cells when transplanted in a rat model of rhizotomy, as opposed to that of cells cultured from the OB. OM cells failed to produce axonal regrowth across the severed roots and functional restoration (forepaw grafting: (Ibrahim et al., 2014; Li, Carlstedt, Berthold, \& Raisman, 2004). However, the results of clinical studies (Tabakow et al., 2013; Tabakow et al., 2014) should also be considered in this regard (see below "OECs to cure SCI: Clinical studies"). In our hands, immortalized rat OEC clonal cell lines originating from the OB develop different morphologies in culture depending on the composition of the culture medium. Additionally, many cells lose their p75NTR expression without losing their capacity to promote axon regeneration in co-culture with CNS neurons (Moreno-Flores et al., 2003a; Moreno-Flores et al., 2003b). Indeed, these immortalized clonal cells favour in vivo axonal repair/sprouting/sparing and functional recovery (Moreno-Flores et al., 2006). Nevertheless, the data available do indicate that the cells obtained from the $\mathrm{OM}$ are a mixture of cell populations. 
Such variety in the stem cells and OECs in the OM was also proposed following clinical studies of OM grafts transplanted into regions of SCl (Lima et al., 2006), and the OM has recently been confirmed as a potential source of adult stem cells (Feron, Perry, Girard, \& Mackay-Sim, 2013; Girard et al., 2011; Lindsay et al., 2013; Lindsay, Johnstone, McGrath, Mallinson, \& Barnett, 2016; Lindsay and Barnett, 2017; Nivet et al., 2011; Stamegna et al., 2014; Tome, Lindsay, Riddell, \& Barnett, 2009). In addition to OECs, human OM biopsies contain up to $5 \%$ mesenchymal-like stromal cells from the LP. Using miRNA-based fingerprinting these cells were shown to be $64 \%$ homologous to bone marrow-derived MSCS (BM-MSCs: (Lindsay et al., 2016), although they also had other specific properties. OM-MSCs differed from classical BM-MSCs through their anti-inflammatory properties, secreting less pro-inflammatory cytokines, and their stronger capacity to promote rat oligodendrocyte myelination in vitro (Lindsay et al., 2016). These cells maintain the properties of all MSCs in general and the specific properties of OM-MSCs in particular. Therefore, they may be a good alternative for transplantation after SCI or CNS lesions (Assinck et al., 2017; Laroni et al., 2013).

\section{I MOLECULAR FEATURES AND CELLULAR FUNCTIONS OF OECS}

The adult olfactory system is composed of the OM, which contains the peripheral sensory neurons whose axons form the olfactory nerve, and the $O B$ that is part of the CNS. During the lifetime of a mammal, olfactory sensory neurons die regularly as a result of environmental exposure and they are replaced by newly differentiated neurons. These new neurons grow axons that enter the $O B$ and establish new synapses with their targets (Costanzo, 1985; Doucette, Kiernan, \& Flumerfelt, 1983; Farbman, 1994; Graziadei and Graziadei, 1979; Harding, Graziadei, Monti Graziadei, \& Margolis, 1977). This remarkable capacity of the olfactory system is due to the special properties of the glia cells on which this review focuses, OECs (Doucette, 1984; Doucette, 1990; Doucette, 1991; Raisman, 1985). In addition, precursors in the stem niche of the olfactory system and the characteristics of OECs enable functional neural connections 
with targets in the CNS to be re-established after injury (e.g. transection of the olfactory nerve: (Doucette, 1984; Doucette et al., 1983; Doucette, 1995; Harding et al., 1977).

OECs perform specific functions within the olfactory system. In the OM they provide a favourable environment for the development of sensory axons, which fasciculate to form the first cranial nerve, and that grow through these territories to enter the CNS and establish functional synapses in the OB glomeruli. OECs ensheath, accompany and guide these axons from the OM to the OB (Doucette, 1990; Doucette, 1995; MorenoFlores et al., 2002; Ramon-Cueto and Valverde, 1995). OECs and olfactory axons maintain communication by evoking calcium signals via glutamatergic and purinergic pathways (Rieger, Deitmer, \& Lohr, 2007), and these axons do not establish synapses until they arrive at the glomeruli in the $\mathrm{OB}$. The cytoplasmic prolongations of OECs envelop these packages of axons, acting as an insulator and ensuring they avoid coming into contact with other inhibitory CNS factors that would otherwise restrict axonal growth.

The molecular mechanism by which OECs support axonal outgrowth are yet not fully understood, although several of the molecules responsible for this capacity have been identified in recent years. OECs are known to express a number of proteins that can aid such events, including membrane bound and secreted adhesion molecules that promote axonal growth (Table 1A \& Fig. 4): L1, E-NCAM, laminin, fibronectin, type IV collagen, and amyloid precursor protein (APP)(Doucette, 1996; Franceschini and Barnett, 1996; Kafitz and Greer, 1998; Moreno-Flores et al., 2003a). These molecules can act as favourable substrates for axonal growth, and laminin in particular is a preferential substrate for in vitro neurite extension by olfactory neurons (Kafitz and Greer, 1997).

OECs are also characterized by the secretion of diffusible factors - neurotrophins (NTs) and other trophic factors responsible for neurite extension by olfactory neurons in vitro (Kafitz and Greer, 1999). NTs fulfil an important role in neuronal development, promoting proliferation, survival or axonal outgrowth (Huang and Reichardt, 2001; Huang and Reichardt, 2003) through their specific tyrosine kinase receptors, Trks, 
which in turn activate intracellular signaling through $\mathrm{G}$ proteins like Ras, Rap-1 and Cdc-42 (Huang and Reichardt, 2001; Huang and Reichardt, 2003). Cultured OECS express mRNA for nerve growth factor (NGF), brain derived neurotrophic factor (BDNF), glial cell-derived neurotrophic factor (GDNF), neurturin (NTN) and neuregulins (Boruch et al., 2001; Lipson, Widenfalk, Lindqvist, Ebendal, \& Olson, 2003; MorenoFlores et al., 2002; Pastrana et al., 2007; Woodhall, West, \& Chuah, 2001), as well as their receptors TrkB, TrkC, GFR $\alpha-1$ and GFR $\alpha-2$ (Table 1A \& Fig. 4: (Lipson et al., 2003; Woodhall et al., 2001). In addition, the intracellular presence and the secretion of NGF, BDNF (Pastrana et al., 2007; Woodhall et al., 2001) and neuregulin (Boruch et al., 2001) has been confirmed by immunocytochemistry and ELISA (Table 2). While some contradictory results have been obtained regarding NT-4 and ciliary neurotrophic factor (CNTF) mRNA expression ((Boruch et al., 2001; Lipson et al., 2003), some of these studies were carried out on a clonal OEC line. Moreover, mRNA for S100 $\beta$, CNTF, BMP7/OP-1 and artemin has been detected in the ONL of the OB, as has that encoding the RET and TrkC receptors in the ONL (Lipson et al., 2003).

Considering their patterns of expression, it seems that some of these trophic factors may exert an autocrine effect on OECs, e.g. the ligand/receptor pairs NGF/p75NTR, BDNF/TrkB, GDNF/GFR $\alpha-1$ and NTN/GFR $\alpha-2$. In the case of GDNF and NTN, conflicting results have been reported regarding the expression of the transducing subunit of these receptors, RET. RET mRNA was not detected in cultured OECs, suggesting that these cells lack RET and thus, as they would be unable to transduce the signals from GDNF and NTN, and that they might simply bind and present these factors to growing neurons (Woodhall et al., 2001). However, the subunits of these receptors and RET mRNA were detected in the ONL of the OB (Lipson et al., 2003), where OECs constitute the main type of cell. Thus, the function of GDNF and NTN in the olfactory system still remains uncertain.

Specific neuregulins, such as NRG-1 isoforms, are trophic factors for OECs, acting through ErbB receptors (Moreno-Flores et al., 2002) given that OECs express ErbB2, 3 and 4 in culture (Table 1A: (Moreno-Flores et al., 2003b; Pollock, Franceschini, Graham, Marchionni, \& Barnett, 1999). Therefore, neuregulins may also exert autocrine effects on these cells. OECs also express other molecules that have neurotrophic effects, like 
S100ß (Franceschini and Barnett, 1996; Lipson et al., 2003; Vincent et al., 2005), and that may fulfil important functions in brain development (Barger, Wolchok, \& Van Eldik, 1992; Marshak, 1990; Modi and Kanungo, 2010). Similarly, they produce cytokines that can play a relevant role in neuroprotection and repair (Table 1A \& Fig. 4), including interleukin-6, CX3CL1/Fractalkine (Nan, Getchell, Partin, \& Getchell, 2001; Roet and Verhaagen, 2014; Ruitenberg et al., 2008), and transforming growth factor $\beta 3$ (TGFB3) (Pastrana et al., 2006). OECs also express cytokines receptors, like tumour necrosis factor receptors (TNFR) (Roet and Verhaagen, 2014), interleukin-1 receptor like-1 (IL1RL1) (Pastrana et al., 2006) and after bulbectomy, interleukin-6 receptor (IL6R) and Leukemia inhibitory factor receptor (LIFR) (Nan et al., 2001). Importantly, OECs secrete proteases that promote axonal regeneration, such as MMP2 (matrix metalloprotease 2), MMP9 and serpine-1 (Tables 1A, 2 \& Fig. 4: (Pastrana et al., 2006; Simon et al., 2011).

Some subtypes of OECs express specific molecules, and a subpopulation of OECs with low p75NTR has been shown to overexpress genes that regulate the inflammatory response and axon guidance, such as the EphB2 receptor (Honore et al., 2012). Also, a high p75NTR subpopulation overexpresses molecules that modulate the extracellular matrix, neurite outgrowth and axonal fasciculation/defasciculation, including Laminin, collagen type $V$, alpha 1 and alpha2, and collagen type I, alpha 1 (Honore et al., 2012). Moreover, LP-OECs express type $V$, alpha 4 collagen and a specific combination of proteins important for development, including CD44, integrin- $\beta 1$, Notch 3 , VEGF (Vascular Endothelial Growth Factor), and the chondroitin sulphate proteoglycan 4, NG2 (Au and Roskams, 2003).

OECs not only express factors that promote neuroregeneration but they also express some inhibitory factors (Table 1B \& Fig. 4), although the significance of this is not yet well understood. OECs express Nogo and their NgR receptor (Nocentini et al., 2012; Su et al., 2007; Woodhall, West, Vickers, \& Chuah, 2003), and the latter has a direct effect on the capacity of OECs to migrate on myelin or myelin-derived substrates in vitro (Nocentini et al., 2012; Reginensi et al., 2015). Significantly, this phenomenon may affect their ability to penetrate the glial scar. Several molecules have been seen to regulate OEC migration, either positively, like GDNF (Cao et al., 2006), or negatively like 
Myelin, NogoA, chondroitin sulphate proteoglycans (CSPGs (Nocentini et al., 2012; Reginensi et al., 2015; Su et al., 2007), the axonal guidance molecule Slit-2, ligand of Robo receptors (Huang et al., 2011; Wang and Huang, 2012), and fibulin-3 (Vukovic et al., 2009b). Furthermore, OECs express other inhibitory molecules (Table 1B \& Fig. 4) like Ephrin A1 in long passaged and immortalized OECs (Pastrana et al., 2006) and secreted semaphorins (e.g., Sema3A: Table 2), although this is required for olfactory axon guidance and patterning of the $\mathrm{OB}$ (Schwarting et al., 2000). As indicated above, a low p75NTR OEC subpopulation overexpresses the EphB2 receptor (Honore et al., 2012) that mediates axon repulsion (Klein, 2012; Orioli and Klein, 1997), and LP-OECS express the CSPG 4, NG2 (Au and Roskams, 2003). The inhibitory influence of NG2 on axon growth is still highly controversial because it has been associated with both inhibitory effects (Fidler et al., 1999; Tan, Colletti, Rorai, Skene, \& Levine, 2006; Ughrin, Chen, \& Levine, 2003) and the permissiveness of NG2 expressing cells (Busch et al., 2010; Vadivelu et al., 2015; Yang et al., 2006). At present, new exciting findings are still emerging in this field (see (Nishihara et al., 2015) and it appears that the expression of NG2 by some cells it is not necessarily correlated with the inhibition of axon regeneration. In fact, the effects of NG2 may depend on the expression of other molecules, such as MMP9 (Vadivelu et al., 2015) or MMP14 (Nishihara et al., 2015).

\section{I OECS IN SPINAL CORD INJURY (SCI) REPAIR}

\subsection{CNS Regeneration: a brief overview}

From Cajal's historic studies, it was clear that unlike PNS neurons, adult CNS neurons do not regenerate (Ramon y Cajal, 1928). In pioneering studies, this was shown not to be due to an intrinsic or irreversible incapacity of the CNS neurons (Bray, VillegasPerez, Vidal-Sanz, \& Aguayo, 1987; Vidal-Sanz, Bray, Villegas-Perez, Thanos, \& Aguayo, 1987), findings that stimulated the use of peripheral nerve and SchC grafts to foster regeneration in the CNS, with promising results (reviewed in (Jones et al., 2001; Oudega and $\mathrm{Xu}, 2006)$. 
Intrinsic restrictions that prevent adult CNS neurons from expressing the genes necessary to re-initiate their "developmental" program after injury has been demonstrated, and these may be overcome. Dorsal root ganglia (DRG) sensory neurons regenerate the central branch and dorsal column sensory projections after injury, yet only after a conditioning lesion of the peripheral axonal branches of these neurons (injuring the sciatic nerve for example). Under these conditions, CNS axons of DRG neurons regenerate and this is accompanied by an important increase in the levels of DRG-CAMP (Bomze et al., 2001; Neumann, Bradke, Tessier-Lavigne, \& Basbaum, 2002; Qiu et al., 2002). As a result, these neurons are no longer inhibited by myelin associated glycoprotein (MAG), an effect that is PKA dependent (Qiu et al., 2002). Direct intraganglionic injection of cAMP analogues (di-butyryl-cAMP) enables DRG neurons to grow on an inhibitory substrate (in culture) and to regenerate dorsal column sensory projections after lesion in vivo (Neumann et al., 2002; Qiu et al., 2002). In an elegant study, central sensory projections of DRG neurons were shown to regenerate in transgenic mice co-expressing the growth cone proteins GAP43 and CAP23, without the induction of a conditioning lesion (Bomze et al., 2001). Indeed, the regeneration of central sensory projections dependent on peripheral lesion takes place in conjunction with an increase in the expression of GAP43 by DRG neurons. Moreover, this regeneration is dependent on STAT3 activation and on the presence of interleukin6, although not in all cases (Cafferty et al., 2004; Hannila and Filbin, 2008; Qiu, Cafferty, McMahon, \& Thompson, 2005). Thus, GAP43 and/or CAP23, or other alternative proteins needed for axon growth (but no longer expressed in the adult CNS), may be necessary for the regeneration of some injured neurons (Moreno-Flores and Avila, 2010).

There is a wealth of experimental evidence that the microenvironment of CNS injury is fundamental in the inhibition of axon outgrowth and regeneration. Adult CNS neurons are normally surrounded by an organized extracellular matrix (ECM), referred to as the perineuronal net (PNN: Fig. 4), which can be visualized by immunostaining or by lectin labelling (e.g. with Wisteria floribunda agglutinin: (Miyata, Nishimura, Hayashi, \& Oohira, 2005). Some CSPGs, hyalectans of the aggrecan family, are anchored to the PNN by Hyaluronan ( $\mathrm{HA})$, and this binding is stabilized by small proteins called link 
proteins (Hardingham, 1979). HA is considered central to the structure of the CNS ECM and the PNN is known to be rich in CSPGs that inhibit neurite outgrowth (Celio, Spreafico, De Biasi, \& Vitellaro-Zuccarello, 1998; Crespo, Asher, Lin, Rhodes, \& Fawcett, 2007; Rhodes and Fawcett, 2004). Thus, in normal physiological conditions in which they do not need to regrow their dendrites or axons, adult neurons are surrounded by these stable "cages". After CNS lesion, the neuron-glia architecture is completely modified, provoking molecular changes and affecting the interactions between neural cells. Some neurons die as a direct consequence of the lesion and others die later, in a secondary process driven by neurotransmitter excitotoxicity and inflammatory responses. Soon after lesion, a glial reaction occurs giving way to the formation of a "glial scar" to re-establish the CNS glial boundary (glia limitans). This glial scar contains many elements and it is the main source of molecules that inhibit axon regeneration (Bovolenta, Wandosell, \& Nieto-Sampedro, 1992; Bovolenta, Wandosell, \& NietoSampedro, 1993a; Bovolenta, Fernaud-Espinosa, Mendez-Otero, \& Nieto-Sampedro, 1997; David and Lacroix, 2003; Sandvig, Berry, Barrett, Butt, \& Logan, 2004; Silver and Miller, 2004).

Following CNS lesion, astrocytes become hypertrophic and they express molecules that strongly inhibit axonal regrowth (e.g. CSPGs: (Bovolenta et al., 1997; Carri, Perris, Johansson, \& Ebendal, 1988; Davies, Goucher, Doller, \& Silver, 1999; Dou and Levine, 1994; Fidler et al., 1999; McKeon, Schreiber, Rudge, \& Silver, 1991; McKeon, Hoke, \& Silver, 1995; Muir, Engvall, Varon, \& Manthorpe, 1989; Niederost, Zimmermann, Schwab, \& Bandtlow, 1999; Smith-Thomas et al., 1994). Several CSPGs from reactive astrocytes are upregulated after CNS injury, including aggrecan (CSPG1), versican (CSPG2), neurocan (CSPG3) and phosphacan (Asher et al., 2000; Fawcett and Asher, 1999; Levine, 1994; McKeon, Jurynec, \& Buck, 1999; Plant, Bates, \& Bunge, 2001; Yiu and He, 2006). By eliminating CSPG glycosaminoglycan (GAG) chains, CSPG inhibitory activity is attenuated (Bovolenta et al., 1993a; Fidler et al., 1999; McKeon et al., 1995; Moon, Asher, Rhodes, \& Fawcett, 2001; Zuo, Neubauer, Dyess, Ferguson, \& Muir, 1998) and see (Moreno-Flores and Avila, 2010) for review). In terms of their receptors, the common leukocyte antigen-related phosphatase (LAR), protein tyrosine phosphatase $\sigma(P T P \sigma), N g R$ and $\mathrm{NgR3}$ have recently been identified as receptors for the 
inhibitory glycosylated side chains of CSPGs (Dickendesher et al., 2012; Fisher et al., 2011; Shen et al., 2009). Moreover, microglia cells proliferate and also become reactive (Bovolenta, Wandosell, \& Nieto-Sampedro, 1993b; Fernaud-Espinosa, Nieto-Sampedro, \& Bovolenta, 1993).

The neuronal bodies that contribute to the damaged axonal tracts in the SC lie at a distance from the site of injury. Hence, these neurons may remain alive after $\mathrm{SCl}$, although the spinal tracts may be interrupted and disorganized at the lesion site, and myelin would shift from its highly structured physiological state to that of a chaotic net. Several components of the myelin net are potent inhibitors for axonal growth: Nogo A, B and C; MAG; and oligodendrocyte myelin glycoprotein OMgp or MOG (Filbin, 2003; He and Koprivica, 2004; Moreno-Flores and Avila, 2010; Oertle and Schwab, 2003; Raisman, 2004; Yang and Strittmatter, 2007; Yiu and He, 2003). The receptors of these molecules present in the presumptive regenerating axons also play a fundamental role in regeneration: NgR, NgR2 and NgR3 (Yiu and He, 2006). This picture is becoming more complete as new molecules are identified as myelin receptors: the human leukocyte immunoglobulin-like receptor B2 (LILRB2, a member of the B type subfamily of LILR receptors) and its orthologue in mice, the paired immunoglobulin-like receptor B (PirB) that is an MHC class 1 receptor (Atwal et al., 2008) and references therein]. Nogo, MAG and OMgp bind to NgRs and PirB (Atwal et al., 2008), and MAG also to binds to NgR2 but not NgR3 (Lauren, Airaksinen, Saarma, \& Timmusk, 2003; Lauren et al., 2007; Venkatesh et al., 2005). NgR couples to LINGO 1 and p75NTR or TAJ/TROY, constituting the complete receptor complex (Domeniconi et al., 2002; Fournier, GrandPre, \& Strittmatter, 2001; Liu, Fournier, GrandPre, \& Strittmatter, 2002; Mi et al., 2004; Park et al., 2005; Shao et al., 2005; Wang, Kim, Sivasankaran, Segal, \& He, 2002; Wong et al., 2002). This receptor complex mediates the signalling of its ligands, in turn modulating the activity of the Rho GTPases and inhibiting axonal regeneration (Niederost, Oertle, Fritsche, McKinney, \& Bandtlow, 2002; Kubo, Yamaguchi, Iwata, \& Yamashita, 2008; Kubo and Yamashita, 2007; McKerracher and Higuchi, 2006; Mimura et al., 2006; Yamashita, Higuchi, \& Tohyama, 2002; Yamashita, Tucker, \& Barde, 1999). The inhibitory role of Nogo proteins after SCl has been studied thoroughly, showing that these molecules block axon regeneration through $\mathrm{NgRs}$ 
(Moreno-Flores and Avila, 2010). More recently, H2-Kb and H2-Db, two ligands of PirB, were associated to a worse prognosis following CNS injury. In this context, $\mathrm{H} 2-\mathrm{Kb}$ and $\mathrm{H} 2$-Db KO mice, or those lacking the PirB receptor, develop a smaller infarct volume and they experiment better motor recovery, probably due to weakened astrocyte activation and to enhanced corticospinal projection into the denervated areas in animals subjected to focal ischemia (Adelson et al., 2012).

Additionally, some other "negative" influences on axonal growth that direct axons to their appropriate territories during development, are also disorganized in the scar, such as axon guidance ligands and receptors, impeding axonal growth through the lesion site. In the glial scar, secreted and membrane semaphorins/receptors are expressed, like sema3A and sema4D/Plexin B1, as well as Eph receptors/ligands such as EphB3/EphrinA4 (Cregg et al., 2014; Fawcett, Schwab, Montani, Brazda, \& Muller, 2012; Silver and Miller, 2004).

Finally, another important problem that leads to deficient axon regeneration is the lack of trophic support for the injured CNS neurons. In experimental models in vivo, the neurotrophins, FGF-2 and GDNF can all promote regrowth of different axonal tracts (Bradbury et al., 1999; Eggers et al., 2008; Kwon et al., 2007; Mills, Allchorne, Griffin, Woolf, \& Costigan, 2007; Ramer, Duraisingam, Priestley, \& McMahon, 2001; Ramer, Priestley, \& McMahon, 2000; Ramer et al., 2002; Romero, Rangappa, Garry, \& Smith, 2001; Schnell, Schneider, Kolbeck, Barde, \& Schwab, 1994; Tang, Cai, Nelson, Peng, \& Smith, 2004; Tang, Heron, Mashburn, \& Smith, 2007; Vavrek, Girgis, Tetzlaff, Hiebert, \& Fouad, 2006; Zhang, Dijkhuizen, Anderson, Lieberman, \& Verhaagen, 1998). Additionally, when fibroblasts, SchCs and OECs are combined with growth factors or engineered to express neurotrophins, they effectively promote axon regrowth/plasticity of different neurons and spinal tracts (Bregman et al., 2002; Coumans et al., 2001; Grill et al., 1997; Grill et al., 1997; Liu et al., 1999; Menei, Montero-Menei, Whittemore, Bunge, \& Bunge, 1998; Ruitenberg et al., 2003; Ruitenberg et al., 2005; Runyan and Phelps, 2009; Tuszynski et al., 1998; Xu, Guenard, Kleitman, Aebischer, \& Bunge, 1995; Zhang et al., 2009), inducing functional recovery (Grill et al., 1997; Liu et al., 1999; Ruitenberg et al., 2003). 


\subsection{OEC transplantation in animal models of SCI}

Only some cell populations in the nervous system can continuously regenerate throughout adult life, such as the olfactory receptor neurons in the context of the OEC environment (Ruitenberg and Vukovic, 2008; Schwob et al., 2016). Since OECs usually surround these growing olfactory axons in the adult mammalian CNS, it is reasonable to hypothesise that they might facilitate CNS axon regrowth after injury (Barnett and Chang, 2004; Barnett and Riddell, 2007; Franssen et al., 2007; Moreno-Flores et al., 2002; Moreno-Flores and Avila, 2010; Raisman, 2001; Raisman and Li, 2007; Richter and Roskams, 2008). In recent years, the use of OECs to treat SCI has been studied extensively, and in fact, several studies in different models have confirmed their neuro-reparative capacity in response to acute (Garcia-Alias, Lopez-Vales, Fores, Navarro, \& Verdu, 2004; Leng, He, Li, Wang, \& Cao, 2013; Li et al., 1997; Li, Field, \& Raisman, 1998; Lopez-Vales, Garcia-Alias, Fores, Navarro, \& Verdu, 2004; Lopez-Vales et al., 2006; Lu et al., 2001; Ramon-Cueto et al., 1998; Ramon-Cueto et al., 2000) and delayed/chronic lesions (Lopez-Vales et al., 2006; Lopez-Vales, Fores, Navarro, \& Verdu, 2007; Lu, Feron, Mackay-Sim, \& Waite, 2002; Plant, Christensen, Oudega, \& Bunge, 2003). Their reparative ability is due to a combination of several factors (see section "Molecular features and cellular functions of OECs"). OECs can preserve the lesion area by dampening the inflammatory response, as well as by decreasing cavitation and the size of the glial scar. They may also promote angiogenesis and axon regrowth/plasticity in different tracts, or remyelination, in some cases in association with functional recovery (Andrews and Stelzner, 2007; Garcia-Alias et al., 2004; Lakatos, Franklin, \& Barnett, 2000; Lakatos, Barnett, \& Franklin, 2003; Lopez-Vales et al., 2004; O'Toole, West, \& Chuah, 2007; Plant et al., 2003; Ramer et al., 2004; Ruitenberg et al., 2003; Ruitenberg et al., 2005; Takami et al., 2002). Both OM and OB OECs have neuroreparative capacity, being able to promote a decrease in the size of the lesion and of the cavity in the SC. However, they exhibit different properties in terms of promoting sprouting of spinal axonal tracts, integration and migration (Richter et al., 2005) and see section "Molecular features and cellular functions of $\left.O E C s^{\prime \prime}\right)$. In the next sections we will consider each of these different functional aspects of OECs after transplantation in $\mathrm{SCl}$ animal models. 


\subsubsection{Interaction of OECs with the glial scar}

As the glial scar is one of the biggest barriers to neuroregeneration, interventions to prevent or limit its development will have a strong impact on regenerative success. Thus, the outgrowth of new axons must occur in a microenvironment rich in inhibitory factors (see section "CNS Regeneration: a brief overview") and the balance of these with promoting factors presented by OECs will define the final response. In contrast to SchCs, OECs interact with astrocytes and meningeal cells, and they can mingle with astrocytes in culture and in the glial scar (Andrews and Stelzner, 2007; Franssen, Roet, de Bree, \& Verhaagen, 2009; Lakatos et al., 2000; Li, Li, \& Raisman, 2005; MorenoFlores et al., 2006; Ramer et al., 2004; Santos-Silva et al., 2007). Recently, light was shed on this fundamental difference between these cell types, even though they are both derived from the neural crest. It was first demonstrated that the capacity to form SchC-astrocyte boundaries depended on the secretion of highly sulphated heparan sulphate proteoglycans (HSPGs), which was higher in SchCs than in OECs. These boundaries were disrupted with antibodies against FGF1 and FGF9, signalling through FGF receptor-IIIb, an event that is modulated by the sulphation of HSPGs and that is driven by the weaker expression of the extracellular 6-0-endosulfatase enzymes Sulf 1 and Sulf2 by SchCs (Higginson et al., 2012). SchCs engineered to express both sulphatases acquire the ability to integrate with astrocytes without forming boundaries, enhancing their integrin-dependent motility in the presence of astrocytes (O'Neill et al., 2017). These interesting findings have important implications to increase the effectiveness of cell therapy in $\mathrm{SCl}$ and CNS injuries.

The OEC-astrocyte interaction implies a change in the scar, the outer membranes of OECs being able to form a continuum to bridge the gap. This may be a crucial event for the regrowth of axons within the lesion area after $\mathrm{SCl}$. OECs also produce extracellular matrix proteases in parallel with their ability to penetrate the gliotic tissue of the SC, which correlates with corticospinal tract regeneration (Pastrana et al., 2006). Moreover, it has been demonstrated that OECs can reduce astrocytic reactivity and CSPG expression (Garcia-Alias et al., 2004; Lakatos et al., 2003; O'Toole et al., 2007). 
All these properties of OECs could make removal of the glial scar unnecessary, since a positive balance of membrane and secreted stimulating factors provided by OECS would decrease the inhibitory tendency, permitting axon repair. As such, OECs should be distributed over the lesion and thus, their capacity to migrate would be fundamental. Indeed, OEC migration has been reported in the unlesioned SC (Deng et al., 2006; Lee et al., 2004), being extensive in the X-irradiated SC and brain (Imaizumi, Lankford, Waxman, Greer, \& Kocsis, 1998; Lankford, Sasaki, Radtke, \& Kocsis, 2008; Lankford, Brown, Sasaki, \& Kocsis, 2014). Although migration in SCl was initially described (Ramon-Cueto et al., 1998), the capacity of OECs to migrate seems to be limited or inexistent in several SC lesion models depending on the approaches adopted (Andrews and Stelzner, 2007; Collazos-Castro, Muneton-Gomez, \& Nieto-Sampedro, 2005; Lee et al., 2004; Lu et al., 2006; Moreno-Flores et al., 2006; Pearse et al., 2007; Ramer et al., 2004). When OECs were transplanted in a transection context and studied by magnetic resonance imaging (MRI), these cells failed to cross the gap of the SC (Lee et al., 2004). However, cells transplanted at the stump migrated a short distance, half that in the normal SC. Similar limited migration has been described in another study, yet restricted to only a small number of cells (Pearse et al., 2007), whereas even shorter migration distances $(\leq 1 \mathrm{~mm}$ ) were reported elsewhere (Deng et al., 2006; Ramer et al., 2004; Reginensi et al., 2015; Richter et al., 2005).

The site of transplantation also varied in these studies, with OECs transplanted at the lesion site (Collazos-Castro et al., 2005; Pearse et al., 2007; Ramer et al., 2004; Richter et al., 2005), outside the injury (Pearse et al., 2007; Reginensi et al., 2015; Richter et al., 2005) or both at and outside the lesion site, rostrally and caudally (Andrews and Stelzner, 2007; Moreno-Flores et al., 2006). In a hemisection model performed contralateral, and several $\mathrm{mm}$ rostral to the transplantation site, significant OEC migration was reported, albeit less than in the intact SC (Deng et al., 2006). OEC migration from sites rostral and caudal to the lesion site was also reported elsewhere, being higher for LP cells than for those from the OB (Richter et al., 2005). In our own experience, we detected limited migration of OECs in the dorso-ventral axis after injection at several sites, into the lesion and $1 \mathrm{~mm}$ caudal or rostral (Moreno-Flores et al., 2006). Limited migration was also reported in a subsequent study and the injection 
pressure influenced in the distribution of the cells (Andrews and Stelzner, 2007). However, when we quantified rostral and caudal migration (around $1 \mathrm{~mm}$ ) in a SCI contusion model in which cells of an OEC line were injected laterally on both sides of the lesion, migration by modified OECs secreting the Nogo receptor ectodomain was enhanced (around $2 \mathrm{~mm}$ : (Reginensi et al., 2015). Therefore, it generally seems that OECs can migrate better in an uninjured SC than in the lesioned one. OECs seem to be able to migrate to the lesion site but when injected directly into the epicentre of the lesion, they fail to migrate out and are unable to cross the gap in some contexts.

With regards the factors that aid the migration of these cells, reactive astrocytes in the glial scar attract OECs in a model of SC hemisection by secreting TNF- $\alpha$ (Su et al., 2009). Additionally, GDNF can promote OEC migration in vivo and in vitro (Cao et al., 2006). Our previous results reinforce the idea that most of the factors inhibiting axon elongation and regrowth after lesion may also affect OEC migration (Reginensi et al., 2015). In fact, all the molecules thought to inhibit OEC migration-NogoA, CSPGs, fibulin-3, and Slit2- are overexpressed in CNS scars after lesion (Cregg et al., 2014; He and Koprivica, 2004; Lukovic et al., 2014; Nocentini et al., 2012; Reginensi et al., 2015; Vukovic et al., 2009a).

In summary, multiple factors seem to be fundamental in choosing where to transplant cells. The role of OECs/glial scar interactions or the idea of bridging the gap are not negligible. For example, the cells in a transection model are probably not going to be able to cross the gap if this is not filled or bridged in some way. The best way to carry out transplantation is probably to use several injection/transplantation sites, in particular the epicentre of the lesion in conjunction with other additional points. We will address these issues further in the section "OEGS to cure SCI: Clinical studies".

\subsubsection{Axon repair and functional recovery}

In animal models of $\mathrm{SCl}$ (Table 3), OECs have the ability to promote axon regrowth/sprouting/sparing (Chuah et al., 2004; Garcia-Alias et al., 2004; Ibrahim, Kirkwood, Raisman, \& Li, 2009; Imaizumi, Lankford, \& Kocsis, 2000; Li et al., 1997; Li et al., 1998; Lopez-Vales et al., 2006; Lopez-Vales et al., 2007; Lu et al., 2001; Lu et al., 2002; Moreno-Flores et al., 2006; Plant et al., 2003; Ramon-Cueto and Nieto- 
Sampedro, 1994; Ramon-Cueto et al., 1998; Ramon-Cueto et al., 2000; Richter et al., 2005). In all these studies, the axons re-growing from supraspinal or DRG neurons were assessed and they were identified using retrograde, anterograde and transganglion tracers, such as fluorogold/fluororuby, wheat germ agglutininhorseradish peroxidase, Dil, biotinylated dextran amine or cholera toxin subunit $B$ ((Chuah et al., 2004; Ibrahim et al., 2009; Li et al., 1997; Li et al., 1998; Lopez-Vales et al., 2006; Lopez-Vales et al., 2007; Lu et al., 2001; Lu et al., 2002; Moreno-Flores et al., 2006; Plant et al., 2003; Ramon-Cueto et al., 1998; Ramon-Cueto et al., 2000; Toft, Scott, Barnett, \& Riddell, 2007). Moreover, markers like GAP-43, calcitonin generelated peptide (CGRP), neurofilament, serotonin and noradrenalin have been used to identify axons in contact with OEC grafts (Gorrie et al., 2010; Li, Decherchi, \& Raisman, 2003; Lu et al., 2001; Lu et al., 2002; Plant et al., 2003; Ramon-Cueto and NietoSampedro, 1994; Ramon-Cueto et al., 1998; Ramon-Cueto et al., 2000; Richter et al., 2005). Additional evidence of OEC-induced axon regrowth into and through the lesion site comes from electrophysiological studies (see below and(Garcia-Alias et al., 2004; Ibrahim et al., 2009; Imaizumi, Lankford, Burton, Fodor, \& Kocsis, 2000; Imaizumi et al., 2000; Li et al., 2003; Li, Li, Chen, Chang, \& Duan, 2011; Lopez-Vales et al., 2004; LopezVales et al., 2006; Lopez-Vales et al., 2007; Lu et al., 2001; Toft et al., 2007).

It is clearly fundamental to achieve functional recuperation in transplanted animals to consider OEC transplants an effective therapeutic strategy to treat $\mathrm{SCl}$. One of the first studies using OECs transplants in $\mathrm{SCl}$ (complete transection) assessed a long survival time and after 7 months, the transplanted rats had regained the ability to use their hind limbs for scaling and they recovered a reflex to skin stimulation (Ramon-Cueto et al., 2000). Subsequent studies showed functional recovery after OEC transplantation using the Basso, Beattie, Bresnahan locomotor scale (BBB) and several other behavioral motor and sensory tests. Functional recovery paralleled the anatomical findings in some such studies, supporting OEC induced axon repair even after chronic SCI (DeLucia et al., 2003; Garcia-Alias et al., 2004; Ibrahim et al., 2009; Li et al., 2003; Li et al., 2011; Lopez-Vales et al., 2006; Lopez-Vales et al., 2007; Lu et al., 2001; Lu et al., 2002; Moreno-Flores et al., 2006; Plant et al., 2003; Ramon-Cueto et al., 2000; Ruitenberg et al., 2003). However, it was not possible to demonstrate such a 
relationship between functional recovery and axon regrowth with OM cells (Yamamoto, Raisman, Li, \& Li, 2009), and in other studies functional recovery was poorer, although some compensatory mechanisms in movement appeared after OEC transplantation (Ruitenberg et al., 2005).

Electrophysiological studies have been used to evaluate OEC transplantation, with animals showing some recovery of action or evoked potentials (Garcia-Alias et al., 2004; Ibrahim et al., 2009; Imaizumi et al., 2000; Imaizumi et al., 2000; Lopez-Vales et al., 2004; Lopez-Vales et al., 2006; Lopez-Vales et al., 2007; Li et al., 2003; Li et al., 2011; Lu et al., 2001; Toft et al., 2007), in several cases correlated with functional recovery (Garcia-Alias et al., 2004; Ibrahim et al., 2009; Li et al., 2003; Lopez-Vales et al., 2004; Lopez-Vales et al., 2006; Lopez-Vales et al., 2007; Lu et al., 2001; Toft et al., 2007). However, it remains unclear if functional recovery mediated by OEC transplants reflects appropriate reconnections of severed nerve fibres, or if they are due to other indirect mechanisms in incomplete lesions. The preservation of surviving fibres or the formation of alternative pathways may also be responsible for the functional amelioration, for example collateral sprouting and reconnection through long propiospinal interneurons (Deumens, Koopmans, \& Joosten, 2005; Bareyre et al., 2004; Toft et al., 2007; Yamamoto et al., 2009).

OECs can act directly as a physical substrate for neurite/axon growth, this being more effectively promoted when the OECs are in close contact with neurons, as demonstrated in vitro (Chung et al., 2004; Moreno-Flores et al., 2002; Moreno-Flores et al., 2003b; Sonigra, Brighton, Jacoby, Hall, \& Wigley, 1999) and in vivo (Li et al., 2005). OECs seem to be able to extend cytoplasmic processes and generate channellike structures across the astroglial borders of the lesion (Andrews and Stelzner, 2007), which would be useful for the growth of regenerating axons. These channels have an outer basal lamina overlaid by fibroblasts and a bare inner surface in contact with nerve fibres, this being postulated as a determinant for their regenerative capacity formulated as the "pathway hypothesis" (Li et al., 2005). The capacity of OECs to penetrate and to digest the glial scar would permit them to establish bridges, generating a pro-regenerative substrate (for references see the section "Interaction of OECs with the glial scar"). In addition, their ability to secrete neurotrophic factors 
seems to be fundamental to this effect (Lipson et al., 2003; Pastrana et al., 2007; Pellitteri, Spatuzza, Russo, \& Stanzani, 2007; Pellitteri, Spatuzza, Russo, Zaccheo, \& Stanzani, 2009; Sasaki, Hains, Lankford, Waxman, \& Kocsis, 2006). Their secretory profile (see "Molecular features and cellular functions of OECs") might account for the capacity of OEC grafts to facilitate the regeneration of some spinal tracts but not others in the lesioned SC, depending on their trophic requirements (Jones et al., 2001; Moreno-Flores et al., 2002). However, this profile can be altered or improved by gene transfer (Ruitenberg et al., 2005; Ruitenberg et al., 2003). The secretion of other factors would also contribute to the neuroregenerative properties of OECs (Pastrana et al., 2006; Simon et al., 2011). Adult neurons in the CNS are normally surrounded and stabilized by the PNN, which inhibits neurite outgrowth (Celio et al., 1998; Rhodes and Fawcett, 2004). It was previously demonstrated that MMP2 can also digest CSPGs of the PNN in vitro (Fig. 4) and enhance axon growth (Pastrana et al., 2006). Moreover, MMP2 can digest CSPGs in the glial scar (Fig. 4; see section "Interaction of OECs with the glial scar"), and the ability to secrete MMP2 and other proteases like PAI-1 was also fundamental for the proregenerative properties of OECs (Pastrana et al., 2006; Simon et al., 2011). Indeed, MMP2 production correlates with corticospinal tract regeneration in vivo (Moreno-Flores et al., 2006; Pastrana et al., 2006).

Finally, the Scavenger receptor class B member 2 (SCARB2) type III glycoprotein is produced by OECs, which is key for their neurite growth ability (Roet et al., 2013; Roet and Verhaagen, 2014). This protein is located primarily in the limiting membranes of lysosomes and endosomes. SCARB2 gene transfer can mediate regeneration of dorsal column sensory axons in the injured SC (Roet et al., 2013; Roet and Verhaagen, 2014), and this action is probably related to lipid transfer mechanisms and the synthesis of cholesterol-containing lipoproteins. Glial cells secrete lipoproteins containing cholesterol, and they can promote neurite outgrowth and synapse formation in cultures of retinal ganglion cells and DRG neurons (Handelmann, Boyles, Weisgraber, Mahley, \& Pitas, 1992; Hayashi, Campenot, Vance, \& Vance, 2009; Mauch et al., 2001). The transfer of lipids and cholesterol to growing axons is important for membrane synthesis during regeneration after injury (Boyles et al., 1989; Jurevics, Bouldin, Toews, \& Morell, 1998; Li, Fowler, Neil, Colton, \& Vitek, 2010). It is known that damage in the 
CNS leads to the synthesis of proteins involved in lipid metabolism and cholesterol, and that pharmacological or genetic interference with cholesterol reuse dampens local axonal growth (Roet and Verhaagen, 2014).

In summary, OECs can guide and stimulate the growth of olfactory axons towards their targets, and they can provide and regulate the lipid transfer necessary for this process (Roet and Verhaagen, 2014). As such, it can be inferred that one of the main mechanisms for OEC-dependent axon repair in the CNS may rely on lipid metabolism in these cells and in their ability to transfer them to the growing axons.

\subsubsection{Myelination}

Demyelination is widespread in the sub-chronic phase of the SCI, at 7 DPI (Blight, 1985; Plemel et al., 2014), and it might block action potentials (Blight, 1983) or render axons more susceptible to degeneration (Irvine and Blakemore, 2008; Plemel et al., 2014). However, axonal conduction can be achieved without remyelination, even if denuded axons persist in association with demyelinating lesion (Felts, Baker, \& Smith, 1997), and deficits in electrical conduction may occur that are not due to demyelination. Significantly, such acute deficiencies were not evident contralateral to the lesion but they developed 1-2 weeks later, and they persisted in chronic states when remyelination should have taken place (Arvanian et al., 2009; Plemel et al., 2014). There are many issues to clarify regarding the persistence of oligodendrocyte death (over weeks) and demyelination after $\mathrm{SCl}$. Therefore, remyelination as an intervention strategy after $\mathrm{SCl}$ remains controversial, even though it is generally considered an important therapeutic target (Plemel et al., 2014). Hence, in this section we will consider the capacity of OECs to produce myelination, directly or indirectly, implicating other cells such as SchCs.

It has been demonstrated that foetal OECs have the ability to myelinate DRG neurites in vitro, with these cells having different growth requirements to SchCs with regards the assembly of a basal lamina (Devon and Doucette, 1992; Devon and Doucette, 1995). From those initial studies, it was then demonstrated that OECs can directly myelinate axons after SCI (Akiyama, Lankford, Radtke, Greer, \& Kocsis, 2004; Imaizumi et al., 2000; Imaizumi et al., 2000; Lankford et al., 2008; Lankford et al., 2014; Sasaki, Lankford, Zemedkun, \& Kocsis, 2004; Sasaki, Li, Lankford, Radtke, \& Kocsis, 2007). This 
was shown with engineered green fluorescent protein (GFP), alkaline phosphataseexpressing OECs, transgenic pig OECS expressing the human complement inhibitory protein CD59, or with OECs preloaded with 5- (and 6)-carboxyfluorescein diacetate succinimidyl ester. When transplanted, these OECs were able to myelinate the majority of axons in a peripheral-like manner, about half of which were associated with compacted myelin (Sasaki et al., 2004). Further evidence came from using transgenic mice expressing GFP under the control of CNPase promoter. This fluorescent protein was expressed in the $\mathrm{OB}$ in vivo and in culture, co-localizing with the OEC marker, p75NTR. When transplanted after sciatic nerve transection, these GFP-expressing OECs were associated to and myelinated the regenerating peripheral nerve (Radtke, Sasaki, Lankford, Gallo, \& Kocsis, 2011). Furthermore, OEC transplantation has been shown to promote remyelination in models of SC demyelination, both in rodents and primates (Akiyama et al., 2004; Barnett et al., 2000; Franklin, Gilson, Franceschini, \& Barnett, 1996; Imaizumi et al., 1998; Lankford et al., 2008; Radtke et al., 2004; Sasaki et al., 2006).

However, other conflicting findings have also been presented, for example when invasive SchCs appeared to be responsible for remyelination as opposed to engineered Lac-Z expressing OECs (Boyd, Lee, Skihar, Doucette, \& Kawaja, 2004). These OECs might have attracted these exogenous SchCs to the SC and indeed, OEC conditioned medium may be a chemoattractant for SchCs in vitro, with NGF representing an important driver of this effect (Cao et al., 2007). Moreover, oligodendrocyte precursor proliferation has been proposed to influence remyelination after $\mathrm{SCl}$ (Czepiel, Boddeke, \& Copray, 2015; Jiang et al., 2008), such that the activation of this glial lineage after OEC transplantation may be in part involved in remyelination, together with SchCs (Masgutova, Savchenko, Viktorov, Masgutov, \& Chelyshev, 2010).

\subsubsection{Combining OECs with other treatments}

As indicated above, OECs can induce axonal repair and/or functional improvement in $\mathrm{SCl}$, alone or when combined with SchC grafts, SchCs and chondroitinase, or with SchCs combined with elevated cAMP (Bunge, 2008; Fouad et al., 2005; Fouad, Pearse, Tetzlaff, \& Vavrek, 2009; Ramon-Cueto et al., 1998; Takami et al., 2002; Vavrek, Pearse, \& Fouad, 2007). However, in some SCl models, SchC grafts and OECs have a 
similar capacity to promote functional/electrophysiological recovery and/or regeneration of certain axonal tracts (Garcia-Alias et al., 2004; Imaizumi et al., 2000; Imaizumi et al., 2000), improving the efficacy of SchCs on occasion (Takami et al., 2002).

OECs have also been used in conjunction with several kinds of stem cells and in a model of incomplete $\mathrm{SCl}$, better BBB functional recovery was achieved by transplanting foetal neural stem cells along with adult OECs (Wang et al., 2010). In addition, cotransplantation of foetal (Deng et al., 2008) or adult OECs (Wu et al., 2015) with adult human (Deng et al., 2008) or rat (Wu et al., 2015) BM-MSCs had a beneficial effect in a contusion $\mathrm{SCl}$ model, as judged by histopathological and functional evaluation (BBB and transcranial magnetic motor-evoked potentials). Hind limb recovery may have been related to a significant anti-apoptotic effect (Wu et al., 2015), although significant effects on tissue sparing have been seen and functional tests (BBB) improved following transplantation of juvenile LP-OECS or BM-MSCS to treat compressive SCI (Amemori, Jendelova, Ruzickova, Arboleda, \& Sykova, 2010). In this study there were no significant differences between the individual treatments and combining both types of cells (Amemori et al., 2010).

In a study combining glial scar ablation, LP grafts and transplantation of cultured LPOECs from adult rats prevented scar reformation, along with an increase in the repaired tissue (transplanted tissue/cells integration), a marked reduction or even the disappearance of the lesion cavity, and a significant increase in the PO positive myelination. Surprisingly, there was no significant functional restoration according to the BBB (Zhang, Huang, Gates, \& Holmberg, 2011). Several possibilities for these effects were discussed but the correct interpretation should probably take into account that the impairment in the BBB after the contusion lesion was not very large in this study when compared to similar SCl studies (Deng et al., 2008; Wu et al., 2015). Moreover, values pre-surgery were not reported nor was a sham operated control group used.

Carlos Lima's therapeutic approach for SCl involved OM transplantation (see section "OECs to cure SCI: Clinical studies"), based on the idea of that this tissue is composed 
of multiple cell types, including OECs and stem cells. As such, the use of the OM avoids the need to expose cells to an artificial tissue culture environment (Lima et al., 2006). In recent years, a stem cell-like population has been identified in the OE and another one in the LP (Tome et al., 2009). OM-MSCs have been isolated from the LP and characterized in different laboratories (Delorme et al., 2010; Feron et al., 2013; Girard et al., 2011; Lindsay et al., 2010; Lindsay et al., 2013; Lindsay and Barnett, 2017). Transplanted olfactory MSCs differentiated into neurons and stimulated neuroplasticity after lesions in the hippocampus promoted neurogenesis (Nivet et al., 2011). These cells could produce dopaminergic neurons in a rat model of Parkinson disease (Murrell et al., 2008) and recently, it was demonstrated that OM-MSCs from the LP promote remyelination and the earlier recovery of gait coordination in a model of incomplete SCI (Lindsay et al., 2017). OM-MSCs secrete factors that modulate OEC behaviour in vitro, enhancing the extension of processes and their alignment along neurites, thereby promoting axon sheathing (Lindsay et al., 2013; Lindsay et al., 2016). OM-MSC conditioned medium promoted myelination in vitro (Lindsay et al., 2013). OEC conditioned medium can induce neural stem cells, umbilical cord blood MSCs and OM-MSCs to differentiate into neurons (Duan et al., 2011; Ge, Liu, Liu, \& Lu, 2016; Zeng et al., 2013). Indeed, the combined use of OM-OECs with OM-MSCs was proposed as a novel strategy for $\mathrm{SCl}$ via autologous transplantation of both cell types (Ge et al., 2016).

Finally, combining OEC transplantation with other treatments may improve the outcome of $\mathrm{SCl}$ therapy. A combination of OECs with local (in the red nucleus) or systemic cAMP (subcutaneous infusion of Rolipram) was used in a model of dorsolateral funiculus crush. Although OECs could attenuate the astrocytic reaction and retraction of the rubrospinal axons, producing a tendency towards a smaller lesion, neither OECs alone nor the combined treatment could promote regrowth of the axotomized axons through the lesion site (Bretzner et al., 2010). The therapeutic effect of combining OEC transplantation with acidic fibroblast growth factor (aFGF) has also been evaluated using complete SC transection (Botero, 2015; Gomez, 2009). Local reparative activation was evident in the injured SC tissue, leading to functional recovery as evaluated using the BBB scale (Botero, 2015; Gomez, 2009). This 
combination functioned in a similar way in chronic and acute SCI (Botero, 2015) when evaluated using a neurological assessment (Gomez et al., 2015). Transplanted rats showed motor and sensory recovery in both the acute and chronic phase. Confocal microscopy established that this combined treatment induced axon repair, with axons traversing the cavity and joining the cranial and caudal segments of the lesion. Transplantation/aFGF also decreased the size of the glial scar and the number of reactive astrocytes. The ultrastructural analysis showed remyelination compatible with central and peripheral myelin. These results confirm the positive effect of transplanting OECs and aFGF to induce $\mathrm{SCl}$ recovery (Botero, 2015).

\section{I OECS TO CURE SCI: CLINICAL STUDIES}

Studies with OECs have not only been performed in experimental animal models but a moderate number of clinical studies have also been performed on humans in several countries. The human foetal $O B$ is a viable source of OECs for heterologous transplantation, as has been used in China. Although these heterologous transplants have been performed on a large number of SCl patients (Huang et al., 2009), and in patients with amyotrophic lateral sclerosis or Friedreich's Ataxia, it is difficult to ascertain the contribution of the OEC component in these bulb-derived cell mixtures. This clinical approach has also raised ethical and legal issues in other countries (Watts, 2005). Several problems have to be considered when evaluating the results of the use of this treatment in China:

-The source of the foetal OB-derived cells for the patient treatment must be obtained in accordance with applicable Chinese guidelines, both institutional and governmental. -The transplanted foetal OB-derived cells were not well characterized in most cases (see exception below: (Guest, Herrera, \& Qian, 2006).

-A rigorous clinical study was not performed, incorporating the corresponding controls or with a complete evaluation of the patients before and after transplantation surgery. -This surgery was offered to all patients willing a travel to China and pay for a cure for their condition. 
-There has been no systematic follow-up by independent clinicians.

Nevertheless, there have been some independent evaluations of this procedure and in one of these the results from seven patients transplanted in China were disappointing, with no functional improvement and some perioperative morbidity (Dobkin, Curt, \& Guest, 2006). It was indicated that the procedures used on this group did not necessarily meet international standards for either safety or efficacy, and it was concluded that physicians should not recommend this procedure to their patients. By contrast, a positive effect was reported in one complete tetraplegic C3 ASIA A patient transplanted with foetal OB-derived cells in China (cultured cells labelled for nestin and GFAP). The young patient (18 years old) improved one ASIA (American Spinal Injury Association) motor grade shortly after transplantation (48 hours), while a sensory improvement occurred 4 days after the procedure and then changed slowed. The patient shifted to C5 motor and C4 sensory complete tetraplegia and it was thought that the remaining intact fibres were implicated in these early responses, although the need for further independent analysis was recognised (Guest et al., 2006).

Another study involving the same team in China involved the use of OEC in combination with SchCs, recruiting several patients to a double blind clinical study. The benefits of using both types of cells and their combination were examined for transplantation in cervical, chronic, complete SCI. In 2014, they reported results from 5 patients ( 3 received OECs, 1 SCs and 1 OECs+SCs) and two control cases. The neurological assessments were performed according to the American Spinal Injury Association guidelines, and using the International Association of Neurorestoratology (IANR) Functional Rating Scales in combination with electrophysiological tests. Although this study is prospective and very preliminary, all five patients showed very significant functional improvement at 6 months of follow-up (Chen et al., 2014).

Autologous transplants have been carried out in seven patients using OM grafts in Portugal, all of which showed improvement in their ASIA motor scores. Two ASIA A patients became ASIA C (Lima et al., 2006), although some adverse effects were reported, such as a sensory decline in one patient and transient pain that responded to medication. A collaborative Indian pilot study was not able to demonstrate efficacy in five chronic, motor complete SCl patients (Chhabra et al., 2009). Moreover, a later 
study that enrolled 20 patients that underwent preoperative rehabilitation with no change in the ASIA impairment scale (AIS). Rehabilitation was maintained after the procedure, with one patient suffering aseptic meningitis and some minor adverse effects occurring in the other four patients. AIS grades improved in 11 of the 20 patients, and some of them improved in terms of new voluntary electromyography responses (15 patients) and somatosensory evoked potentials (4 patients: (Lima et al., 2010). However, as in the case of the Chinese studies, these results were not independently confirmed and raised some doubts in the field (personnel observations). More evidence will be needed in the future to support this treatment.

Other groups have worked with mucosal-derived cultured OECs and a phase 1/Ila clinical trial was completed in Australia at The National Centre for Adult Stem Cell Research, Griffith University (Feron et al., 2005; Mackay-Sim et al., 2008). The main objective was to test the feasibility and safety of autologous transplantation of OECs to treat SCl in humans (Feron et al., 2005). The participants were three paraplegic males ranging from 18-55 years old, with stable and complete thoracic injuries, and three matched control patients. The patient's OECs were grown and purified in vitro from nasal biopsies and the cells were characterized for the OEC markers $\left(\mathrm{S} 100^{+}\right.$and $\mathrm{GFAP}^{+}$ $>95 \%$ and p75NTR $^{+}:$76-88\%). Autologous cells were injected into the region of the damaged SC, employing a different number of cells in each patient: 12,20 and 28 million. An evaluation was made before transplantation and at regular intervals thereafter, including MRI, medical, neurological and psychosocial assessment, and a standard ASIA and Functional Independence Measure assessment. The participants were followed up for 3 years, concluding that the transplantation of autologous OECS is feasible and safe for SCl (Feron et al., 2005; Mackay-Sim et al., 2008). Although this clinical study is very preliminary, with the inclusion of only a few patients, functional recovery outcomes were also evaluated three years after transplantation. They found very modest findings, with no significant functional improvements except in one patient who showed an improvement over three segments in sensitivity (Mackay-Sim et al., 2008). However, they concluded that the procedure is feasible and safe, despite the inconvenience of the surgery and injection of the cells into the SC. Nevertheless, all 
cell therapy clinical trials for SCl to date imply having to "touch" the SC again, with the corresponding risk to patients.

Another group from Poland recently conducted a phase I clinical trial using autologous OM OECs and olfactory nerve fibroblasts (ONFs), comparing three transplanted patients to three controls (22-26 years old). Multiple injections (120-212) were used to transplant $1.8,1.9$ and $21.2 \times 10^{6}$ cells (with $10,25.7$ and $12 \%$ S $100^{+}$OECs, respectively), demonstrating the safety and feasibility of transplanting these cells. Additionally, functional improvements were demonstrated in two of the patients 1 year posttransplantation, which shifted from ASIA A to ASIA C and ASIA B. The third patient experimented improved function of the first spinal segments below the injury, although he remained as ASIA A (Tabakow et al., 2013). However, the patient that improved from SCI ASIA A to $C$ with OM transplantation had suffered a knife injury to the SC at T10-T11, a very particular type of lesion with unique features (Guest and Dietrich, 2015).

In 2014 a clinical case was described in which autologous transplantation of $\mathrm{OB}$ OECS/ONFs was performed in a combinatorial treatment that included re-transection of the SC to eliminate scar tissue (Tabakow et al., 2014). The treated 38 year old patient presented a very particular type of penetrating SC lesion inflicted with a knife at the T9 level, similar to that of the patient in a previous study (Tabakow et al., 2013). This stab lesion left a thin rim of tissue on the right lateral column of the SC that connected both stumps of the cord, which were separated by $8 \mathrm{~mm}$. The lesion produced an ASIA A functional deficit and even with rehabilitation, the deficit was stable 21 months after injury. The patient was treated in several ways, involving the removal of the glial scar (resection of the $\mathrm{SC}$ ) and increasing the gap to $10 \mathrm{~mm}$ but maintaining the rim of tissue left after the lesion. The patient was treated with four strips of peripheral nerve taken from the patient's sural nerve and 96 microinjections with a mixture of $5 \times 10^{5}$ OECs/ONFs cells (16\% OECs p75NTR ${ }^{+}$) administered at 24 different sites in the proximal and distal stump of the SC. The patient was continued to receive rehabilitation after surgery and there were no adverse effects in the 19 months after the procedure. Treatment produced a dramatic functional recovery, with the ASIA score of the patient shifting from complete SCI ASIA A to ASIA B 6 months post- 
surgery and finally, to ASIA C 11 months after the procedure. This score was maintained for a further 8 months, the last time point reported in the study. In addition to re-sectioning the lesion (to remove the inhibitory glial scar), in this case $O B$ glial cells were combined with peripheral nerve bridges (composed of SchCs, ONFs and intercellular matrix) and intensive rehabilitation, introducing new parameters to the therapeutic strategy (Tabakow et al., 2014). The possible spontaneous recovery from this lesion was very low, taking into account that the patient had been under rehabilitation for 21 months prior to the intervention. Although in the first 13 months after lesion the patient was subjected to a number of different rehabilitation programs, these were incomplete and interrupted because of the need to treat different complications (infections, pressure ulcers and inflammation of the deep venous system of the lower limbs). Hence, the patient was subjected to an additional intense neurorehabilitation program for 8 months before receiving the experimental treatment to rule out spontaneous recovery. This programme did not produce an improvement in his condition, which only ameliorated impressively after the surgery. Therefore, and taking into account data from different studies on late spontaneous recovery (see discussion in Tabakow et al., 2014), the probability of spontaneous recovery in this patient was considered to be lower than $1 \%$ (Tabakow et al., 2014). However, examining the published data of this study more closely, there appeared to be possible decompression of a cystic structure that extended from the ventral cord to the dorsal arachnoid, maintained within the separated dural layers, which may have contributed to recovery in conjunction with the detethering of dural adhesions (Guest and Dietrich, 2015). With respect to the mechanisms underlying the functional changes, the possibility of unprecedented extent of axonal regeneration $(10 \mathrm{~cm})$ was considered, yet some concerns were raised about this matter. For example, the preserved tissue in the lateral column of the right SC might contain corticospinal axons that sent out collaterals, which could explain motor function recovery in the left leg (the latency of motor evoked potentials returning to the normal range).

There are several issues that must be defined more accurately in relation to the clinical use of OECs. While the method of culture is fundamental, it may not be possible to standardize transplants for different subjects, which will make it even more difficult to 
interpret new studies (Guest and Dietrich, 2015). The OM seems to be the most accessible tissue to prepare OECs for autologous transplantation. In fact, patients with SC transection who were transplanted with OM- (Tabakow et al., 2013) or OB-OECs (Tabakow et al., 2014) had similar outcomes, although peripheral nerve autografts were not used in the former. Thus, the need to use $O B$ and peripheral grafts is not fully demonstrated in these studies (Guest and Dietrich, 2015).

Transplantation of OM cells has produced different results to that of $O B$ cells in the same rhizotomy model of lesion. This was attributed to the different composition of the cultures, which we have already addressed above, and to the low percentage of p75NTR positive OECs in the OM preparations (Ibrahim et al., 2014). However, in this respect it is necessary to consider the two clinical studies carried out in Poland (Tabakow et al., 2013; Tabakow et al., 2014). In the later study, a combined treatment was given to the patient with the transected SC, transplantation with $5 \times 10^{5}$ OB-cells with $16 \%$ of p75NTR ${ }^{+}$OECs (Tabakow et al., 2014), whereas p75NTR and S100 expression was used to identify OECs in the OEC/ONF mixture in the earlier study. The patient denoted as $\mathrm{T} 1$, also with the SC transected by a knife, recovered similarly to the patient in the 2014 study (ASIA A to C). Thus, both patients presented similar types of lesion (transection) and a similar degree of recovery. Patient T1 recovered the best of the three patients in this study with the OM cells grafted, even though he was transplanted with the smallest number of cells $\left(1.8 \times 10^{6}\right)$ and with the lowest

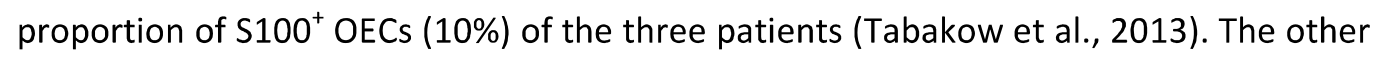
two patients had a different type of lesion (compression), and they were transplanted with $1.9 \times 10^{6}$ and $21.2 \times 10^{6} \mathrm{OM}$ cells, $25.7 \%$ and $12 \%$ of which were $\mathrm{S} 10 \mathrm{O}^{+}$, respectively. The functional recovery of these patients was poorer than both patients with the transection SC, although the total number of OECs they received was much higher. It is possible that surpassing a threshold of "true" OECs in the culture is sufficient to ensure an effect, and that specific factors related to each patient might account for these differences, such as the type of injury (Guest and Dietrich, 2015) or treatment. However, the mixed nature of the OM cultures, containing different cell types in addition to OECs, such as OM-MSC, ONFs and/or other p75NTR cells would do 
necessary a more accurate characterization. This can be fundamental to achieve uniform, or at least more predictable, treatments.

In some cases it might not be possible to establish a primary culture from the mucosa for different reasons. For example, in the case of the patient indicated above (Tabakow et al., 2014) it was due to chronic allergic sinusitis, although other possibilities include poor efficiency of the cultures (possibly due to the patient's age), contamination of cultures, etc. (Moreno-Flores and Avila, 2006; Moreno-Flores and Avila, 2010). To obtain OECs from a patient's OB has obvious problems related to the invasiveness of the surgery, even though it was accomplished with expertise in the work of Tabakow et al. The potential complications of craniotomy are well known, even using a minimally invasive approach, and they have also to be considered (Czyz, Tabakow, Hernandez-Sanchez, Jarmundowicz, \& Raisman, 2015; Guest and Dietrich, 2015).

The rationale behind our previous approaches (Moreno-Flores et al., 2003b; MorenoFlores et al., 2003a) aimed to resolve all these problems, including the composition of the cultures and the availability of regenerative OECs. We prepared primary cultures from human OB-OECs cadaver donors and we reversibly immortalized them (GarciaEscudero et al., 2010; Lim et al., 2010). Additionally, we also prepared cultures of human OM-cells that retained the capacity for axonal regeneration in a co-culture model (Garcia-Escudero et al., 2012). Our final aim was to prepare cell banks with batches of biosecure, histocompatible, "de-immortalized" OEC clonal lines. These cells would be typed and quantified for axonal regeneration using co-culture models with adult CNS neurons (Moreno-Flores and Avila, 2006; Moreno-Flores and Avila, 2010). However, the legal and ethical problems of transplantation with genetically modified cells, even for cells with modifications that would include extraordinary biosecurity measures are not inconsiderable. Nevertheless, this interesting possibility might be addressed in the future, trying to ensure the best biosecurity for patients and using OECs alone, or in combined treatments with cellular and pharmacological agents.

\section{I CONCLUSIONS AND FUTURE PERSPECTIVES}


In this review, we have set out the current status of research into OECs and the possibility of using these cells to treat $\mathrm{SCl}$ : morphological aspects, physiological functions, and the factors that they produce and that can be used to restore CNS function. Taking into account all the biological characteristics described in this review, we conclude that these cells possess a notable ability to stimulate axon repair/plasticity and/or to support the sparing of axons in the CNS.

These studies have revealed that OECs can act as therapeutic agents in several different ways. They are able to stimulate angiogenesis, and to modify PNNs and the glial scar (producing different proteinases like MMP2 and PAI-1: Fig. 4), especially when mixed with reactive astrocytes. In this way they can foster the outgrowth of axons to differing degrees, as well as through the production of trophic factors like NGF, BDNF and GDNF. Finally, they can also produce new myelination of the injured/repaired axons by direct or indirect mechanisms. OECs are a unique type of glia found exclusively in the olfactory system and as such, they are relatively accessible in rodents and humans. Therefore, they can be extracted for autologous grafting, which removes the likelihood of producing an immune rejection response.

Many laboratories have now used OECs in different acute and chronic experimental models of $\mathrm{SCl}$, some of which have produced a surprising degree of functional recovery when evaluated with different tests. Finally, several clinical trials have been conducted, with promising results. Today, OECs are considered an interesting avenue to explore in cell transplantation research in order to restore the integrity and functionality of the CNS, specifically in response to $\mathrm{SCl}$ and in demyelinating diseases. Hence, OECs appear to represent a promising tool that will probably be very fruitful in the near future, particularly in combination with other strategies. 


\section{List of Abbreviations}

aFGF: Acidic Fibroblastic Growth Factor

AIS: ASIA Impairment Scale

APP: Amyloid Precursor Protein

ASIA: American Spinal Injury Association

BBB: Basso, Beattie and Bresnahan Scale

BDNF: Brain Derived Neurotrophic Factor

BM-MSC: Bone Marrow Mesenchymal Stem Cell

cAMP: Cyclic Adenosine Monophosphate

CGRP: Calcitonin Gene-Related Peptide

CNS: Central Nervous System

CNTF: Ciliary Neurotrophic Factor

CSPG: Chondroitin Sulphate Proteoglycans

DMEM: Dulbecco's Modified Eagle Medium

DPI: Days Post Injury

DRG: Dorsal Root Ganglia

E-NCAM: Embryonic Neural Adhesion Molecule

ECM: Extracellular Matrix

GFAP: Glial Fibrillary Acidic Protein

GFP: Green Fluorescent Protein

GAG: Glycosaminoglycan

GBC: Globose Basal Cell

GDNF: Glial Cell-Derived Neurotrophic Factor

GFP: Green Fluorescent Protein

GMF: Genetically Modified Fibroblast

HA: Hyaluronan

HBC: Horizontal Basal Cell

HSPGs: Heparan Sulphate Proteoglycans

IL1RL1: Interleukin-1 Receptor Like-1

IL-6R: Interleukin-6 Receptor

LAR: Leukocyte Antigen-Related Protein 
LIFR: Leukemia Inhibitory Factor Receptor

LILR: Leukocyte Immunoglobulin-like Receptor

LILRB2: Part of B Type Subfamily of LILR receptors

LP: Lamina Propria

MAG: Myelin Associated Glycoprotein

MMP: Matrix Metalloproteinase

MSC: Mesenchymal Stem Cell

MRI: Magnetic Resonance Imaging

NGF: Nerve Growth Factor

NPY: Neuropeptide Y

NgR: Nogo Receptor

Nogo-A: Myelin Associated Proteins

NT: Neurotrophin

NTN: Neurturin

OB: Olfactory Bulb

OECs: Olfactory Ensheathing Glia Cells

OM: Olfactory Mucosa

OMgp: Myelin Oligodendrocyte Glycoprotein

OM-MSC: Olfactory Mucosa-Mesenchymal Stem Cells

ONF: Olfactory Nerve Fibroblast

ONL: Olfactory Nerve Layer

p75NTR: Low Affinity Receptor of NGF

PirB: Paired Immunoglobulin-like Receptor B

PKA: Protein Kinase A

PNN: Perineuronal Net

PNS: Peripheral Nervous System

PTPo: Protein Tyrosine Phosphatase $\sigma$

S100ß: Calcium Associated Protein

SchC: Schwann Cell

SC: Spinal Cord

SCI: Spinal Cord Injury

SCARB: Scavenger Receptor Class B member 2 
Sema: Semaphorin

TGF $\beta 3$ : Transforming Growth Factor $\beta 3$

TNFR: Tumour Necrosis Factor Receptors

Trk: Tyrosine Receptor Kinase

VEGF: Vascular Endothelial Growth Factor 


\section{REFERENCES}

Adelson, J. D., Barreto, G. E., Xu, L., Kim, T., Brott, B. K., Ouyang, Y., . . Giffard, R. G. (2012). Neuroprotection from stroke in the absence of $\mathrm{MHCl}$ or PirB. Neuron, 73(6), 1100-1107. doi:10.1016/j.neuron.2012.01.020

Ahuja, C. S., Martin, A. R., \& Fehlings, M. (2016). Recent advances in managing a spinal cord injury secondary to trauma. F1000Research, 5 doi:10.12688/f1000research.7586.1

Akiyama, Y., Lankford, K., Radtke, C., Greer, C. A., \& Kocsis, J. D. (2004). Remyelination of spinal cord axons by olfactory ensheathing cells and schwann cells derived from a transgenic rat expressing alkaline phosphatase marker gene. Neuron Glia Biology, 1(1), 47-55. doi:10.1017/S1740925X04000079

Alexander, C. L., Fitzgerald, U. F., \& Barnett, S. C. (2002). Identification of growth factors that promote long-term proliferation of olfactory ensheathing cells and modulate their antigenic phenotype. Glia, 37(4), 349-364.

Amemori, T., Jendelová, P., Růzicková, K., Arboleda, D., \& Syková, E. (2010). Cotransplantation of olfactory ensheathing glia and mesenchymal stromal cells does not have synergistic effects after spinal cord injury in the rat. Cytotherapy, 12(2), 212-225. doi:10.3109/14653240903440103

Andrews, M. R., \& Stelzner, D. J. (2007). Evaluation of olfactory ensheathing and schwann cells after implantation into a dorsal injury of adult rat spinal cord. Journal of Neurotrauma, 24(11), 1773-1792. doi:10.1089/neu.2007.0353

Arvanian, V. L., Schnell, L., Lou, L., Golshani, R., Hunanyan, A., Ghosh, A., . . Mendell, L. M. (2009). Chronic spinal hemisection in rats induces a progressive decline in transmission in uninjured fibers to motoneurons. Experimental Neurology, 216(2), 471-480. doi:10.1016/j.expneurol.2009.01.004

Asher, R. A., Morgenstern, D. A., Fidler, P. S., Adcock, K. H., Oohira, A., Braistead, J. E., . . . Fawcett, J. W. (2000). Neurocan is upregulated in injured brain and in cytokinetreated astrocytes. The Journal of Neuroscience: The Official Journal of the Society for Neuroscience, 20(7), 2427-2438. 
Assinck, P., Duncan, G. J., Hilton, B. J., Plemel, J. R., \& Tetzlaff, W. (2017). Cell transplantation therapy for spinal cord injury. Nature Neuroscience, 20(5), 637647. doi:10.1038/nn.4541

Atwal, J. K., Pinkston-Gosse, J., Syken, J., Stawicki, S., Wu, Y., Shatz, C., \& TessierLavigne, M. (2008). PirB is a functional receptor for myelin inhibitors of axonal regeneration. Science (New York, N.Y.), 322(5903), 967-970. doi:10.1126/science.1161151

Au, E., \& Roskams, A. J. (2002). Culturing olfactory ensheathing glia from the mouse olfactory epithelium. Methods in Molecular Biology (Clifton, N.J.), 198, 49-54. doi:049

Au, E., \& Roskams, A. J. (2003). Olfactory ensheathing cells of the lamina propria in vivo and in vitro. Glia, 41(3), 224-236. doi:10.1002/glia.10160

Au, W. W., Treloar, H. B., \& Greer, C. A. (2002). Sublaminar organization of the mouse olfactory bulb nerve layer. The Journal of Comparative Neurology, 446(1), 68-80.

Balentine, J. D. (1988). Spinal cord trauma: In search of the meaning of granular axoplasm and vesicular myelin. Journal of Neuropathology and Experimental Neurology, 47(2), 77-92.

Bareyre, F. M., Kerschensteiner, M., Raineteau, O., Mettenleiter, T. C., Weinmann, O., \& Schwab, M. E. (2004). The injured spinal cord spontaneously forms a new intraspinal circuit in adult rats. Nature Neuroscience, 7(3), 269-277. doi:10.1038/nn1195

Barger, S. W., Wolchok, S. R., \& Van Eldik, L. J. (1992). Disulfide-linked S100 beta dimers and signal transduction. Biochimica Et Biophysica Acta, 1160(1), 105-112.

Barnett, S. C., Alexander, C. L., Iwashita, Y., Gilson, J. M., Crowther, J., Clark, L., . . Franklin, R. J. (2000). Identification of a human olfactory ensheathing cell that can effect transplant-mediated remyelination of demyelinated CNS axons. Brain: $A$ Journal of Neurology, 123 ( Pt 8), 1581-1588. 
Barnett, S. C., Hutchins, A. M., \& Noble, M. (1993). Purification of olfactory nerve ensheathing cells from the olfactory bulb. Developmental Biology, 155(2), 337350. doi:10.1006/dbio.1993.1033

Barnett, S. C., \& Chang, L. (2004). Olfactory ensheathing cells and CNS repair: Going solo or in need of a friend? Trends in Neurosciences, 27(1), 54-60. doi:10.1016/j.tins.2003.10.011

Barnett, S. C., \& Riddell, J. S. (2007). Olfactory ensheathing cell transplantation as a strategy for spinal cord repair--what can it achieve? Nature Clinical Practice. Neurology, 3(3), 152-161. doi:10.1038/ncpneuro0447

Barraud, P., Seferiadis, A. A., Tyson, L. D., Zwart, M. F., Szabo-Rogers, H. L., Ruhrberg, C., ... Baker, C. V. H. (2010). Neural crest origin of olfactory ensheathing glia. Proceedings of the National Academy of Sciences of the United States of America, 107(49), 21040-21045. doi:10.1073/pnas.1012248107

Blight, A. R. (1983). Axonal physiology of chronic spinal cord injury in the cat: Intracellular recording in vitro. Neuroscience, 10(4), 1471-1486.

Blight, A. R. (1985). Delayed demyelination and macrophage invasion: A candidate for secondary cell damage in spinal cord injury. Central Nervous System Trauma: Journal of the American Paralysis Association, 2(4), 299-315. doi:10.1089/cns.1985.2.299

Bomze, H. M., Bulsara, K. R., Iskandar, B. J., Caroni, P., \& Skene, J. H. (2001). Spinal axon regeneration evoked by replacing two growth cone proteins in adult neurons. Nature Neuroscience, 4(1), 38-43. doi:10.1038/82881

Boruch, A. V., Conners, J. J., Pipitone, M., Deadwyler, G., Storer, P. D., Devries, G. H., \& Jones, K. J. (2001). Neurotrophic and migratory properties of an olfactory ensheathing cell line. Glia, 33(3), 225-229.

Botero, L. (2015). Evaluation of axonal regeneration in rats with acute and chronic spinal cord injury after olfactory ensheathing glia cells transplantation and aFGF treatment Thesis/Dissertation 
Botero, L., Gomez, R. M., \& Chaparro, O. (2013). [Pathogenesis of spinal cord injuries and mechanisms of repair induced by olfactory ensheathing cells]. Revista De Neurologia, 56(10), 521-531.

Bovolenta, P., Fernaud-Espinosa, I., Méndez-Otero, R., \& Nieto-Sampedro, M. (1997). Neurite outgrowth inhibitor of gliotic brain tissue. mode of action and cellular localization, studied with specific monoclonal antibodies. The European Journal of Neuroscience, 9(5), 977-989.

Bovolenta, P., Wandosell, F., \& Nieto-Sampedro, M. (1992). CNS glial scar tissue: A source of molecules which inhibit central neurite outgrowth. Progress in Brain Research, 94, 367-379.

Bovolenta, P., Wandosell, F., \& Nieto-Sampedro, M. (1993a). Characterization of a neurite outgrowth inhibitor expressed after CNS injury. The European Journal of Neuroscience, 5(5), 454-465.

Bovolenta, P., Wandosell, F., \& Nieto-Sampedro, M. (1993b). Neurite outgrowth inhibitors associated with glial cells and glial cell lines. Neuroreport, 5(3), 345-348.

Boyd, J. G., Lee, J., Skihar, V., Doucette, R., \& Kawaja, M. D. (2004). LacZ-expressing olfactory ensheathing cells do not associate with myelinated axons after implantation into the compressed spinal cord. Proceedings of the National Academy of Sciences of the United States of America, 101(7), 2162-2166. doi:10.1073/pnas.0303842101

Boyd, J. G., Jahed, A., McDonald, T. G., Krol, K. M., Van Eyk, J. E., Doucette, R., \& Kawaja, M. D. (2006). Proteomic evaluation reveals that olfactory ensheathing cells but not schwann cells express calponin. Glia, 53(4), 434-440. doi:10.1002/glia.20299

Boyles, J. K., Zoellner, C. D., Anderson, L. J., Kosik, L. M., Pitas, R. E., Weisgraber, K. H., . .. Ignatius, M. J. (1989). A role for apolipoprotein E, apolipoprotein A-I, and low density lipoprotein receptors in cholesterol transport during regeneration and remyelination of the rat sciatic nerve. The Journal of Clinical Investigation, 83(3), 1015-1031. doi:10.1172/JCl113943 
Bradbury, E. J., Khemani, S., Von, R., King, n., Priestley, J. V., \& McMahon, S. B. (1999). NT-3 promotes growth of lesioned adult rat sensory axons ascending in the dorsal columns of the spinal cord. The European Journal of Neuroscience, 11(11), 38733883.

Bray, G. M., Villegas-Pérez, M. P., Vidal-Sanz, M., \& Aguayo, A. J. (1987). The use of peripheral nerve grafts to enhance neuronal survival, promote growth and permit terminal reconnections in the central nervous system of adult rats. The Journal of Experimental Biology, 132, 5-19.

Bregman, B. S., Coumans, J., Dai, H. N., Kuhn, P. L., Lynskey, J., McAtee, M., \& Sandhu, F. (2002). Transplants and neurotrophic factors increase regeneration and recovery of function after spinal cord injury. Progress in Brain Research, 137, 257273. Retrieved from

https://www.ncbi.nlm.nih.gov/pubmed/?term=Transplants+and+neurotrophic+fa ctors+increase+regeneration+and+recovery+of+function+after+spinal+cord+injury

Bretzner, F., Plemel, J. R., Liu, J., Richter, M., Roskams, A. J., \& Tetzlaff, W. (2010). Combination of olfactory ensheathing cells with local versus systemic CAMP treatment after a cervical rubrospinal tract injury. Journal of Neuroscience Research, 88(13), 2833-2846. doi:10.1002/jnr.22440

Bunge, M. B. (2008). Novel combination strategies to repair the injured mammalian spinal cord. The Journal of Spinal Cord Medicine, 31(3), 262-269.

Busch, S. A., Horn, K. P., Cuascut, F. X., Hawthorne, A. L., Bai, L., Miller, R. H., \& Silver, J. (2010). Adult NG2+ cells are permissive to neurite outgrowth and stabilize sensory axons during macrophage-induced axonal dieback after spinal cord injury. The Journal of Neuroscience: The Official Journal of the Society for Neuroscience, 30(1), 255-265. doi:10.1523/JNEUROSCI.3705-09.2010

Cafferty, W. B. J., Gardiner, N. J., Das, P., Qiu, J., McMahon, S. B., \& Thompson, S. W. N. (2004). Conditioning injury-induced spinal axon regeneration fails in interleukin-6 knock-out mice. The Journal of Neuroscience: The Official Journal of the Society for Neuroscience, 24(18), 4432-4443. doi:10.1523/JNEUROSCI.2245-02.2004 
Cao, L., Su, Z., Zhou, Q., Lv, B., Liu, X., Jiao, L., . . He, C. (2006). Glial cell line-derived neurotrophic factor promotes olfactory ensheathing cells migration. Glia, 54(6), 536-544. doi:10.1002/glia.20403

Cao, L., Zhu, Y., Su, Z., Lv, B., Huang, Z., Mu, L., \& He, C. (2007). Olfactory ensheathing cells promote migration of schwann cells by secreted nerve growth factor. Glia, 55(9), 897-904. doi:10.1002/glia.20511

Carr, V. M., Farbman, A. I., Colletti, L. M., \& Morgan, J. I. (1991). Identification of a new non-neuronal cell type in rat olfactory epithelium. Neuroscience, 45(2), 433-449.

Carri, N. G., Perris, R., Johansson, S., \& Ebendal, T. (1988). Differential outgrowth of retinal neurites on purified extracellular matrix molecules. Journal of Neuroscience Research, 19(4), 428-439. doi:10.1002/jnr.490190407

Carter, L. A., MacDonald, J. L., \& Roskams, A. J. (2004). Olfactory horizontal basal cells demonstrate a conserved multipotent progenitor phenotype. The Journal of Neuroscience: The Official Journal of the Society for Neuroscience, 24(25), 56705683. doi:10.1523/JNEUROSCI.0330-04.2004

Celio, M. R., Spreafico, R., De Biasi, S., \& Vitellaro-Zuccarello, L. (1998). Perineuronal nets: Past and present. Trends in Neurosciences, 21(12), 510-515.

Chen, L., Huang, H., Xi, H., Zhang, F., Liu, Y., Chen, D., \& Xiao, J. (2014). A prospective randomized double-blind clinical trial using a combination of olfactory ensheathing cells and schwann cells for the treatment of chronic complete spinal cord injuries. Cell Transplantation, 23 Suppl 1, 35. doi:10.3727/096368914X685014

Cheng, H., Cao, Y., \& Olson, L. (1996). Spinal cord repair in adult paraplegic rats: Partial restoration of hind limb function. Science (New York, N.Y.), 273(5274), 510-513. Retrieved from https://www.ncbi.nlm.nih.gov/pubmed/?term=Spinal+cord+repair+in+adult+para plegic+rats\%3A+partial+restoration+of+hind+limb+function

Chhabra, H. S., Lima, C., Sachdeva, S., Mittal, A., Nigam, V., Chaturvedi, D., .. Khan, T. a. H. (2009). Autologous olfactory [corrected] mucosal transplant in chronic spinal 
cord injury: An indian pilot study. Spinal Cord, 47(12), 887-895.

doi:10.1038/sc.2009.54

Chuah, M. I., \& Au, C. (1991). Olfactory schwann cells are derived from precursor cells in the olfactory epithelium. Journal of Neuroscience Research, 29(2), 172-180. doi:10.1002/jnr.490290206

Chuah, M. I., Choi-Lundberg, D., Weston, S., Vincent, A. J., Chung, R. S., Vickers, J. C., \& West, A. K. (2004). Olfactory ensheathing cells promote collateral axonal branching in the injured adult rat spinal cord. Experimental Neurology, 185(1), 1525.

Chuah, M. I., \& West, A. K. (2002). Cellular and molecular biology of ensheathing cells. Microscopy Research and Technique, 58(3), 216-227. doi:10.1002/jemt.10151

Chung, R. S., Woodhouse, A., Fung, S., Dickson, T. C., West, A. K., Vickers, J. C., \& Chuah, M. I. (2004). Olfactory ensheathing cells promote neurite sprouting of injured axons in vitro by direct cellular contact and secretion of soluble factors. Cellular and Molecular Life Sciences: CMLS, 61(10), 1238-1245. doi:10.1007/s00018-004-4026-y

Collazos-Castro, J. E., Muñetón-Gómez, V. C., \& Nieto-Sampedro, M. (2005). Olfactory glia transplantation into cervical spinal cord contusion injuries. Journal of Neurosurgery. Spine, 3(4), 308-317. doi:10.3171/spi.2005.3.4.0308

Costanzo, R. M. (1985). Neural regeneration and functional reconnection following olfactory nerve transection in hamster. Brain Research, 361(1-2), 258-266.

Coumans, J. V., Lin, T. T., Dai, H. N., MacArthur, L., McAtee, M., Nash, C., \& Bregman, B. S. (2001). Axonal regeneration and functional recovery after complete spinal cord transection in rats by delayed treatment with transplants and neurotrophins. The Journal of Neuroscience: The Official Journal of the Society for Neuroscience, 21(23), 9334-9344.

Cregg, J. M., DePaul, M. A., Filous, A. R., Lang, B. T., Tran, A., \& Silver, J. (2014). Functional regeneration beyond the glial scar. Experimental Neurology, 253, 197207. doi:10.1016/j.expneurol.2013.12.024 
Crespo, D., Asher, R. A., Lin, R., Rhodes, K. E., \& Fawcett, J. W. (2007). How does chondroitinase promote functional recovery in the damaged CNS? Experimental Neurology, 206(2), 159-171. doi:10.1016/j.expneurol.2007.05.001

Czepiel, M., Boddeke, E., \& Copray, S. (2015). Human oligodendrocytes in remyelination research. Glia, 63(4), 513-530. doi:10.1002/glia.22769

Czyz, M., Tabakow, P., Hernandez-Sanchez, I., Jarmundowicz, W., \& Raisman, G. (2015). Obtaining the olfactory bulb as a source of olfactory ensheathing cells with the use of minimally invasive neuroendoscopy-assisted supraorbital keyhole approach-cadaveric feasibility study. British Journal of Neurosurgery, 29(3), 362-370. doi:10.3109/02688697.2015.1006170

David, S., \& Lacroix, S. (2003). Molecular approaches to spinal cord repair. Annual Review of Neuroscience, 26, 411-440. doi:10.1146/annurev.neuro.26.043002.094946

Davies, S. J., Goucher, D. R., Doller, C., \& Silver, J. (1999). Robust regeneration of adult sensory axons in degenerating white matter of the adult rat spinal cord. The Journal of Neuroscience: The Official Journal of the Society for Neuroscience, 19(14), 5810-5822.

Delorme, B., Nivet, E., Gaillard, J., Häupl, T., Ringe, J., Devèze, A., . . Féron, F. (2010). The human nose harbors a niche of olfactory ectomesenchymal stem cells displaying neurogenic and osteogenic properties. Stem Cells and Development, 19(6), 853-866. doi:10.1089/scd.2009.0267

DeLucia, T. A., Conners, J. J., Brown, T. J., Cronin, C. M., Khan, T., \& Jones, K. J. (2003). Use of a cell line to investigate olfactory ensheathing cell-enhanced axonal regeneration. Anatomical Record. Part B, New Anatomist, 271(1), 61-70. doi:10.1002/ar.b.10014

Deng, C., Gorrie, C., Hayward, I., Elston, B., Venn, M., Mackay-Sim, A., \& Waite, P. (2006). Survival and migration of human and rat olfactory ensheathing cells in intact and injured spinal cord. Journal of Neuroscience Research, 83(7), 1201-1212. doi:10.1002/jnr.20817 
Deng, Y. B., Liu, Y., Zhu, W. B., Bi, X. B., Wang, Y. Z., Ye, M. H., \& Zhou, G. -. (2008). The co-transplantation of human bone marrow stromal cells and embryo olfactory ensheathing cells as a new approach to treat spinal cord injury in a rat model. Cytotherapy, 10(6), 551-564. doi:10.1080/14653240802165673

Deshpande, D. M., Kim, Y., Martinez, T., Carmen, J., Dike, S., Shats, I., ... Kerr, D. A. (2006). Recovery from paralysis in adult rats using embryonic stem cells. Annals of Neurology, 60(1), 32-44. doi:10.1002/ana.20901

Deumens, R., Koopmans, G. C., \& Joosten, E. A. J. (2005). Regeneration of descending axon tracts after spinal cord injury. Progress in Neurobiology, 77(1-2), 57-89. doi:10.1016/j.pneurobio.2005.10.004

Devon, R., \& Doucette, R. (1992). Olfactory ensheathing cells myelinate dorsal root ganglion neurites. Brain Research, 589(1), 175-179. Retrieved from https://www.ncbi.nlm.nih.gov/pubmed/?term=Olfactory+ensheathing+cells+myel inate+dorsal+root+ganglion+neurites

Devon, R., \& Doucette, R. (1995). Olfactory ensheathing cells do not require L-ascorbic acid in vitro to assemble a basal lamina or to myelinate dorsal root ganglion neurites. Brain Research, 688(1-2), 223-229.

Dickendesher, T. L., Baldwin, K. T., Mironova, Y. A., Koriyama, Y., Raiker, S. J., Askew, K. L., . . Giger, R. J. (2012). NgR1 and NgR3 are receptors for chondroitin sulfate proteoglycans. Nature Neuroscience, 15(5), 703-712. doi:10.1038/nn.3070

Dobkin, B. H., Curt, A., \& Guest, J. (2006). Cellular transplants in china: Observational study from the largest human experiment in chronic spinal cord injury. Neurorehabilitation and Neural Repair, 20(1), 5-13. doi:10.1177/1545968305284675

Domeniconi, M., Cao, Z., Spencer, T., Sivasankaran, R., Wang, K., Nikulina, E., . . Filbin, M. (2002). Myelin-associated glycoprotein interacts with the Nogo66 receptor to inhibit neurite outgrowth. Neuron, 35(2), 283-290.

Dou, C. L., \& Levine, J. M. (1994). Inhibition of neurite growth by the NG2 chondroitin sulfate proteoglycan. The Journal of Neuroscience: The Official Journal of the Society for Neuroscience, 14(12), 7616-7628. 
Doucette, J. R. (1984). The glial cells in the nerve fiber layer of the rat olfactory bulb. The Anatomical Record, 210(2), 385-391. doi:10.1002/ar.1092100214

Doucette, J. R., Kiernan, J. A., \& Flumerfelt, B. A. (1983). The re-innervation of olfactory glomeruli following transection of primary olfactory axons in the central or peripheral nervous system. Journal of Anatomy, 137 (Pt 1), 1-19.

Doucette, R. (1990). Glial influences on axonal growth in the primary olfactory system. Glia, 3(6), 433-449. doi:10.1002/glia.440030602

Doucette, R. (1991). PNS-CNS transitional zone of the first cranial nerve. The Journal of Comparative Neurology, 312(3), 451-466. doi:10.1002/cne.903120311

Doucette, R. (1993). Glial cells in the nerve fiber layer of the main olfactory bulb of embryonic and adult mammals. Microscopy Research and Technique, 24(2), 113130. doi:10.1002/jemt.1070240204

Doucette, R. (1995). Olfactory ensheathing cells: Potential for glial cell transplantation into areas of CNS injury. Histology and Histopathology, 10(2), 503-507.

Doucette, R. (1996). Immunohistochemical localization of laminin, fibronectin and collagen type IV in the nerve fiber layer of the olfactory bulb. International Journal of Developmental Neuroscience: The Official Journal of the International Society for Developmental Neuroscience, 14(7-8), 945-959.

Duan, D., Rong, M., Zeng, Y., Teng, X., Zhao, Z., Liu, B., .. . Lu, M. (2011). Electrophysiological characterization of NSCs after differentiation induced by OEC conditioned medium. Acta Neurochirurgica, 153(10), 2085-2090. doi:10.1007/s00701-011-0955-z

Eggers, R., Hendriks, W. T. J., Tannemaat, M. R., van Heerikhuize, J. J., Pool, C. W., Carlstedt, T. P., ... Verhaagen, J. (2008). Neuroregenerative effects of lentiviral vector-mediated GDNF expression in reimplanted ventral roots. Molecular and Cellular Neurosciences, 39(1), 105-117. doi:10.1016/j.mcn.2008.05.018

Erceg, S., Ronaghi, M., Oria, M., Roselló, M. G., Aragó, M. A. P., Lopez, M. G., . . Stojkovic, M. (2010). Transplanted oligodendrocytes and motoneuron progenitors generated from human embryonic stem cells promote locomotor recovery after 
spinal cord transection. Stem Cells (Dayton, Ohio), 28(9), 1541-1549.

doi:10.1002/stem.489

Farbman, A. I. (1994). The cellular basis of olfaction. Endeavour, 18(1), 2-8.

Fawcett, J. W., \& Asher, R. A. (1999). The glial scar and central nervous system repair. Brain Research Bulletin, 49(6), 377-391.

Fawcett, J. W., Schwab, M. E., Montani, L., Brazda, N., \& Müller, H. W. (2012).

Defeating inhibition of regeneration by scar and myelin components. Handbook of Clinical Neurology, 109, 503-522. doi:10.1016/B978-0-444-52137-8.00031-0

Felts, P. A., Baker, T. A., \& Smith, K. J. (1997). Conduction in segmentally demyelinated mammalian central axons. The Journal of Neuroscience: The Official Journal of the Society for Neuroscience, 17(19), 7267-7277.

Fernaud-Espinosa, I., Nieto-Sampedro, M., \& Bovolenta, P. (1993). Differential activation of microglia and astrocytes in aniso- and isomorphic gliotic tissue. Glia, 8(4), 277-291. doi:10.1002/glia.440080408

Féron, F., Perry, C., Cochrane, J., Licina, P., Nowitzke, A., Urquhart, S., . . Mackay-Sim, A. (2005). Autologous olfactory ensheathing cell transplantation in human spinal cord injury. Brain: A Journal of Neurology, 128(Pt 12), 2951-2960. doi:10.1093/brain/awh657

Féron, F., Perry, C., Girard, S. D., \& Mackay-Sim, A. (2013). Isolation of adult stem cells from the human olfactory mucosa. Methods in Molecular Biology (Clifton, N.J.), 1059, 107-114. doi:10.1007/978-1-62703-574-3_10

Fidler, P. S., Schuette, K., Asher, R. A., Dobbertin, A., Thornton, S. R., Calle-Patino, Y., . . Fawcett, J. W. (1999). Comparing astrocytic cell lines that are inhibitory or permissive for axon growth: The major axon-inhibitory proteoglycan is NG2. The Journal of Neuroscience: The Official Journal of the Society for Neuroscience, 19(20), 8778-8788.

Filbin, M. T. (2003). Myelin-associated inhibitors of axonal regeneration in the adult mammalian CNS. Nature Reviews. Neuroscience, 4(9), 703-713. doi:10.1038/nrn1195 
Fisher, D., Xing, B., Dill, J., Li, H., Hoang, H. H., Zhao, Z., . . Li, S. (2011). Leukocyte common antigen-related phosphatase is a functional receptor for chondroitin sulfate proteoglycan axon growth inhibitors. The Journal of Neuroscience: The Official Journal of the Society for Neuroscience, 31(40), 14051-14066. doi:10.1523/JNEUROSCI.1737-11.2011

Forni, P. E., Taylor-Burds, C., Melvin, V. S., Williams, T., Williams, T., \& Wray, S. (2011). Neural crest and ectodermal cells intermix in the nasal placode to give rise to GnRH-1 neurons, sensory neurons, and olfactory ensheathing cells. The Journal of Neuroscience: The Official Journal of the Society for Neuroscience, 31(18), 69156927. doi:10.1523/JNEUROSCI.6087-10.2011

Fouad, K., Pearse, D. D., Tetzlaff, W., \& Vavrek, R. (2009). Transplantation and repair: Combined cell implantation and chondroitinase delivery prevents deterioration of bladder function in rats with complete spinal cord injury. Spinal Cord, 47(10), 727732. doi:10.1038/sc.2009.10

Fouad, K., Schnell, L., Bunge, M. B., Schwab, M. E., Liebscher, T., \& Pearse, D. D. (2005). Combining schwann cell bridges and olfactory-ensheathing glia grafts with chondroitinase promotes locomotor recovery after complete transection of the spinal cord. The Journal of Neuroscience: The Official Journal of the Society for Neuroscience, 25(5), 1169-1178. doi:10.1523/JNEUROSCI.3562-04.2005

Fournier, A. E., GrandPre, T., \& Strittmatter, S. M. (2001). Identification of a receptor mediating nogo-66 inhibition of axonal regeneration. Nature, 409(6818), 341-346. doi:10.1038/35053072

Franceschini, I. A., \& Barnett, S. C. (1996). Low-affinity NGF-receptor and E-N-CAM expression define two types of olfactory nerve ensheathing cells that share a common lineage. Developmental Biology, 173(1), 327-343. doi:10.1006/dbio.1996.0027

Franklin, R. J., Gilson, J. M., Franceschini, I. A., \& Barnett, S. C. (1996). Schwann cell-like myelination following transplantation of an olfactory bulb-ensheathing cell line into areas of demyelination in the adult CNS. Glia, 17(3), 217-224. doi:AID-

GLIA4\&gt;3.0.CO;2-Y 
Franssen, E. H. P., de Bree, F. M., \& Verhaagen, J. (2007). Olfactory ensheathing glia: Their contribution to primary olfactory nervous system regeneration and their regenerative potential following transplantation into the injured spinal cord. Brain Research Reviews, 56(1), 236-258. doi:10.1016/j.brainresrev.2007.07.013

Franssen, E. H. P., Roet, K. C. D., de Bree, F. M., \& Verhaagen, J. (2009). Olfactory ensheathing glia and schwann cells exhibit a distinct interaction behavior with meningeal cells. Journal of Neuroscience Research, 87(7), 1556-1564. doi:10.1002/jnr.21979

Franzen, R., Martin, D., Daloze, A., Moonen, G., \& Schoenen, J. (1999). Grafts of meningeal fibroblasts in adult rat spinal cord lesion promote axonal regrowth. Neuroreport, 10(7), 1551-1556.

Frisch, D. (1967). Ultrastructure of mouse olfactory mucosa. The American Journal of Anatomy, 121(1), 87-120. doi:10.1002/aja.1001210107

García-Alías, G., López-Vales, R., Forés, J., Navarro, X., \& Verdú, E. (2004). Acute transplantation of olfactory ensheathing cells or schwann cells promotes recovery after spinal cord injury in the rat. Journal of Neuroscience Research, 75(5), 632641. doi:10.1002/jnr.20029

García-Escudero, V., García-Gómez, A., Gargini, R., Martín-Bermejo, M. J., Langa, E., de Yébenes, J. G., .. . Lim, F. (2010). Prevention of senescence progression in reversibly immortalized human ensheathing glia permits their survival after deimmortalization. Molecular Therapy: The Journal of the American Society of Gene Therapy, 18(2), 394-403. doi:10.1038/mt.2009.268

García-Escudero, V., García-Gómez, A., Langa, E., Martín-Bermejo, M. J., RamírezCamacho, R., García-Berrocal, J. R., . . . Lim, F. (2012). Patient-derived olfactory mucosa cells but not lung or skin fibroblasts mediate axonal regeneration of retinal ganglion neurons. Neuroscience Letters, 509(1), 27-32. doi:10.1016/j.neulet.2011.12.037

Ge, L., Liu, K., Liu, Z., \& Lu, M. (2016). Co-transplantation of autologous OM-MSCs and OM-OECs: A novel approach for spinal cord injury. Reviews in the Neurosciences, 27(3), 259-270. doi:10.1515/revneuro-2015-0030 
Gerzanich, V., Woo, S. K., Vennekens, R., Tsymbalyuk, O., Ivanova, S., Ivanov, A., . . Simard, J. M. (2009). De novo expression of Trpm4 initiates secondary hemorrhage in spinal cord injury. Nature Medicine, 15(2), 185-191. doi:10.1038/nm.1899

Girard, S. D., Devéze, A., Nivet, E., Gepner, B., Roman, F. S., \& Féron, F. (2011). Isolating nasal olfactory stem cells from rodents or humans. Journal of Visualized Experiments: JoVE, (54) doi:10.3791/2762

Gomez, R. M. (2009). The use of olfactory ensheathing glia cells and synthetic proteins for functional recovery in a model of spinal cord section in vivo Thesis/Dissertation

Gómez, R. M., Ghotme, K., Botero, L., Bernal, J. E., Pérez, R., Barreto, G. E., \& Bustos, R. H. (2016). Ultrastructural analysis of olfactory ensheathing cells derived from olfactory bulb and nerve of neonatal and juvenile rats. Neuroscience Research, 103, 10-17. doi:10.1016/j.neures.2015.07.012

Gomez, R. M., Ghotme, K., Niño, J. J., Quiroz-Padilla, M., Vargas, D., Domínguez, A. R., . . Sanchez, M. Y. (2015). Combined strategy for a reliable evaluation of spinal cord injury using an in vivo model. Central Nervous System Agents in Medicinal Chemistry,

Gorrie, C. A., Hayward, I., Cameron, N., Kailainathan, G., Nandapalan, N., Sutharsan, R., ... Waite, P. M. E. (2010). Effects of human OEC-derived cell transplants in rodent spinal cord contusion injury. Brain Research, 1337, 8-20.

doi:10.1016/j.brainres.2010.04.019

Graziadei, P. P., \& Graziadei, G. A. (1979). Neurogenesis and neuron regeneration in the olfactory system of mammals. I. morphological aspects of differentiation and structural organization of the olfactory sensory neurons. Journal of Neurocytology, 8(1), 1-18.

Griffiths, I. R., Burns, N., \& Crawford, A. R. (1978). Early vascular changes in the spinal grey matter following impact injury. Acta Neuropathologica, 41(1), 33-39.

Retrieved from https://www.ncbi.nlm.nih.gov/pubmed/?term=Early+vascular+changes+in+the+sp $\underline{\text { inal+grey+matter+following+impact+injury }}$ 
Grill, R. J., Blesch, A., \& Tuszynski, M. H. (1997). Robust growth of chronically injured spinal cord axons induced by grafts of genetically modified NGF-secreting cells. Experimental Neurology, 148(2), 444-452. doi:10.1006/exnr.1997.6704

Grill, R., Murai, K., Blesch, A., Gage, F. H., \& Tuszynski, M. H. (1997). Cellular delivery of neurotrophin-3 promotes corticospinal axonal growth and partial functional recovery after spinal cord injury. The Journal of Neuroscience: The Official Journal of the Society for Neuroscience, 17(14), 5560-5572.

Guest, J., Herrera, L. P., \& Qian, T. (2006). Rapid recovery of segmental neurological function in a tetraplegic patient following transplantation of fetal olfactory bulbderived cells. Spinal Cord, 44(3), 135-142. doi:10.1038/sj.sc.3101820

Guest, J., \& Dietrich, W. D. (2015). Commentary regarding the recent publication by tabakow et al., "functional regeneration of supraspinal connections in a patient with transected spinal cord following transplantation of bulbar olfactory ensheathing cells with peripheral nerve bridging". Journal of Neurotrauma, 32(15), 1176-1178. doi:10.1089/neu.2014.3790

Handelmann, G. E., Boyles, J. K., Weisgraber, K. H., Mahley, R. W., \& Pitas, R. E. (1992). Effects of apolipoprotein $E$, beta-very low density lipoproteins, and cholesterol on the extension of neurites by rabbit dorsal root ganglion neurons in vitro. Journal of Lipid Research, 33(11), 1677-1688.

Hannila, S. S., \& Filbin, M. T. (2008). The role of cyclic AMP signaling in promoting axonal regeneration after spinal cord injury. Experimental Neurology, 209(2), 321332. doi:10.1016/j.expneurol.2007.06.020

Harding, J., Graziadei, P. P., Monti Graziadei, G. A., \& Margolis, F. L. (1977). Denervation in the primary olfactory pathway of mice. IV. biochemical and morphological evidence for neuronal replacement following nerve section. Brain Research, 132(1), 11-28.

Hardingham, T. E. (1979). The role of link-protein in the structure of cartilage proteoglycan aggregates. The Biochemical Journal, 177(1), 237-247.

Hayashi, H., Campenot, R. B., Vance, D. E., \& Vance, J. E. (2009). Protection of neurons from apoptosis by apolipoprotein E-containing lipoproteins does not require 
lipoprotein uptake and involves activation of phospholipase Cgamma1 and inhibition of calcineurin. The Journal of Biological Chemistry, 284(43), 2960529613. doi:10.1074/jbc.M109.039560

He, Z., \& Koprivica, V. (2004). The nogo signaling pathway for regeneration block. Annual Review of Neuroscience, 27, 341-368. doi:10.1146/annurev.neuro.27.070203.144340

Higginson, J. R., Thompson, S. M., Santos-Silva, A., Guimond, S. E., Turnbull, J. E., \& Barnett, S. C. (2012). Differential sulfation remodelling of heparan sulfate by extracellular 6-0-sulfatases regulates fibroblast growth factor-induced boundary formation by glial cells: Implications for glial cell transplantation. The Journal of Neuroscience: The Official Journal of the Society for Neuroscience, 32(45), 1590215912. doi:10.1523/JNEUROSCI.6340-11.2012

Holbrook, E. H., Szumowski, K. E., \& Schwob, J. E. (1995). An immunochemical, ultrastructural, and developmental characterization of the horizontal basal cells of rat olfactory epithelium. The Journal of Comparative Neurology, 363(1), 129-146. doi:10.1002/cne.903630111

Honoré, A., Le Corre, S., Derambure, C., Normand, R., Duclos, C., Boyer, O., . . . Guérout, N. (2012). Isolation, characterization, and genetic profiling of subpopulations of olfactory ensheathing cells from the olfactory bulb. Glia, 60(3), 404-413. doi:10.1002/glia.22274

Huang, E. J., \& Reichardt, L. F. (2001). Neurotrophins: Roles in neuronal development and function. Annual Review of Neuroscience, 24, 677-736. doi:10.1146/annurev.neuro.24.1.677

Huang, E. J., \& Reichardt, L. F. (2003). Trk receptors: Roles in neuronal signal transduction. Annual Review of Biochemistry, 72, 609-642. doi:10.1146/annurev.biochem.72.121801.161629 Huang, H., Chen, L., Xi, H., Wang, Q., Zhang, J., Liu, Y., \& Zhang, F. (2009). [Olfactory ensheathing cells transplantation for central nervous system diseases in 1,255 patients]. Zhongguo Xiu Fu Chong Jian Wai Ke Za Zhi = Zhongguo Xiufu Chongjian 
Waike Zazhi = Chinese Journal of Reparative and Reconstructive Surgery, 23(1), 1420.

Huang, Z., Wang, Y., Cao, L., Su, Z., Zhu, Y., Chen, Y., . . He, C. (2008). Migratory properties of cultured olfactory ensheathing cells by single-cell migration assay. Cell Research, 18(4), 479-490. doi:10.1038/cr.2008.38

Huang, Z., Wang, Y., Su, Z., Geng, J., Chen, Y., Yuan, X., \& He, C. (2011). Slit-2 repels the migration of olfactory ensheathing cells by triggering Ca2+-dependent cofilin activation and RhoA inhibition. Journal of Cell Science, 124(Pt 2), 186-197. doi:10.1242/jcs.071357

Ibanez, C., Ito, D., Zawadzka, M., Jeffery, N. D., \& Franklin, R. J. M. (2007). Calponin is expressed by fibroblasts and meningeal cells but not olfactory ensheathing cells in the adult peripheral olfactory system. Glia, 55(2), 144-151. doi:10.1002/glia.20443 Ibrahim, A. G., Kirkwood, P. A., Raisman, G., \& Li, Y. (2009). Restoration of hand function in a rat model of repair of brachial plexus injury. Brain: $A$ Journal of Neurology, 132(Pt 5), 1268-1276. doi:10.1093/brain/awp030

Ibrahim, A., Li, D., Collins, A., Tabakow, P., Raisman, G., \& Li, Y. (2014). Comparison of olfactory bulbar and mucosal cultures in a rat rhizotomy model. Cell Transplantation, 23(11), 1465-1470. doi:10.3727/096368913X676213

Imaizumi, T., Lankford, K. L., Burton, W. V., Fodor, W. L., \& Kocsis, J. D. (2000). Xenotransplantation of transgenic pig olfactory ensheathing cells promotes axonal regeneration in rat spinal cord. Nature Biotechnology, 18(9), 949-953. doi:10.1038/79432

Imaizumi, T., Lankford, K. L., \& Kocsis, J. D. (2000). Transplantation of olfactory ensheathing cells or schwann cells restores rapid and secure conduction across the transected spinal cord. Brain Research, 854(1-2), 70-78.

Imaizumi, T., Lankford, K. L., Waxman, S. G., Greer, C. A., \& Kocsis, J. D. (1998). Transplanted olfactory ensheathing cells remyelinate and enhance axonal conduction in the demyelinated dorsal columns of the rat spinal cord. The Journal of Neuroscience: The Official Journal of the Society for Neuroscience, 18(16), 61766185. 
Irvine, K. A., \& Blakemore, W. F. (2008). Remyelination protects axons from demyelination-associated axon degeneration. Brain: A Journal of Neurology, 131(Pt 6), 1464-1477. doi:10.1093/brain/awn080

Iwatsuki, K., Yoshimine, T., Kishima, H., Aoki, M., Yoshimura, K., Ishihara, M., . . Lima, C. (2008). Transplantation of olfactory mucosa following spinal cord injury promotes recovery in rats. Neuroreport, 19(13), 1249-1252. doi:10.1097/WNR.0b013e328305b70b

Jahed, A., Rowland, J. W., McDonald, T., Boyd, J. G., Doucette, R., \& Kawaja, M. D. (2007). Olfactory ensheathing cells express smooth muscle alpha-actin in vitro and in vivo. The Journal of Comparative Neurology, 503(2), 209-223. doi:10.1002/cne.21385

Jani, H. R., \& Raisman, G. (2004). Ensheathing cell cultures from the olfactory bulb and mucosa. Glia, 47(2), 130-137. doi:10.1002/glia.20038

Jiang, S., Ballerini, P., Buccella, S., Giuliani, P., Jiang, C., Huang, X., \& Rathbone, M. P. (2008). Remyelination after chronic spinal cord injury is associated with proliferation of endogenous adult progenitor cells after systemic administration of guanosine. Purinergic Signalling, 4(1), 61-71. doi:10.1007/s11302-007-9093-8

Jones, L. L., Oudega, M., Bunge, M. B., \& Tuszynski, M. H. (2001). Neurotrophic factors, cellular bridges and gene therapy for spinal cord injury. The Journal of Physiology, 533(Pt 1), 83-89.

Jurevics, H., Bouldin, T. W., Toews, A. D., \& Morell, P. (1998). Regenerating sciatic nerve does not utilize circulating cholesterol. Neurochemical Research, 23(3), 401406.

Kafitz, K. W., \& Greer, C. A. (1997). Role of laminin in axonal extension from olfactory receptor cells. Journal of Neurobiology, 32(3), 298-310.

Kafitz, K. W., \& Greer, C. A. (1998). Differential expression of extracellular matrix and cell adhesion molecules in the olfactory nerve and glomerular layers of adult rats. Journal of Neurobiology, 34(3), 271-282. 
Kafitz, K. W., \& Greer, C. A. (1999). Olfactory ensheathing cells promote neurite extension from embryonic olfactory receptor cells in vitro. Glia, 25(2), 99-110.

Kanno, H., Pearse, D. D., Ozawa, H., Itoi, E., \& Bunge, M. B. (2015). Schwann cell transplantation for spinal cord injury repair: Its significant therapeutic potential and prospectus. Reviews in the Neurosciences, 26(2), 121-128. doi:10.1515/revneuro-2014-0068

Katoh, H., Shibata, S., Fukuda, K., Sato, M., Satoh, E., Nagoshi, N., . . Okano, H. (2011). The dual origin of the peripheral olfactory system: Placode and neural crest. Molecular Brain, 4, 34. doi:10.1186/1756-6606-4-34

Klein, R. (2012). Eph/ephrin signalling during development. Development (Cambridge, England), 139(22), 4105-4109. doi:10.1242/dev.074997

Kubo, T., Yamaguchi, A., Iwata, N., \& Yamashita, T. (2008). The therapeutic effects of rho-ROCK inhibitors on CNS disorders. Therapeutics and Clinical Risk Management, 4(3), 605-615.

Kubo, T., \& Yamashita, T. (2007). Rho-ROCK inhibitors for the treatment of CNS injury. Recent Patents on CNS Drug Discovery, 2(3), 173-179.

Kwon, B. K., Liu, J., Lam, C., Plunet, W., Oschipok, L. W., Hauswirth, W., . . Tetzlaff, W. (2007). Brain-derived neurotrophic factor gene transfer with adeno-associated viral and lentiviral vectors prevents rubrospinal neuronal atrophy and stimulates regeneration-associated gene expression after acute cervical spinal cord injury. Spine, 32(11), 1164-1173. doi:10.1097/BRS.0b013e318053ec35

Lakatos, A., Franklin, R. J., \& Barnett, S. C. (2000). Olfactory ensheathing cells and schwann cells differ in their in vitro interactions with astrocytes. Glia, 32(3), 214225.

Lakatos, A., Barnett, S. C., \& Franklin, R. J. M. (2003). Olfactory ensheathing cells induce less host astrocyte response and chondroitin sulphate proteoglycan expression than schwann cells following transplantation into adult CNS white matter. Experimental Neurology, 184(1), 237-246. 
Lankford, K. L., Brown, R. J., Sasaki, M., \& Kocsis, J. D. (2014). Olfactory ensheathing cells, but not schwann cells, proliferate and migrate extensively within moderately X-irradiated juvenile rat brain. Glia, 62(1), 52-63. doi:10.1002/glia.22583

Lankford, K. L., Sasaki, M., Radtke, C., \& Kocsis, J. D. (2008). Olfactory ensheathing cells exhibit unique migratory, phagocytic, and myelinating properties in the $\mathrm{X}$ irradiated spinal cord not shared by schwann cells. Glia, 56(15), 1664-1678. doi:10.1002/glia.20718

Laroni, A., Novi, G., Kerlero de Rosbo, N., \& Uccelli, A. (2013). Towards clinical application of mesenchymal stem cells for treatment of neurological diseases of the central nervous system. Journal of Neuroimmune Pharmacology: The Official Journal of the Society on Neurolmmune Pharmacology, 8(5), 1062-1076. doi:10.1007/s11481-013-9456-6

Laurén, J., Airaksinen, M. S., Saarma, M., \& Timmusk, T. (2003). Two novel mammalian nogo receptor homologs differentially expressed in the central and peripheral nervous systems. Molecular and Cellular Neurosciences, 24(3), 581-594.

Laurén, J., Hu, F., Chin, J., Liao, J., Airaksinen, M. S., \& Strittmatter, S. M. (2007). Characterization of myelin ligand complexes with neuronal nogo-66 receptor family members. The Journal of Biological Chemistry, 282(8), 5715-5725. doi:10.1074/jbc.M609797200

Lee, I. -., Bulte, J. W. M., Schweinhardt, P., Douglas, T., Trifunovski, A., Hofstetter, C., . .Spenger, C. (2004). In vivo magnetic resonance tracking of olfactory ensheathing glia grafted into the rat spinal cord. Experimental Neurology, 187(2), 509-516. doi:10.1016/j.expneurol.2004.02.007

Leng, Z., He, X., Li, H., Wang, D., \& Cao, K. (2013). Olfactory ensheathing cell transplantation for spinal cord injury: An 18-year bibliometric analysis based on the web of science. Neural Regeneration Research, 8(14), 1286-1296. doi:10.3969/j.issn.1673-5374.2013.14.005

Leung, C. T., Coulombe, P. A., \& Reed, R. R. (2007). Contribution of olfactory neural stem cells to tissue maintenance and regeneration. Nature Neuroscience, 10(6), 720-726. doi:10.1038/nn1882 
Levine, J. M. (1994). Increased expression of the NG2 chondroitin-sulfate proteoglycan after brain injury. The Journal of Neuroscience: The Official Journal of the Society for Neuroscience, 14(8), 4716-4730. Retrieved from https://www.ncbi.nlm.nih.gov/pubmed/?term=Increased+expression+of+the+NG $\underline{2+\text { chondroitin-sulfate+proteoglycan+after+brain+injur }}$

Li, B. C., Li, Y., Chen, L. F., Chang, J. Y., \& Duan, Z. X. (2011). Olfactory ensheathing cells can reduce the tissue loss but not the cavity formation in contused spinal cord of rats. Journal of the Neurological Sciences, 303(1-2), 67-74. doi:10.1016/j.jns.2011.01.013

Li, F., Fowler, K. A., Neil, J. E., Colton, C. A., \& Vitek, M. P. (2010). An apolipoprotein Emimetic stimulates axonal regeneration and remyelination after peripheral nerve injury. The Journal of Pharmacology and Experimental Therapeutics, 334(1), 106115. doi:10.1124/jpet.110.167882

Li, Y., Field, P. M., \& Raisman, G. (1997). Repair of adult rat corticospinal tract by transplants of olfactory ensheathing cells. Science (New York, N.Y.), 277(5334), 2000-2002.

Li, Y., Field, P. M., \& Raisman, G. (1998). Regeneration of adult rat corticospinal axons induced by transplanted olfactory ensheathing cells. The Journal of Neuroscience: The Official Journal of the Society for Neuroscience, 18(24), 10514-10524. Retrieved from https://www.ncbi.nlm.nih.gov/pubmed/?term=Regeneration+of+adult+rat+cortic ospinal+axons+induced+by+transplanted+olfactory+ensheathing+cells

Li, Y., Carlstedt, T., Berthold, C., \& Raisman, G. (2004). Interaction of transplanted olfactory-ensheathing cells and host astrocytic processes provides a bridge for axons to regenerate across the dorsal root entry zone. Experimental Neurology, 188(2), 300-308. doi:10.1016/j.expneurol.2004.04.021

Li, Y., Decherchi, P., \& Raisman, G. (2003). Transplantation of olfactory ensheathing cells into spinal cord lesions restores breathing and climbing. The Journal of Neuroscience: The Official Journal of the Society for Neuroscience, 23(3), 727-731. 
Li, Y., Li, D., \& Raisman, G. (2005). Interaction of olfactory ensheathing cells with astrocytes may be the key to repair of tract injuries in the spinal cord: The 'pathway hypothesis'. Journal of Neurocytology, 34(3-5), 343-351. doi:10.1007/s11068-005-8361-1

Lim, F., Martín-Bermejo, M. J., García-Escudero, V., Gallego-Hernández, M. T., GarcíaGómez, A., Rábano, A., . . Moreno-Flores, M. T. (2010). Reversibly immortalized human olfactory ensheathing glia from an elderly donor maintain neuroregenerative capacity. Glia, 58(5), 546-558. doi:10.1002/glia.20944

Lima, C., Escada, P., Pratas-Vital, J., Branco, C., Arcangeli, C. A., Lazzeri, G., . . Peduzzi, J. D. (2010). Olfactory mucosal autografts and rehabilitation for chronic traumatic spinal cord injury. Neurorehabilitation and Neural Repair, 24(1), 10-22. doi:10.1177/1545968309347685

Lima, C., Pratas-Vital, J., Escada, P., Hasse-Ferreira, A., Capucho, C., \& Peduzzi, J. D. (2006). Olfactory mucosa autografts in human spinal cord injury: A pilot clinical study. The Journal of Spinal Cord Medicine, 29(3), 206. Retrieved from https://www.ncbi.nlm.nih.gov/pubmed/?term=Olfactory+mucosa+autografts+in+ human+spinal+cord+injury\%3A+a+pilot+clinical

Lindsay, S. L., \& Barnett, S. C. (2017). Are nestin-positive mesenchymal stromal cells a better source of cells for CNS repair? Neurochemistry International, 106, 101-107. doi:10.1016/j.neuint.2016.08.001

Lindsay, S. L., Johnstone, S. A., Mountford, J. C., Sheikh, S., Allan, D. B., Clark, L., \& Barnett, S. C. (2013). Human mesenchymal stem cells isolated from olfactory biopsies but not bone enhance CNS myelination in vitro. Glia, 61(3), 368-382. doi:10.1002/glia.22440

Lindsay, S. L., Riddell, J. S., \& Barnett, S. C. (2010). Olfactory mucosa for transplantmediated repair: A complex tissue for a complex injury? Glia, 58(2), 125-134. doi:10.1002/glia.20917

Lindsay, S. L., Toft, A., Griffin, J., M M Emraja, A., Barnett, S. C., \& Riddell, J. S. (2017). Human olfactory mesenchymal stromal cell transplants promote remyelination 
and earlier improvement in gait co-ordination after spinal cord injury. Glia, 65(4), 639-656. doi:10.1002/glia.23117

Lindsay, S. L., Johnstone, S. A., McGrath, M. A., Mallinson, D., \& Barnett, S. C. (2016). Comparative miRNA-based fingerprinting reveals biological differences in Human olfactory mucosa- and bone-marrow-derived mesenchymal stromal cells. Stem Cell Reports, 6(5), 729-742. doi:10.1016/j.stemcr.2016.03.009

Lipson, A. C., Widenfalk, J., Lindqvist, E., Ebendal, T., \& Olson, L. (2003). Neurotrophic properties of olfactory ensheathing glia. Experimental Neurology, 180(2), 167-171.

Liu, B. P., Fournier, A., GrandPré, T., \& Strittmatter, S. M. (2002). Myelin-associated glycoprotein as a functional ligand for the nogo-66 receptor. Science (New York, N.Y.), 297(5584), 1190-1193. doi:10.1126/science.1073031

Liu, Y., Kim, D., Himes, B. T., Chow, S. Y., Schallert, T., Murray, M., . . Fischer, I. (1999). Transplants of fibroblasts genetically modified to express BDNF promote regeneration of adult rat rubrospinal axons and recovery of forelimb function. The Journal of Neuroscience: The Official Journal of the Society for Neuroscience, 19(11), 4370-4387. Retrieved from https://www.ncbi.nlm.nih.gov/pubmed/?term=Transplants+of+fibroblasts+geneti cally+modified+to+express+BDNF+promote+regeneration+of+adult+rat+rubrospin al+axons+and+recovery+of+forelimb+function.

López-Vales, R., Forés, J., Navarro, X., \& Verdú, E. (2007). Chronic transplantation of olfactory ensheathing cells promotes partial recovery after complete spinal cord transection in the rat. Glia, 55(3), 303-311. doi:10.1002/glia.20457

López-Vales, R., Forés, J., Verdú, E., \& Navarro, X. (2006). Acute and delayed transplantation of olfactory ensheathing cells promote partial recovery after complete transection of the spinal cord. Neurobiology of Disease, 21(1), 57-68. doi:10.1016/j.nbd.2005.06.011

López-Vales, R., García-Alías, G., Forés, J., Navarro, X., \& Verdú, E. (2004). Increased expression of cyclo-oxygenase 2 and vascular endothelial growth factor in lesioned spinal cord by transplanted olfactory ensheathing cells. Journal of Neurotrauma, 21(8), 1031-1043. doi:10.1089/0897715041651105 
Losey, P., \& Anthony, D. C. (2014). Impact of vasculature damage on the outcome of spinal cord injury: A novel collagenase-induced model may give new insights into the mechanisms involved. Neural Regeneration Research, 9(20), 1783-1786. doi:10.4103/1673-5374.143422

Losey, P., Young, C., Krimholtz, E., Bordet, R., \& Anthony, D. C. (2014). The role of hemorrhage following spinal-cord injury. Brain Research, 1569, 9-18. doi:10.1016/j.brainres.2014.04.033

Lu, J., Féron, F., Ho, S. M., Mackay-Sim, A., \& Waite, P. M. (2001). Transplantation of nasal olfactory tissue promotes partial recovery in paraplegic adult rats. Brain Research, 889(1-2), 344-357.

Lu, J., Féron, F., Mackay-Sim, A., \& Waite, P. M. E. (2002). Olfactory ensheathing cells promote locomotor recovery after delayed transplantation into transected spinal cord. Brain: A Journal of Neurology, 125(Pt 1), 14-21.

Lu, P., Wang, Y., Graham, L., McHale, K., Gao, M., Wu, D., . . Tuszynski, M. H. (2012). Long-distance growth and connectivity of neural stem cells after severe spinal cord injury. Cell, 150(6), 1264-1273. doi:10.1016/j.cell.2012.08.020

Lu, P., Yang, H., Culbertson, M., Graham, L., Roskams, A. J., \& Tuszynski, M. H. (2006). Olfactory ensheathing cells do not exhibit unique migratory or axonal growthpromoting properties after spinal cord injury. The Journal of Neuroscience: The Official Journal of the Society for Neuroscience, 26(43), 11120-11130. doi:10.1523/JNEUROSCI.3264-06.2006

Lukovic, D., Valdés-Sanchez, L., Sanchez-Vera, I., Moreno-Manzano, V., Stojkovic, M., Bhattacharya, S. S., \& Erceg, S. (2014). Brief report: Astrogliosis promotes functional recovery of completely transected spinal cord following transplantation of hESC-derived oligodendrocyte and motoneuron progenitors. Stem Cells (Dayton, Ohio), 32(2), 594-599. doi:10.1002/stem.1562

Mackay-Sim, A., Féron, F., Cochrane, J., Bassingthwaighte, L., Bayliss, C., Davies, W., . . Geraghty, T. (2008). Autologous olfactory ensheathing cell transplantation in human paraplegia: A 3-year clinical trial. Brain: A Journal of Neurology, 131(Pt 9), 2376-2386. doi:10.1093/brain/awn173 
Marshak, D. R. (1990). S100 beta as a neurotrophic factor. Progress in Brain Research, $86,169-181$. Retrieved from https://www.ncbi.n/m.nih.gov/pubmed/?term=S100+beta+as+a+neurotrophic+fa ctor+Marshak

Masgutova, G. A., Savchenko, E. A., Viktorov, I. V., Masgutov, R. F., \& Chelyshev, Y. A. (2010). Reaction of oligoglia to spinal cord injury in rats and transplantation of human olfactory ensheathing cells. Bulletin of Experimental Biology and Medicine, 149(1), 135-139.

Mauch, D. H., Nägler, K., Schumacher, S., Göritz, C., Müller, E. C., Otto, A., \& Pfrieger, F. W. (2001). CNS synaptogenesis promoted by glia-derived cholesterol. Science (New York, N.Y.), 294(5545), 1354-1357. doi:10.1126/science.294.5545.1354

Mayeur, A., Duclos, C., Honoré, A., Gauberti, M., Drouot, L., do Rego, J., . . Guérout, N. (2013). Potential of olfactory ensheathing cells from different sources for spinal cord repair. PloS One, 8(4), e62860. doi:10.1371/journal.pone.0062860

McDonald, J. W., \& Sadowsky, C. (2002). Spinal-cord injury. Lancet (London, England), 359(9304), 417-425. doi:10.1016/S0140-6736(02)07603-1

McKeon, R. J., Höke, A., \& Silver, J. (1995). Injury-induced proteoglycans inhibit the potential for laminin-mediated axon growth on astrocytic scars. Experimental Neurology, 136(1), 32-43. doi:10.1006/exnr.1995.1081

McKeon, R. J., Jurynec, M. J., \& Buck, C. R. (1999). The chondroitin sulfate proteoglycans neurocan and phosphacan are expressed by reactive astrocytes in the chronic CNS glial scar. The Journal of Neuroscience: The Official Journal of the Society for Neuroscience, 19(24), 10778-10788.

McKeon, R. J., Schreiber, R. C., Rudge, J. S., \& Silver, J. (1991). Reduction of neurite outgrowth in a model of glial scarring following CNS injury is correlated with the expression of inhibitory molecules on reactive astrocytes. The Journal of Neuroscience: The Official Journal of the Society for Neuroscience, 11(11), 33983411. 
McKerracher, L., \& Higuchi, H. (2006). Targeting rho to stimulate repair after spinal cord injury. Journal of Neurotrauma, 23(3-4), 309-317. doi:10.1089/neu.2006.23.309

Menei, P., Montero-Menei, C., Whittemore, S. R., Bunge, R. P., \& Bunge, M. B. (1998). Schwann cells genetically modified to secrete human BDNF promote enhanced axonal regrowth across transected adult rat spinal cord. The European Journal of Neuroscience, $10(2), 607-621$.

Mi, S., Lee, X., Shao, Z., Thill, G., Ji, B., Relton, J., . . Pepinsky, R. B. (2004). LINGO-1 is a component of the nogo- 66 receptor/p75 signaling complex. Nature Neuroscience, 7(3), 221-228. doi:10.1038/nn1188

Miller, A. M., Treloar, H. B., \& Greer, C. A. (2010). Composition of the migratory mass during development of the olfactory nerve. The Journal of Comparative Neurology, 518(24), 4825-4841. doi:10.1002/cne.22497

Mills, C. D., Allchorne, A. J., Griffin, R. S., Woolf, C. J., \& Costigan, M. (2007). GDNF selectively promotes regeneration of injury-primed sensory neurons in the lesioned spinal cord. Molecular and Cellular Neurosciences, 36(2), 185-194. doi:10.1016/j.mcn.2007.06.011

Mimura, F., Yamagishi, S., Arimura, N., Fujitani, M., Kubo, T., Kaibuchi, K., \& Yamashita, T. (2006). Myelin-associated glycoprotein inhibits microtubule assembly by a rhokinase-dependent mechanism. The Journal of Biological Chemistry, 281(23), 15970-15979. doi:10.1074/jbc.M510934200

Miyata, S., Nishimura, Y., Hayashi, N., \& Oohira, A. (2005). Construction of perineuronal net-like structure by cortical neurons in culture. Neuroscience, 136(1), 95-104. doi:10.1016/j.neuroscience.2005.07.031

Modi, P. K., \& Kanungo, M. S. (2010). Age-dependent expression of S100beta in the brain of mice. Cellular and Molecular Neurobiology, 30(5), 709-716. doi:10.1007/s10571-009-9495-y

Moon, L. D., Asher, R. A., Rhodes, K. E., \& Fawcett, J. W. (2001). Regeneration of CNS axons back to their target following treatment of adult rat brain with chondroitinase ABC. Nature Neuroscience, 4(5), 465-466. doi:10.1038/87415 
Moreno-Flores, M. T., \& Avila, J. (2010). The quest to repair the damaged spinal cord. In Atta-ur-Rahman, \& M.Iqbal Choudhary (Eds.), Frontiers in CNS drug discovery (pp. 497-518). Sharjah, U.A.E: Bentham books.

Moreno-Flores, M. T., Bradbury, E. J., Martín-Bermejo, M. J., Agudo, M., Lim, F., Pastrana, E., ... Wandosell, F. (2006). A clonal cell line from immortalized olfactory ensheathing glia promotes functional recovery in the injured spinal cord. Molecular Therapy: The Journal of the American Society of Gene Therapy, 13(3), 598-608. doi:10.1016/j.ymthe.2005.11.014

Moreno-Flores, M. T., Díaz-Nido, J., Wandosell, F., \& Avila, J. (2002). Olfactory ensheathing glia: Drivers of axonal regeneration in the central nervous system? Journal of Biomedicine \& Biotechnology, 2(1), 37-43. doi:10.1155/S1110724302000372

Moreno-Flores, M. T., Lim, F., Martín-Bermejo, M. J., Díaz-Nido, J., Avila, J., \& Wandosell, F. (2003a). High level of amyloid precursor protein expression in neurite-promoting olfactory ensheathing glia (OEG) and OEG-derived cell lines. Journal of Neuroscience Research, 71(6), 871-881. doi:10.1002/jnr.10527

Moreno-Flores, M. T., Lim, F., Martín-Bermejo, M. J., Díaz-Nido, J., Avila, J., \& Wandosell, F. (2003b). Immortalized olfactory ensheathing glia promote axonal regeneration of rat retinal ganglion neurons. Journal of Neurochemistry, 85(4), 861-871.

Moreno-Flores, M. T., \& Avila, J. (2006). The quest to repair the damaged spinal cord. Recent Patents on CNS Drug Discovery, 1(1), 55-63.

Moreno-Manzano, V., Rodríguez-Jiménez, F. J., García-Roselló, M., Laínez, S., Erceg, S., Calvo, M. T., ... Stojkovic, M. (2009). Activated spinal cord ependymal stem cells rescue neurological function. Stem Cells (Dayton, Ohio), 27(3), 733-743. doi:10.1002/stem.24

Muir, D., Engvall, E., Varon, S., \& Manthorpe, M. (1989). Schwannoma cell-derived inhibitor of the neurite-promoting activity of laminin. The Journal of Cell Biology, 109(5), 2353-2362. 
Murrell, W., Wetzig, A., Donnellan, M., Féron, F., Burne, T., Meedeniya, A., . . MackaySim, A. (2008). Olfactory mucosa is a potential source for autologous stem cell therapy for parkinson's disease. Stem Cells (Dayton, Ohio), 26(8), 2183-2192. doi:10.1634/stemcells.2008-0074

Nan, B., Getchell, M. L., Partin, J. V., \& Getchell, T. V. (2001). Leukemia inhibitory factor, interleukin-6, and their receptors are expressed transiently in the olfactory mucosa after target ablation. The Journal of Comparative Neurology, 435(1), 6077.

Neumann, S., Bradke, F., Tessier-Lavigne, M., \& Basbaum, A. I. (2002). Regeneration of sensory axons within the injured spinal cord induced by intraganglionic CAMP elevation. Neuron, 34(6), 885-893.

Niederöst, B. P., Zimmermann, D. R., Schwab, M. E., \& Bandtlow, C. E. (1999). Bovine CNS myelin contains neurite growth-inhibitory activity associated with chondroitin sulfate proteoglycans. The Journal of Neuroscience: The Official Journal of the Society for Neuroscience, 19(20), 8979-8989.

Niederöst, B., Oertle, T., Fritsche, J., McKinney, R. A., \& Bandtlow, C. E. (2002). Nogo-A and myelin-associated glycoprotein mediate neurite growth inhibition by antagonistic regulation of RhoA and Rac1. The Journal of Neuroscience: The Official Journal of the Society for Neuroscience, 22(23), 10368-10376.

Nishihara, T., Remacle, A. G., Angert, M., Shubayev, I., Shiryaev, S. A., Liu, H., . . Shubayev, V. I. (2015). Matrix metalloproteinase-14 both sheds cell surface neuronal glial antigen 2 (NG2) proteoglycan on macrophages and governs the response to peripheral nerve injury. The Journal of Biological Chemistry, 290(6), 3693-3707. doi:10.1074/jbc.M114.603431

Nivet, E., Vignes, M., Girard, S. D., Pierrisnard, C., Baril, N., Devèze, A., . . Roman, F. S. (2011). Engraftment of human nasal olfactory stem cells restores neuroplasticity in mice with hippocampal lesions. The Journal of Clinical Investigation, 121(7), 2808-2820. doi:10.1172/JCl44489

Nocentini, S., Reginensi, D., Garcia, S., Carulla, P., Moreno-Flores, M. T., Wandosell, F., . . . del Río, J. A. (2012). Myelin-associated proteins block the migration of olfactory 
ensheathing cells: An in vitro study using single-cell tracking and traction force microscopy. Cellular and Molecular Life Sciences: CMLS, 69(10), 1689-1703. doi:10.1007/s00018-011-0893-1

Novikova, L. N., Brohlin, M., Kingham, P. J., Novikov, L. N., \& Wiberg, M. (2011). Neuroprotective and growth-promoting effects of bone marrow stromal cells after cervical spinal cord injury in adult rats. Cytotherapy, 13(7), 873-887. doi:10.3109/14653249.2011.574116

Oertle, T., \& Schwab, M. E. (2003). Nogo and its paRTNers. Trends in Cell Biology, 13(4), 187-194.

Okano, H. (2002). Stem cell biology of the central nervous system. Journal of Neuroscience Research, 69(6), 698-707. doi:10.1002/jnr.10343

O'Neill, P., Lindsay, S. L., Pantiru, A., Guimond, S. E., Fagoe, N., Verhaagen, J., . . . Barnett, S. C. (2017). Sulfatase-mediated manipulation of the astrocyte-schwann cell interface. Glia, 65(1), 19-33. doi:10.1002/glia.23047

Orioli, D., \& Klein, R. (1997). The eph receptor family: Axonal guidance by contact repulsion. Trends in Genetics: TIG, 13(9), 354-359.

O'Toole, D. A., West, A. K., \& Chuah, M. I. (2007). Effect of olfactory ensheathing cells on reactive astrocytes in vitro. Cellular and Molecular Life Sciences: CMLS, 64(10), 1303-1309. doi:10.1007/s00018-007-7106-y

Oudega, M., \& Xu, X. (2006). Schwann cell transplantation for repair of the adult spinal cord. Journal of Neurotrauma, 23(3-4), 453-467. doi:10.1089/neu.2006.23.453

Park, J. B., Yiu, G., Kaneko, S., Wang, J., Chang, J., He, X. L., . . He, Z. (2005). A TNF receptor family member, TROY, is a coreceptor with nogo receptor in mediating the inhibitory activity of myelin inhibitors. Neuron, 45(3), 345-351. doi:10.1016/j.neuron.2004.12.040

Pastrana, E., Moreno-Flores, M. T., Avila, J., Wandosell, F., Minichiello, L., \& Diaz-Nido, J. (2007). BDNF production by olfactory ensheathing cells contributes to axonal regeneration of cultured adult CNS neurons. Neurochemistry International, 50(3), 491-498. doi:10.1016/j.neuint.2006.10.004 
Pastrana, E., Moreno-Flores, M. T., Gurzov, E. N., Avila, J., Wandosell, F., \& Diaz-Nido, J. (2006). Genes associated with adult axon regeneration promoted by olfactory ensheathing cells: A new role for matrix metalloproteinase 2. The Journal of Neuroscience: The Official Journal of the Society for Neuroscience, 26(20), 53475359. doi:10.1523/JNEUROSCI.1111-06.2006

Pearse, D. D., Sanchez, A. R., Pereira, F. C., Andrade, C. M., Puzis, R., Pressman, Y., . . Bunge, M. B. (2007). Transplantation of schwann cells and/or olfactory ensheathing glia into the contused spinal cord: Survival, migration, axon association, and functional recovery. Glia, 55(9), 976-1000. doi:10.1002/glia.20490

Pellitteri, R., Spatuzza, M., Russo, A., \& Stanzani, S. (2007). Olfactory ensheathing cells exert a trophic effect on the hypothalamic neurons in vitro. Neuroscience Letters, 417(1), 24-29. doi:10.1016/j.neulet.2007.02.065

Pellitteri, R., Spatuzza, M., Russo, A., Zaccheo, D., \& Stanzani, S. (2009). Olfactory ensheathing cells represent an optimal substrate for hippocampal neurons: An in vitro study. International Journal of Developmental Neuroscience: The Official Journal of the International Society for Developmental Neuroscience, 27(5), 453458. doi:10.1016/j.ijdevneu.2009.05.001

Pixley, S. K. (1992). The olfactory nerve contains two populations of glia, identified both in vivo and in vitro. Glia, 5(4), 269-284. doi:10.1002/glia.440050405

Plant, G. W., Bates, M. L., \& Bunge, M. B. (2001). Inhibitory proteoglycan immunoreactivity is higher at the caudal than the rostral schwann cell grafttransected spinal cord interface. Molecular and Cellular Neurosciences, 17(3), 471487. doi:10.1006/mcne. 2000.0948

Plant, G. W., Christensen, C. L., Oudega, M., \& Bunge, M. B. (2003). Delayed transplantation of olfactory ensheathing glia promotes sparing/regeneration of supraspinal axons in the contused adult rat spinal cord. Journal of Neurotrauma, 20(1), 1-16. doi:10.1089/08977150360517146

Plemel, J. R., Keough, M. B., Duncan, G. J., Sparling, J. S., Yong, V. W., Stys, P. K., \& Tetzlaff, W. (2014). Remyelination after spinal cord injury: Is it a target for repair? Progress in Neurobiology, 117, 54-72. doi:10.1016/j.pneurobio.2014.02.006 
Pollock, G. S., Franceschini, I. A., Graham, G., Marchionni, M. A., \& Barnett, S. C. (1999). Neuregulin is a mitogen and survival factor for olfactory bulb ensheathing cells and an isoform is produced by astrocytes. The European Journal of Neuroscience, 11(3), 769-780.

Qiu, J., Cafferty, W. B. J., McMahon, S. B., \& Thompson, S. W. N. (2005). Conditioning injury-induced spinal axon regeneration requires signal transducer and activator of transcription 3 activation. The Journal of Neuroscience: The Official Journal of the Society for Neuroscience, 25(7), 1645-1653. doi:10.1523/JNEUROSCI.326904.2005

Qiu, J., Cai, D., Dai, H., McAtee, M., Hoffman, P. N., Bregman, B. S., \& Filbin, M. T. (2002). Spinal axon regeneration induced by elevation of cyclic AMP. Neuron, 34(6), 895-903.

Radtke, C., Akiyama, Y., Brokaw, J., Lankford, K. L., Wewetzer, K., Fodor, W. L., \& Kocsis, J. D. (2004). Remyelination of the nonhuman primate spinal cord by transplantation of $\mathrm{H}$-transferase transgenic adult pig olfactory ensheathing cells. FASEB Journal: Official Publication of the Federation of American Societies for Experimental Biology, 18(2), 335-337. doi:10.1096/fj.03-0214fje

Radtke, C., Sasaki, M., Lankford, K. L., Gallo, V., \& Kocsis, J. D. (2011). CNPase expression in olfactory ensheathing cells. Journal of Biomedicine \& Biotechnology, 2011, 608496. doi:10.1155/2011/608496

Raisman, G. (1985). Specialized neuroglial arrangement may explain the capacity of vomeronasal axons to reinnervate central neurons. Neuroscience, 14(1), 237-254.

Raisman, G. (2001). Olfactory ensheathing cells - another miracle cure for spinal cord injury? Nature Reviews. Neuroscience, 2(5), 369-375. doi:10.1038/35072576

Raisman, G. (2004). Myelin inhibitors: Does NO mean GO? Nature Reviews. Neuroscience, 5(2), 157-161. doi:10.1038/nrn1328

Raisman, G., \& Li, Y. (2007). Repair of neural pathways by olfactory ensheathing cells. Nature Reviews. Neuroscience, 8(4), 312-319. doi:10.1038/nrn2099 
Ramer, L. M., Au, E., Richter, M. W., Liu, J., Tetzlaff, W., \& Roskams, A. J. (2004). Peripheral olfactory ensheathing cells reduce scar and cavity formation and promote regeneration after spinal cord injury. The Journal of Comparative Neurology, 473(1), 1-15. doi:10.1002/cne.20049

Ramer, M. S., Duraisingam, I., Priestley, J. V., \& McMahon, S. B. (2001). Two-tiered inhibition of axon regeneration at the dorsal root entry zone. The Journal of Neuroscience: The Official Journal of the Society for Neuroscience, 21(8), 26512660.

Ramer, M. S., Priestley, J. V., \& McMahon, S. B. (2000). Functional regeneration of sensory axons into the adult spinal cord. Nature, 403(6767), 312-316. doi:10.1038/35002084

Ramer, M. S., Bishop, T., Dockery, P., Mobarak, M. S., O'Leary, D., Fraher, J. P., . . . McMahon, S. B. (2002). Neurotrophin-3-mediated regeneration and recovery of proprioception following dorsal rhizotomy. Molecular and Cellular Neurosciences, 19(2), 239-249. doi:10.1006/mcne.2001.1067

Ramón y Cajal, S., \& May, R. M. (1928). Degeneration \& regeneration of the nervous system, London: Oxford University Press, Humphrey Milford.

Ramón-Cueto, A., Cordero, M. I., Santos-Benito, F. F., \& Avila, J. (2000). Functional recovery of paraplegic rats and motor axon regeneration in their spinal cords by olfactory ensheathing glia. Neuron, 25(2), 425-435.

Ramón-Cueto, A., \& Nieto-Sampedro, M. (1992). Glial cells from adult rat olfactory bulb: Immunocytochemical properties of pure cultures of ensheathing cells. Neuroscience, 47(1), 213-220.

Ramón-Cueto, A., \& Nieto-Sampedro, M. (1994). Regeneration into the spinal cord of transected dorsal root axons is promoted by ensheathing glia transplants. Experimental Neurology, 127(2), 232-244. doi:10.1006/exnr.1994.1099

Ramón-Cueto, A., Plant, G. W., Avila, J., \& Bunge, M. B. (1998). Long-distance axonal regeneration in the transected adult rat spinal cord is promoted by olfactory ensheathing glia transplants. The Journal of Neuroscience: The Official Journal of the Society for Neuroscience, 18(10), 3803-3815. 
Ramón-Cueto, A., \& Valverde, F. (1995). Olfactory bulb ensheathing glia: A unique cell type with axonal growth-promoting properties. Glia, 14(3), 163-173. doi:10.1002/glia.440140302

Reginensi, D., Carulla, P., Nocentini, S., Seira, O., Serra-Picamal, X., Torres-Espín, A., . . del Río, J. A. (2015). Increased migration of olfactory ensheathing cells secreting the nogo receptor ectodomain over inhibitory substrates and lesioned spinal cord. Cellular and Molecular Life Sciences: CMLS, 72(14), 2719-2737. doi:10.1007/s00018-015-1869-3

Rhodes, K. E., \& Fawcett, J. W. (2004). Chondroitin sulphate proteoglycans: Preventing plasticity or protecting the CNS? Journal of Anatomy, 204(1), 33-48. doi:10.1111/j.1469-7580.2004.00261.x

Richter, M. W., Fletcher, P. A., Liu, J., Tetzlaff, W., \& Roskams, A. J. (2005). Lamina propria and olfactory bulb ensheathing cells exhibit differential integration and migration and promote differential axon sprouting in the lesioned spinal cord. The Journal of Neuroscience: The Official Journal of the Society for Neuroscience, 25(46), 10700-10711. doi:10.1523/JNEUROSCI.3632-05.2005

Richter, M. W., \& Roskams, A. J. (2008). Olfactory ensheathing cell transplantation following spinal cord injury: Hype or hope? Experimental Neurology, 209(2), 353367. doi:10.1016/j.expneurol.2007.06.011

Rieger, A., Deitmer, J. W., \& Lohr, C. (2007). Axon-glia communication evokes calcium signaling in olfactory ensheathing cells of the developing olfactory bulb. Glia, 55(4), 352-359. doi:10.1002/glia.20460

Rizek, P. N., \& Kawaja, M. D. (2006). Cultures of rat olfactory ensheathing cells are contaminated with schwann cells. Neuroreport, 17(5), 459-462. doi:10.1097/01.wnr.0000209000.32857.1b

Roet, K. C. D., Franssen, E. H. P., de Bree, F. M., Essing, A. H. W., Zijlstra, S. J., Fagoe, N. D., ... Verhaagen, J. (2013). A multilevel screening strategy defines a molecular fingerprint of proregenerative olfactory ensheathing cells and identifies SCARB2, a protein that improves regenerative sprouting of injured sensory spinal axons. The 
Journal of Neuroscience: The Official Journal of the Society for Neuroscience, 33(27), 11116-11135. doi:10.1523/JNEUROSCI.1002-13.2013

Roet, K. C. D., \& Verhaagen, J. (2014). Understanding the neural repair-promoting properties of olfactory ensheathing cells. Experimental Neurology, 261, 594-609. doi:10.1016/j.expneurol.2014.05.007

Rogers, W. K., \& Todd, M. (2016). Acute spinal cord injury. Best Practice \& Research. Clinical Anaesthesiology, 30(1), 27-39. doi:10.1016/j.bpa.2015.11.003

Romero, M. I., Rangappa, N., Garry, M. G., \& Smith, G. M. (2001). Functional regeneration of chronically injured sensory afferents into adult spinal cord after neurotrophin gene therapy. The Journal of Neuroscience: The Official Journal of the Society for Neuroscience, 21(21), 8408-8416.

Ruitenberg, M. J., Levison, D. B., Lee, S. V., Verhaagen, J., Harvey, A. R., \& Plant, G. W. (2005). NT-3 expression from engineered olfactory ensheathing glia promotes spinal sparing and regeneration. Brain: A Journal of Neurology, 128(Pt 4), 839-853. doi:10.1093/brain/awh424

Ruitenberg, M. J., Plant, G. W., Hamers, F. P. T., Wortel, J., Blits, B., Dijkhuizen, P. A., . . Verhaagen, J. (2003). Ex vivo adenoviral vector-mediated neurotrophin gene transfer to olfactory ensheathing glia: Effects on rubrospinal tract regeneration, lesion size, and functional recovery after implantation in the injured rat spinal cord. The Journal of Neuroscience: The Official Journal of the Society for Neuroscience, 23(18), 7045-7058.

Ruitenberg, M. J., \& Vukovic, J. (2008). Promoting central nervous system regeneration: Lessons from cranial nerve I. Restorative Neurology and Neuroscience, 26(2-3), 183-196.

Ruitenberg, M. J., Vukovic, J., Blomster, L., Hall, J. M., Jung, S., Filgueira, L., . . Plant, G. W. (2008). CX3CL1/fractalkine regulates branching and migration of monocytederived cells in the mouse olfactory epithelium. Journal of Neuroimmunology, 205(1-2), 80-85. doi:10.1016/j.jneuroim.2008.09.010 
Runyan, S. A., \& Phelps, P. E. (2009). Mouse olfactory ensheathing glia enhance axon outgrowth on a myelin substrate in vitro. Experimental Neurology, 216(1), 95-104. doi:10.1016/j.expneurol.2008.11.015

Sandvig, A., Berry, M., Barrett, L. B., Butt, A., \& Logan, A. (2004). Myelin-, reactive glia-, and scar-derived CNS axon growth inhibitors: Expression, receptor signaling, and correlation with axon regeneration. Glia, 46(3), 225-251. doi:10.1002/glia.10315

Santos-Silva, A., Fairless, R., Frame, M. C., Montague, P., Smith, G. M., Toft, A., . . Barnett, S. C. (2007). FGF/heparin differentially regulates schwann cell and olfactory ensheathing cell interactions with astrocytes: A role in astrocytosis. The Journal of Neuroscience: The Official Journal of the Society for Neuroscience, 27(27), 7154-7167. doi:10.1523/JNEUROSCI.1184-07.2007

Sasaki, M., Black, J. A., Lankford, K. L., Tokuno, H. A., Waxman, S. G., \& Kocsis, J. D. (2006). Molecular reconstruction of nodes of ranvier after remyelination by transplanted olfactory ensheathing cells in the demyelinated spinal cord. The Journal of Neuroscience: The Official Journal of the Society for Neuroscience, 26(6), 1803-1812. doi:10.1523/JNEUROSCI.3611-05.2006

Sasaki, M., Hains, B. C., Lankford, K. L., Waxman, S. G., \& Kocsis, J. D. (2006). Protection of corticospinal tract neurons after dorsal spinal cord transection and engraftment of olfactory ensheathing cells. Glia, 53(4), 352-359. doi:10.1002/glia.20285

Sasaki, M., Lankford, K. L., Zemedkun, M., \& Kocsis, J. D. (2004). Identified olfactory ensheathing cells transplanted into the transected dorsal funiculus bridge the lesion and form myelin. The Journal of Neuroscience: The Official Journal of the Society for Neuroscience, 24(39), 8485-8493. doi:10.1523/JNEUROSCI.199804.2004

Sasaki, M., Li, B., Lankford, K. L., Radtke, C., \& Kocsis, J. D. (2007). Remyelination of the injured spinal cord. Progress in Brain Research, 161, 419-433. doi:10.1016/S00796123(06)61030-3

Schnell, L., Schneider, R., Kolbeck, R., Barde, Y. A., \& Schwab, M. E. (1994). Neurotrophin-3 enhances sprouting of corticospinal tract during development and after adult spinal cord lesion. Nature, 367(6459), 170-173. doi:10.1038/367170a0 
Schwarting, G. A., Kostek, C., Ahmad, N., Dibble, C., Pays, L., \& Püschel, A. W. (2000). Semaphorin $3 A$ is required for guidance of olfactory axons in mice. The Journal of Neuroscience: The Official Journal of the Society for Neuroscience, 20(20), 76917697.

Schwob, J. E., Jang, W., Holbrook, E. H., Lin, B., Herrick, D. B., Peterson, J. N., \& Hewitt Coleman, J. (2017). Stem and progenitor cells of the mammalian olfactory epithelium: Taking poietic license. The Journal of Comparative Neurology, 525(4), 1034-1054. doi:10.1002/cne.24105

Shao, Z., Browning, J. L., Lee, X., Scott, M. L., Shulga-Morskaya, S., Allaire, N., . . Mi, S. (2005a). TAJ/TROY, an orphan TNF receptor family member, binds nogo-66 receptor 1 and regulates axonal regeneration. Neuron, 45(3), 353-359. doi:10.1016/j.neuron.2004.12.050

Sharma, H. S. (2007). Neurotrophic factors in combination: A possible new therapeutic strategy to influence pathophysiology of spinal cord injury and repair mechanisms. Current Pharmaceutical Design, 13(18), 1841-1874.

Shen, Y., Tenney, A. P., Busch, S. A., Horn, K. P., Cuascut, F. X., Liu, K., .. Flanagan, J. G. (2009). PTPsigma is a receptor for chondroitin sulfate proteoglycan, an inhibitor of neural regeneration. Science (New York, N.Y.), 326(5952), 592-596. doi:10.1126/science.1178310

Silver, J., \& Miller, J. H. (2004). Regeneration beyond the glial scar. Nature Reviews. Neuroscience, 5(2), 146-156. doi:10.1038/nrn1326

Simón, D., Martín-Bermejo, M. J., Gallego-Hernández, M. T., Pastrana, E., GarcíaEscudero, V., García-Gómez, A., . . Moreno-Flores, M. T. (2011). Expression of plasminogen activator inhibitor-1 by olfactory ensheathing glia promotes axonal regeneration. Glia, 59(10), 1458-1471. doi:10.1002/glia.21189

Smith-Thomas, L. C., Fok-Seang, J., Stevens, J., Du, J. S., Muir, E., Faissner, A., . . . Fawcett, J. W. (1994). An inhibitor of neurite outgrowth produced by astrocytes. Journal of Cell Science, 107 (Pt 6), 1687-1695. 
Sonigra, R. J., Brighton, P. C., Jacoby, J., Hall, S., \& Wigley, C. B. (1999). Adult rat olfactory nerve ensheathing cells are effective promoters of adult central nervous system neurite outgrowth in coculture. Glia, 25(3), 256-269.

Spitzbarth, I., Bock, P., Haist, V., Stein, V. M., Tipold, A., Wewetzer, K., . . Beineke, A. (2011). Prominent microglial activation in the early proinflammatory immune response in naturally occurring canine spinal cord injury. Journal of Neuropathology and Experimental Neurology, 70(8), 703-714. doi:10.1097/NEN.0b013e3182270f8e

Stamegna, J., Girard, S. D., Veron, A., Sicard, G., Khrestchatisky, M., Feron, F., \& Roman, F. S. (2014). A unique method for the isolation of nasal olfactory stem cells in living rats. Stem Cell Research, 12(3), 673-679. doi:10.1016/j.scr.2014.02.010

Su, Z., Cao, L., Zhu, Y., Liu, X., Huang, Z., Huang, A., \& He, C. (2007). Nogo enhances the adhesion of olfactory ensheathing cells and inhibits their migration. Journal of Cell Science, 120(Pt 11), 1877-1887. doi:10.1242/jcs.03448

Su, Z., Yuan, Y., Chen, J., Cao, L., Zhu, Y., Gao, L., .. He, C. (2009). Reactive astrocytes in glial scar attract olfactory ensheathing cells migration by secreted TNF-alpha in spinal cord lesion of rat. PloS One, 4(12), e8141.

doi:10.1371/journal.pone.0008141

Tabakow, P., Jarmundowicz, W., Czapiga, B., Fortuna, W., Miedzybrodzki, R., Czyz, M., . .. Raisman, G. (2013). Transplantation of autologous olfactory ensheathing cells in complete human spinal cord injury. Cell Transplantation, 22(9), 1591-1612. doi:10.3727/096368912X663532

Tabakow, P., Raisman, G., Fortuna, W., Czyz, M., Huber, J., Li, D., . . Jarmundowicz, W. (2014). Functional regeneration of supraspinal connections in a patient with transected spinal cord following transplantation of bulbar olfactory ensheathing cells with peripheral nerve bridging. Cell Transplantation, 23(12), 1631-1655. doi:10.3727/096368914X685131

Takami, T., Oudega, M., Bates, M. L., Wood, P. M., Kleitman, N., \& Bunge, M. B. (2002). Schwann cell but not olfactory ensheathing glia transplants improve hindlimb locomotor performance in the moderately contused adult rat thoracic spinal cord. 
The Journal of Neuroscience: The Official Journal of the Society for Neuroscience, 22(15), 6670-6681. doi:20026636

Tan, A. M., Colletti, M., Rorai, A. T., Skene, J. H. P., \& Levine, J. M. (2006). Antibodies against the NG2 proteoglycan promote the regeneration of sensory axons within the dorsal columns of the spinal cord. The Journal of Neuroscience: The Official Journal of the Society for Neuroscience, 26(18), 4729-4739. doi:10.1523/JNEUROSCI.3900-05.2006

Tang, X., Cai, J., Nelson, K. D., Peng, X., \& Smith, G. M. (2004). Functional repair after dorsal root rhizotomy using nerve conduits and neurotrophic molecules. The European Journal of Neuroscience, 20(5), 1211-1218. doi:10.1111/j.14609568.2004.03595.x

Tang, X., Heron, P., Mashburn, C., \& Smith, G. M. (2007). Targeting sensory axon regeneration in adult spinal cord. The Journal of Neuroscience: The Official Journal of the Society for Neuroscience, 27(22), 6068-6078. doi:10.1523/JNEUROSCI.144207.2007

Taoka, Y., Okajima, K., Uchiba, M., Murakami, K., Kushimoto, S., Johno, M., . . . Takatsuki, K. (1997). Role of neutrophils in spinal cord injury in the rat. Neuroscience, 79(4), 1177-1182.

Tator, C. H. (1998). Biology of neurological recovery and functional restoration after spinal cord injury. Neurosurgery, 42(4), 708.

Tator, C. H., \& Fehlings, M. G. (1991). Review of the secondary injury theory of acute spinal cord trauma with emphasis on vascular mechanisms. Journal of Neurosurgery, 75(1), 15-26. doi:10.3171/jns.1991.75.1.0015

Tator, C. H., \& Koyanagi, I. (1997). Vascular mechanisms in the pathophysiology of human spinal cord injury. Journal of Neurosurgery, 86(3), 483-492. doi:10.3171/jns.1997.86.3.0483

Toft, A., Scott, D. T., Barnett, S. C., \& Riddell, J. S. (2007). Electrophysiological evidence that olfactory cell transplants improve function after spinal cord injury. Brain: $A$ Journal of Neurology, 130(Pt 4), 970-984. doi:10.1093/brain/awm040 
Tomé, M., Lindsay, S. L., Riddell, J. S., \& Barnett, S. C. (2009). Identification of nonepithelial multipotent cells in the embryonic olfactory mucosa. Stem Cells (Dayton, Ohio), 27(9), 2196-2208. doi:10.1002/stem.130

Tomé, M., Siladzic, E., Santos-Silva, A., \& Barnett, S. C. (2007). Calponin is expressed by subpopulations of connective tissue cells but not olfactory ensheathing cells in the neonatal olfactory mucosa. BMC Neuroscience, 8, 74. doi:10.1186/1471-2202-8-74

Tuszynski, M. H., Murai, K., Blesch, A., Grill, R., \& Miller, I. (1997). Functional characterization of NGF-secreting cell grafts to the acutely injured spinal cord. Cell Transplantation, 6(3), 361-368.

Tuszynski, M. H., Weidner, N., McCormack, M., Miller, I., Powell, H., \& Conner, J. (1998). Grafts of genetically modified schwann cells to the spinal cord: Survival, axon growth, and myelination. Cell Transplantation, 7(2), 187-196.

Ubink, R., Halasz, N., Zhang, X., Dagerlind, A., \& Hökfelt, T. (1994). Neuropeptide tyrosine is expressed in ensheathing cells around the olfactory nerves in the rat olfactory bulb. Neuroscience, 60(3), 709-726.

Ughrin, Y. M., Chen, Z. J., \& Levine, J. M. (2003). Multiple regions of the NG2 proteoglycan inhibit neurite growth and induce growth cone collapse. The Journal of Neuroscience: The Official Journal of the Society for Neuroscience, 23(1), 175186.

Urdzíková, L., Jendelová, P., Glogarová, K., Burian, M., Hájek, M., \& Syková, E. (2006). Transplantation of bone marrow stem cells as well as mobilization by granulocytecolony stimulating factor promotes recovery after spinal cord injury in rats. Journal of Neurotrauma, 23(9), 1379-1391. doi:10.1089/neu.2006.23.1379

Vadivelu, S., Stewart, T. J., Qu, Y., Horn, K., Liu, S., Li, Q., . . McDonald, J. W. (2015). NG2+ progenitors derived from embryonic stem cells penetrate glial scar and promote axonal outgrowth into white matter after spinal cord injury. Stem Cells Translational Medicine, 4(4), 401-411. doi:10.5966/sctm.2014-0107

Valverde, F., Santacana, M., \& Heredia, M. (1992). Formation of an olfactory glomerulus: Morphological aspects of development and organization. Neuroscience, 49(2), 255-275. 
Vavrek, R., Girgis, J., Tetzlaff, W., Hiebert, G. W., \& Fouad, K. (2006). BDNF promotes connections of corticospinal neurons onto spared descending interneurons in spinal cord injured rats. Brain: A Journal of Neurology, 129(Pt 6), 1534-1545. doi:10.1093/brain/awl087

Vavrek, R., Pearse, D. D., \& Fouad, K. (2007). Neuronal populations capable of regeneration following a combined treatment in rats with spinal cord transection. Journal of Neurotrauma, 24(10), 1667-1673. doi:10.1089/neu.2007.0290

Venkatesh, K., Chivatakarn, O., Lee, H., Joshi, P. S., Kantor, D. B., Newman, B. A., . . Giger, R. J. (2005). The nogo-66 receptor homolog NgR2 is a sialic acid-dependent receptor selective for myelin-associated glycoprotein. The Journal of Neuroscience: The Official Journal of the Society for Neuroscience, 25(4), 808-822. doi:10.1523/JNEUROSCI.4464-04.2005

Vidal-Sanz, M., Bray, G. M., Villegas-Pérez, M. P., Thanos, S., \& Aguayo, A. J. (1987). Axonal regeneration and synapse formation in the superior colliculus by retinal ganglion cells in the adult rat. The Journal of Neuroscience: The Official Journal of the Society for Neuroscience, 7(9), 2894-2909.

Vincent, A. J., West, A. K., \& Chuah, M. I. (2005). Morphological and functional plasticity of olfactory ensheathing cells. Journal of Neurocytology, 34(1-2), 65-80. doi:10.1007/s11068-005-5048-6

Vukovic, J., Marmorstein, L. Y., McLaughlin, P. J., Sasaki, T., Plant, G. W., Harvey, A. R., \& Ruitenberg, M. J. (2009). Lack of fibulin-3 alters regenerative tissue responses in the primary olfactory pathway. Matrix Biology: Journal of the International Society for Matrix Biology, 28(7), 406-415. doi:10.1016/j.matbio.2009.06.001

Vukovic, J., Ruitenberg, M. J., Roet, K., Franssen, E., Arulpragasam, A., Sasaki, T., . . Plant, G. W. (2009). The glycoprotein fibulin-3 regulates morphology and motility of olfactory ensheathing cells in vitro. Glia, 57(4), 424-443. doi:10.1002/glia.20771

Wang, G., Ao, Q., Gong, K., Zuo, H., Gong, Y., \& Zhang, X. (2010). Synergistic effect of neural stem cells and olfactory ensheathing cells on repair of adult rat spinal cord injury. Cell Transplantation, 19(10), 1325-1337. doi:10.3727/096368910X505855 
Wang, K. C., Kim, J. A., Sivasankaran, R., Segal, R., \& He, Z. (2002). P75 interacts with the nogo receptor as a co-receptor for nogo, MAG and OMgp. Nature, 420(6911), 74-78. doi:10.1038/nature01176

Wang, Y., \& Huang, Z. (2012). Morphological phenotypes of olfactory ensheathing cells display different migratory responses upon slit-2. Experimental Cell Research, 318(15), 1889-1900. doi:10.1016/j.yexcr.2012.05.024

Watts, J. (2005). Controversy in china. Lancet (London, England), 365(9454), 109-110. doi:10.1016/S0140-6736(05)17721-6

Williams, S. K., Franklin, R. J. M., \& Barnett, S. C. (2004). Response of olfactory ensheathing cells to the degeneration and regeneration of the peripheral olfactory system and the involvement of the neuregulins. The Journal of Comparative Neurology, 470(1), 50-62. doi:10.1002/cne.11045

Windus, L. C. E., Claxton, C., Allen, C. L., Key, B., \& St John, J. A. (2007). Motile membrane protrusions regulate cell-cell adhesion and migration of olfactory ensheathing glia. Glia, 55(16), 1708-1719. doi:10.1002/glia.20586

Wong, S. T., Henley, J. R., Kanning, K. C., Huang, K., Bothwell, M., \& Poo, M. (2002). A p75(NTR) and nogo receptor complex mediates repulsive signaling by myelinassociated glycoprotein. Nature Neuroscience, 5(12), 1302-1308. doi:10.1038/nn975

Woodhall, E., West, A. K., \& Chuah, M. I. (2001). Cultured olfactory ensheathing cells express nerve growth factor, brain-derived neurotrophic factor, glia cell linederived neurotrophic factor and their receptors. Brain Research. Molecular Brain Research, 88(1-2), 203-213.

Woodhall, E., West, A. K., Vickers, J. C., \& Chuah, M. I. (2003). Olfactory ensheathing cell phenotype following implantation in the lesioned spinal cord. Cellular and Molecular Life Sciences: CMLS, 60(10), 2241-2253. doi:10.1007/s00018-003-32657

Wu, S., Cui, G., Shao, H., Du, Z., Ng, J. C., \& Peng, C. (2015). The cotransplantation of olfactory ensheathing cells with bone marrow mesenchymal stem cells exerts 
antiapoptotic effects in adult rats after spinal cord injury. Stem Cells International, 2015, 516215. doi:10.1155/2015/516215

Xu, X. M., Guénard, V., Kleitman, N., Aebischer, P., \& Bunge, M. B. (1995). A combination of BDNF and NT-3 promotes supraspinal axonal regeneration into schwann cell grafts in adult rat thoracic spinal cord. Experimental Neurology, 134(2), 261-272. doi:10.1006/exnr.1995.1056

Yamamoto, M., Raisman, G., Li, D., \& Li, Y. (2009). Transplanted olfactory mucosal cells restore paw reaching function without regeneration of severed corticospinal tract fibres across the lesion. Brain Research, 1303, 26-31. doi:10.1016/j.brainres.2009.09.073

Yamashita, T., Tucker, K. L., \& Barde, Y. A. (1999). Neurotrophin binding to the p75 receptor modulates rho activity and axonal outgrowth. Neuron, 24(3), 585-593.

Yamashita, T., Higuchi, H., \& Tohyama, M. (2002). The p75 receptor transduces the signal from myelin-associated glycoprotein to rho. The Journal of Cell Biology, 157(4), 565-570. doi:10.1083/jcb.200202010

Yang, Y. S., \& Strittmatter, S. M. (2007). The reticulons: A family of proteins with diverse functions. Genome Biology, 8(12), 234. doi:10.1186/gb-2007-8-12-234

Yang, Z., Suzuki, R., Daniels, S. B., Brunquell, C. B., Sala, C. J., \& Nishiyama, A. (2006). NG2 glial cells provide a favorable substrate for growing axons. The Journal of Neuroscience: The Official Journal of the Society for Neuroscience, 26(14), 38293839. doi:10.1523/JNEUROSCI.4247-05.2006

Yiu, G., \& He, Z. (2003). Signaling mechanisms of the myelin inhibitors of axon regeneration. Current Opinion in Neurobiology, 13(5), 545-551.

Yiu, G., \& He, Z. (2006). Glial inhibition of CNS axon regeneration. Nature Reviews. Neuroscience, 7(8), 617-627. doi:10.1038/nrn1956

Yu, W. R., \& Fehlings, M. G. (2011). Fas/FasL-mediated apoptosis and inflammation are key features of acute human spinal cord injury: Implications for translational, clinical application. Acta Neuropathologica, 122(6), 747-761. doi:10.1007/s00401011-0882-3 
Zeng, Y., Rong, M., Liu, Y., Liu, J., Lu, M., Tao, X., . . Liu, Z. (2013). Electrophysiological characterisation of human umbilical cord blood-derived mesenchymal stem cells induced by olfactory ensheathing cell-conditioned medium. Neurochemical Research, 38(12), 2483-2489. doi:10.1007/s11064-013-1186-x

Zhang, L., Ma, Z., Smith, G. M., Wen, X., Pressman, Y., Wood, P. M., \& Xu, X. (2009a). GDNF-enhanced axonal regeneration and myelination following spinal cord injury is mediated by primary effects on neurons. Glia, 57(11), 1178-1191. doi:10.1002/glia.20840

Zhang, S., Huang, F., Gates, M., \& Holmberg, E. G. (2011). Scar ablation combined with LP/OEC transplantation promotes anatomical recovery and PO-positive myelination in chronically contused spinal cord of rats. Brain Research, 1399, 1-14. doi:10.1016/j.brainres.2011.05.005

Zhang, Y., Dijkhuizen, P. A., Anderson, P. N., Lieberman, A. R., \& Verhaagen, J. (1998). NT-3 delivered by an adenoviral vector induces injured dorsal root axons to regenerate into the spinal cord of adult rats. Journal of Neuroscience Research, 54(4), 554-562. doi:AID-JNR12>3.0.CO;2-M

Zuo, J., Neubauer, D., Dyess, K., Ferguson, T. A., \& Muir, D. (1998). Degradation of chondroitin sulfate proteoglycan enhances the neurite-promoting potential of spinal cord tissue. Experimental Neurology, 154(2), 654-662. doi:10.1006/exnr.1998.6951

Zurita, M., \& Vaquero, J. (2006). Bone marrow stromal cells can achieve cure of chronic paraplegic rats: Functional and morphological outcome one year after transplantation. Neuroscience Letters, 402(1-2), 51-56. doi:10.1016/j.neulet.2006.03.069

Zurita, M., Vaquero, J., Bonilla, C., Santos, M., De Haro, J., Oya, S., \& Aguayo, C. (2008). Functional recovery of chronic paraplegic pigs after autologous transplantation of bone marrow stromal cells. Transplantation, 86(6), 845-853.

doi:10.1097/TP.0b013e318186198f 


\section{FIGURE LEGENDS}

Figure 1. The neural crest as a source of OECs during development. OEC-precursors originate exclusively from the neural crest. During development, these OEC-precursors migrate to the olfactory placodes (OP; green) to subsequently form part of the olfactory system. Figures were produced using Servier Medical Art.

Figure 2. A schematic representation of the adult olfactory system. The cellular composition and the diverse parts of the olfactory system are shown. GBCs are the main cells that produce neurons as they proliferate (auto-renewal) and generate new olfactory neurons, ORN. These cells extend an apical dendrite and a basal axon across the $L P$, to reach their targets in the olfactory glomeruli situated in the CNS. There, they establish connections with mitral and tufted cells that send information through the olfactory tract to the olfactory cortex. HBCs are usually inactive but when severe injury occurs, they can self-renew and generate most of the olfactory cells needed to restock the olfactory epithelium. HBCs may also be able to generate new OECs. Abbreviations: CNS (Central Nervous System), PNS (Peripheral Nervous System), LP (Lamina Propria), HBC (Horizontal Basal Cells), GBC (Globose Basal Cells), ORNi (Immature Olfactory Receptor Neuron), ORNm (Mature Olfactory Receptor Neuron), OEC (Olfactory Ensheathing Cells). Figures were produced using Servier Medical Art.

Figure 3. OECs express different specific markers. A. OECs have different antigenic phenotypes depending on their location in the CNS or PNS. Generally, OECS express vimentin, S100 $\beta$ and GFAP, although they also can express p75NTR, E-NCAM or NPY depending on the region of the CNS or PNS where they are situated. B. In vitro, OECs can be segregated into two phenotypic subpopulations: i) Schwann cell-like, characterized by a spindle shape and strong p75NTR expression; ii) and astrocyte-like, with a similar morphology to flattened astrocytes and strong E-NCAM expression. GFAP immunostaining in culture has been defined as fibrous for astrocyte-like OECs (Franceschini and Barnett, 1996), yet in our experience (Moreno-Flores et al., 2003b) this staining is always diffuse in OECs, corresponding to weak GFAP expression (in western blots) relative to cultured astrocytes. Abbreviations: CNS (Central Nervous System), GFAP (Glial Fibrillary Acidic Protein), NCAM (Neural Cell Adhesion Molecule), NPY (Neuropeptide Y), PNS (Peripheral Nervous System), LP (Lamina Propria), ONL (Olfactory Nerve Layer), OECs (Olfactory Ensheathing Cells). Figures were produced using Servier Medical Art.

Figure 4. Interactions between OECs and neurons implicated in neuroregeneration. Under physiological conditions OECs and neurons are in permanent communication through the interaction of adhesion molecules, diffusible neurotrophic factors, proteases and cytokines. 
Inhibitory factors, both ligands and receptors, can establish axon pathways and/or hinder OEC migration. Abbreviations: CSPG (Chondroitin sulphate proteoglycans), OECs (Olfactory Ensheathing Cells), PNN (Perineuronal Net). Figures were produced using Servier Medical Art. 


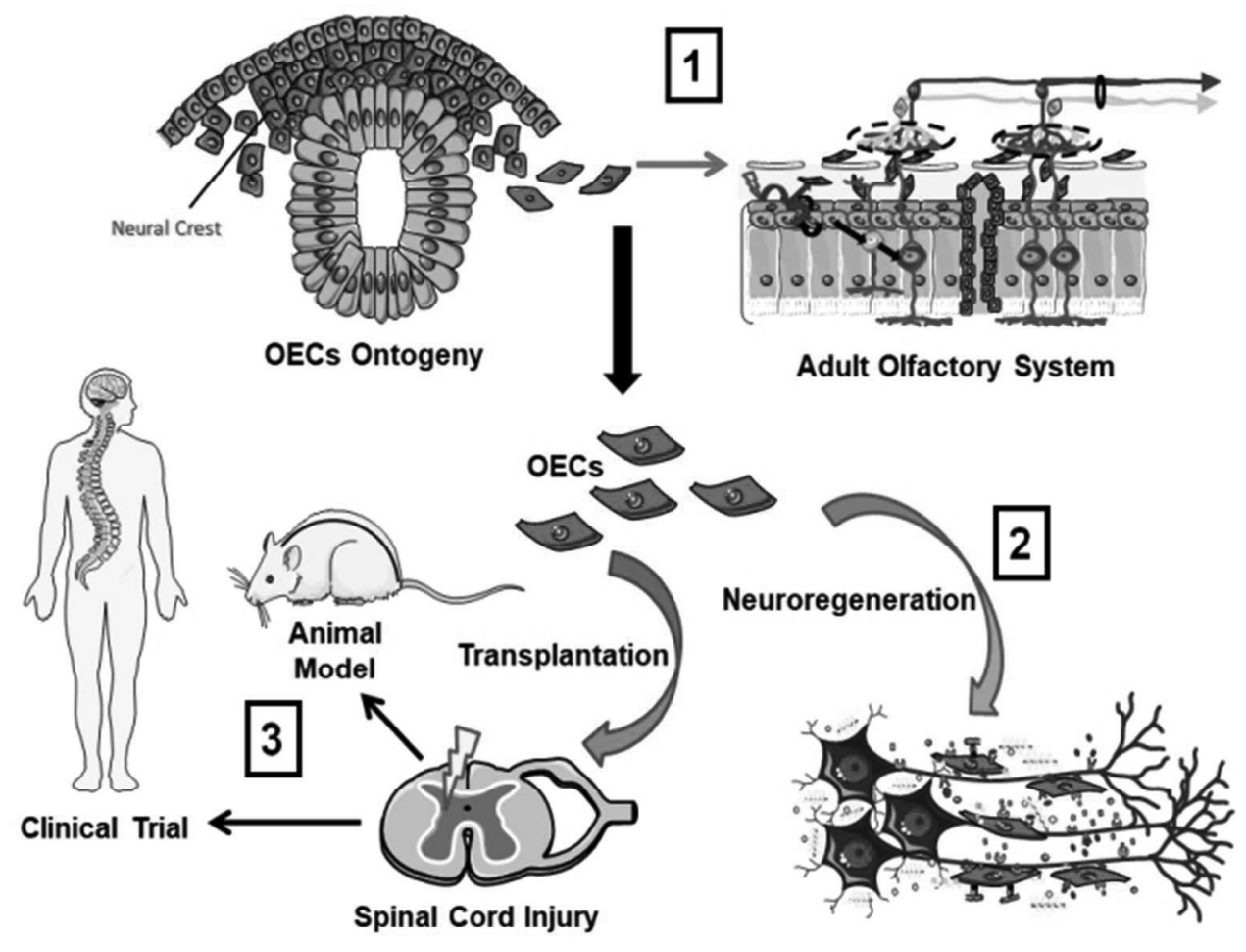

TOCI - summary graphic of the table of contents 


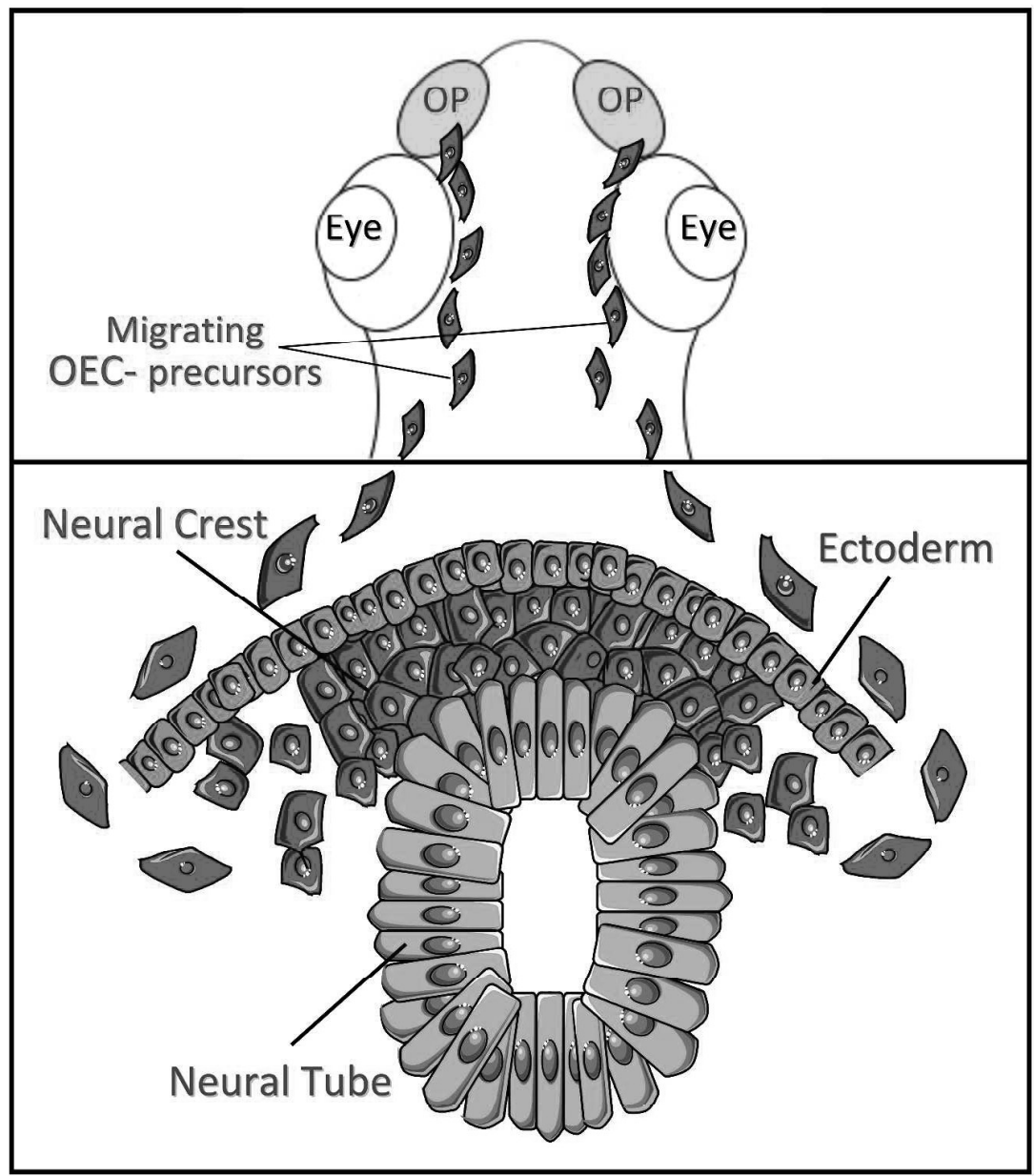

Figure 1. The neural crest as a source of OECs during development. OEC-precursors originate exclusively from the neural crest. During development, these OEC-precursors migrate to the olfactory placodes (OP; green) to subsequently form part of the olfactory system. Figures were produced using Servier Medical Art. 


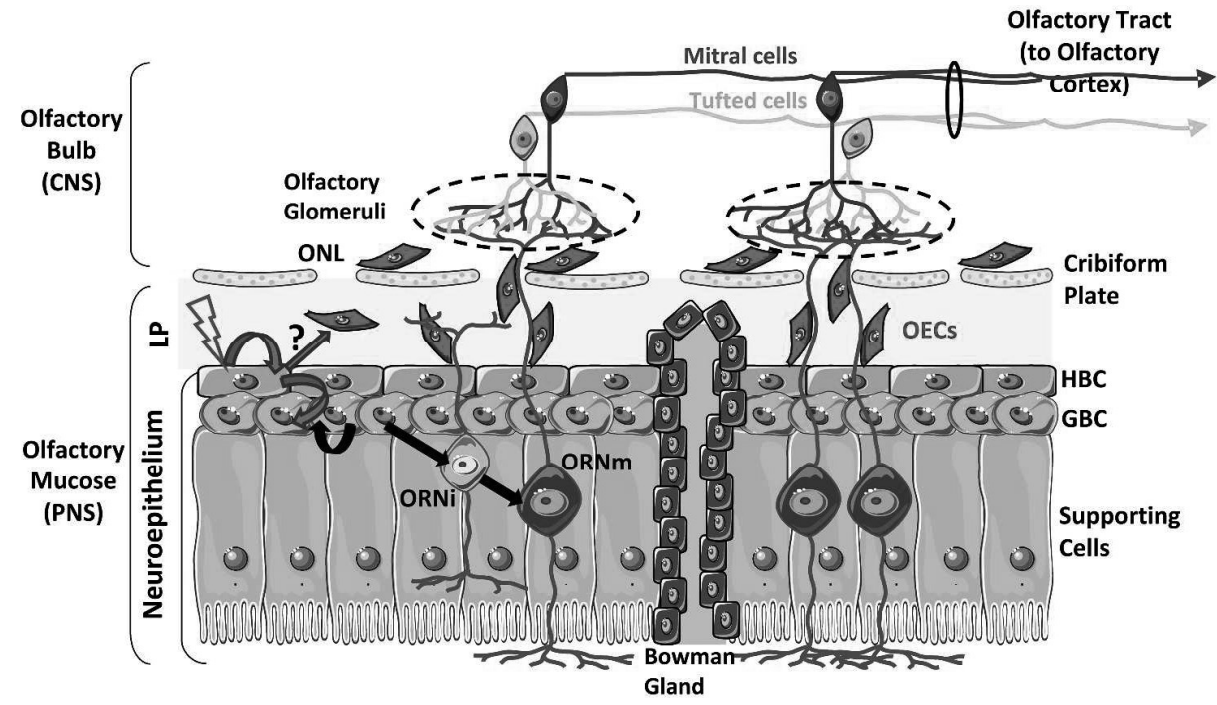

Figure 2. A schematic representation of the adult olfactory system. The cellular composition and the diverse parts of the olfactory system are shown. GBCs are the main cells that produce neurons as they proliferate (auto-renewal) and generate new olfactory neurons, ORN. These cells extend an apical dendrite and a basal axon across the LP, to reach their targets in the olfactory glomeruli situated in the CNS. There, they establish connections with mitral and tufted cells that send information through the olfactory tract to the olfactory cortex. HBCs are usually inactive but when severe injury occurs, they can self-renew and generate most of the olfactory cells needed to restock the olfactory epithelium. HBCs may also be able to generate new OECs. Abbreviations: CNS (Central Nervous System), PNS (Peripheral Nervous System), LP (Lamina Propria), HBC (Horizontal Basal Cells), GBC (Globose Basal Cells), ORNi (Immature Olfactory Receptor Neuron), ORNm (Mature Olfactory Receptor Neuron), OEC (Olfactory Ensheathing Cells). Figures were produced using Servier Medical Art. 


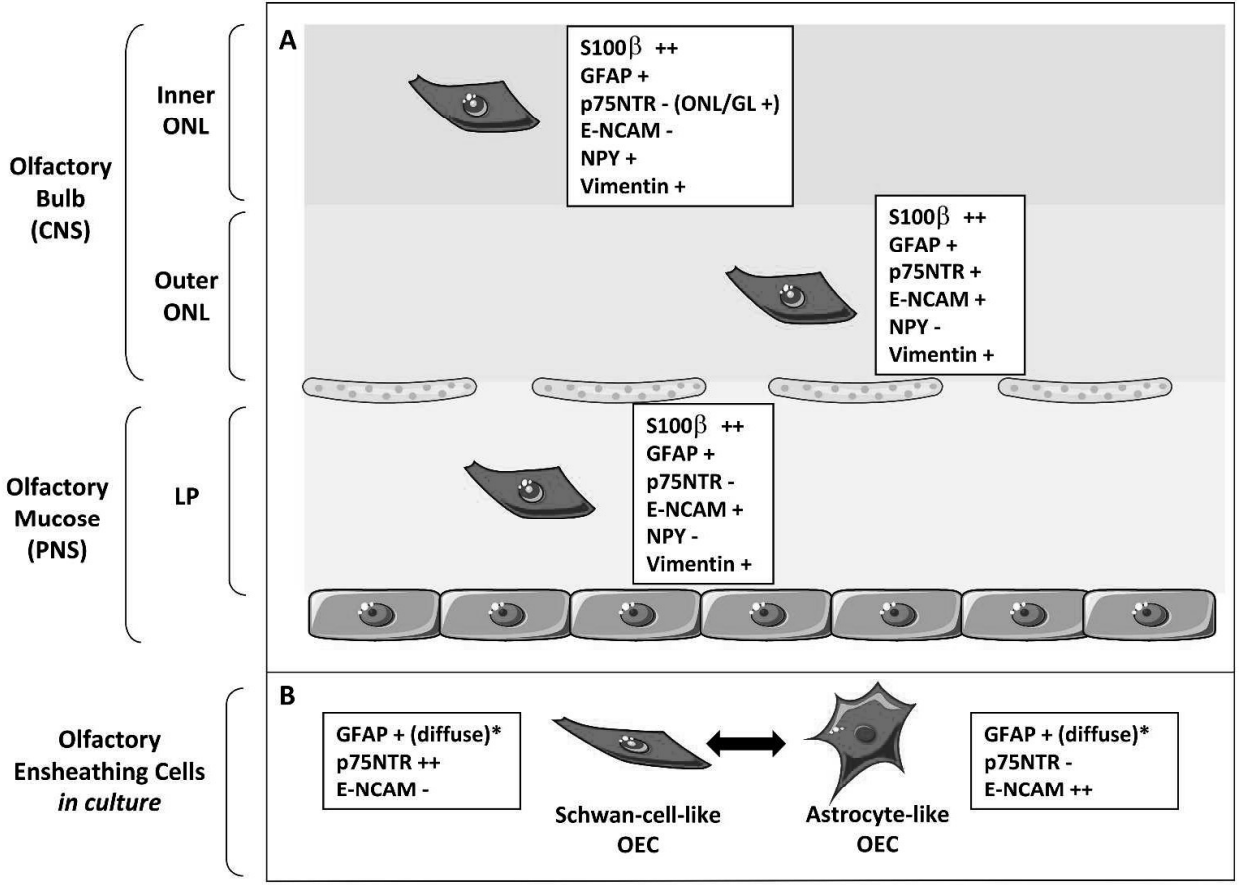

Figure 3. OECs express different specific markers. A. OECs have different antigenic phenotypes depending on their location in the CNS or PNS. Generally, OECs express vimentin, S100 $\beta$ and GFAP, although they also can express p75NTR, E-NCAM or NPY depending on the region of the CNS or PNS where they are situated. B. In vitro, OECs can be segregated into two phenotypic subpopulations: i) Schwann cell-like, characterized by a spindle shape and strong p75NTR expression; ii) and astrocyte-like, with a similar morphology to flattened astrocytes and strong E-NCAM expression. GFAP immunostaining in culture has been defined as fibrous for astrocyte-like OECs (Franceschini and Barnett, 1996), yet in our experience (Moreno-Flores et al., $2003 \mathrm{~b}$ ) this staining is always diffuse in OECs, corresponding to weak GFAP expression (in western blots) relative to cultured astrocytes. Abbreviations: CNS (Central Nervous System), GFAP (Glial Fibrillary Acidic Protein), NCAM (Neural Cell Adhesion Molecule), NPY (Neuropeptide Y), PNS (Peripheral Nervous System), LP (Lamina Propria), ONL (Olfactory Nerve Layer), OECs (Olfactory Ensheathing Cells). Figures were produced using Servier Medical Art. 


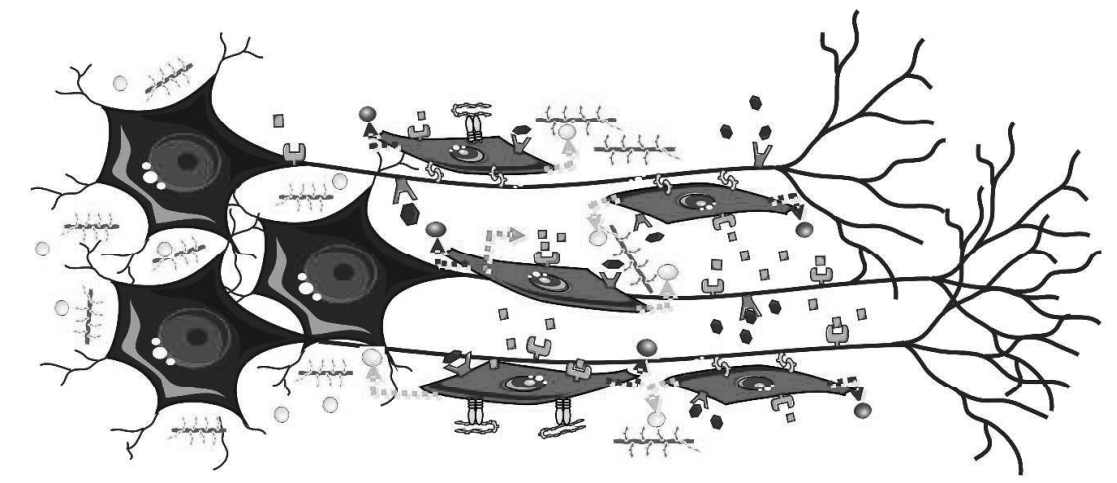

\begin{tabular}{|c|c|c|}
\hline & OECs molecules implicated in ne & euroregeneration \\
\hline Adhesion: & \multirow{2}{*}{\multicolumn{2}{|c|}{$\begin{array}{l}\text { L1, E-NCAM, Laminin, Fibronectin, Type-V Collagen } \\
\text { NGF/p75, BDNF/TrkB, GDNF/GFR } \alpha-1 \text {, NTN/GFR } \alpha-2 \text {, NRG-1/ErbB }\end{array}$}} \\
\hline $\begin{array}{l}\text { Neurotrophic (diffusible) } \\
\text { factors / Receptors }\end{array}$ & & \\
\hline $\begin{array}{l}\text { Proteases (digest CSPG and } \\
\text { PNN) }\end{array}$ & \multirow{3}{*}{$\begin{array}{l}\text { MMP2, MMP9, Serpine-1 } \\
\text { IL-6/IL-6R, CX3CL1/Fractalkine, TGF- } \beta 3 \\
\text { Nogo/NgR, Sema3A, EphrinA }\end{array}$} & \\
\hline Cytokines & & \\
\hline Inhibitory Factors/Receptors & & \\
\hline
\end{tabular}

Figure 4. Interactions between OECs and neurons implicated in neuroregeneration. Under physiological conditions OECs and neurons are in permanent communication through the interaction of adhesion molecules, diffusible neurotrophic factors, proteases and cytokines. Inhibitory factors, both ligands and receptors, can establish axon pathways and/or hinder OEC migration. Abbreviations: CSPG (Chondroitin sulphate proteoglycans), OECs (Olfactory Ensheathing Cells), PNN (Perineuronal Net). Figures were produced using Servier Medical Art. 


\section{TABLE 1. Factors expressed by OECs}

\section{A) Expression of Pro-Regenerative Factors}

\begin{tabular}{|c|c|c|c|c|}
\hline & Factors & References & Receptors & References \\
\hline \multirow{5}{*}{ 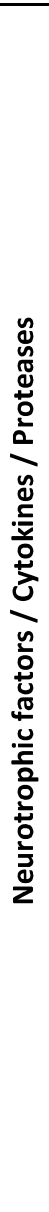 } & $\begin{array}{l}\text { Neuregulins (NRG) } \\
\text { Nerve Growth Factor (NGF) } \\
\text { Brain Derived Neuro-trophic } \\
\text { Factor (BDNF) } \\
\text { Glial cell line-derived } \\
\text { neurotrophic factor (GDNF) } \\
\text { Neurturin (NTN) } \\
\text { Neurotrophin (NT)-4 } \\
\text { Ciliary Neurotrophic Factor } \\
\text { (CNTF) }\end{array}$ & $\begin{array}{c}\text { Boruch et al., } 2001 \\
\text { Lipson et al., } 2003 \\
\text { Moreno-Flores et al., } 2002 \\
\text { Pastrana et al., } 2007 \\
\text { Woodhall et al., } 2001\end{array}$ & $\begin{array}{l}\text { ErbB2-4 } \\
\text { P75NTR } \\
\text { TrkB } \\
\text { TrkC } \\
\text { GFR } \alpha-1 \\
\text { GFR } \alpha-2\end{array}$ & $\begin{array}{l}\text { Franceschini \& Barnett } \\
\qquad 1996 \\
\text { Lipson et al., } 2003 \\
\text { Moreno-Flores et al., } \\
\text { 2003a\&b } \\
\text { Pollock et al., } 1999 \\
\text { Ramón-Cueto\&Nieto- } \\
\text { Sampedro, } 1992 \\
\text { Woodhall et al., } 2001\end{array}$ \\
\hline & S100 $\beta$ & $\begin{array}{l}\text { Franceschini and Barnett, } \\
1996 \\
\text { Lipson et al., } 2003 \\
\text { Moreno-Flores et al., } \\
\text { 2003a\&b } \\
\text { Pastrana et al., } 2006 \\
\text { Lim et al., 2010 } \\
\text { Vincent et al., } 2005\end{array}$ & - & - \\
\hline & $\begin{array}{l}\text { Interleukin-6 } \\
\text { (bulbectomy) } \\
\text { CX3CL1/Fractalkine } \\
\text { Other Cytokines (TGF } 33 \text { ) }\end{array}$ & $\begin{array}{c}\text { Nan et al., } 2001 \\
\text { Ruitenberg et al., } 2008 \\
\text { Pastrana et al., } 2006\end{array}$ & $\begin{array}{l}\text { IL-6R and LIFR } \\
\text { (bulbectomy) } \\
\text { Other cytokine receptors } \\
\text { (TNFR and IL1RL1) }\end{array}$ & $\begin{array}{l}\text { Nan et al., 2001; } \\
\text { Pastrana et al., } 2006 \\
\text { Roet and Verhaagen, } \\
2014\end{array}$ \\
\hline & $\begin{array}{l}\text { Matrix Metalloproteases: } \\
\text { MMP2 and MMP9 }\end{array}$ & Pastrana et al., 2006 & - & - \\
\hline & Serpine-1 & Simon et al., 2011 & - & - \\
\hline $\begin{array}{l}\frac{y}{3} \\
\frac{d}{0} \\
\frac{0}{0} \\
\frac{0}{y} \\
\frac{0}{y} \\
\frac{1}{4}\end{array}$ & $\begin{array}{l}\text { L1 } \\
\text { E-NCAM } \\
\text { Laminin } \\
\text { Fibronectin } \\
\text { Type IV collagen } \\
\text { Amyloid Precursor Protein } \\
\text { (APP) }\end{array}$ & $\begin{array}{c}\text { Doucette, } 1996 \\
\text { Franceschini and Barnett, } \\
1996 \\
\text { Kafitz and Greer, } 1998 \\
\text { Moreno-Flores et al., 2003a }\end{array}$ & - & - \\
\hline
\end{tabular}

\begin{tabular}{|c|c|c|c|c|}
\hline & \multicolumn{4}{|c|}{ B) Expression of Inhibitory Factors } \\
\hline & Factors & References & Receptors/Others & References \\
\hline \multirow{5}{*}{$\frac{\frac{c}{0}}{\frac{0}{\pi}}$} & $\begin{array}{l}\text { Nogo } \\
\text { Myelin } \\
\text { Chondroitin Sulphate } \\
\text { Proteoglycan (CSPG) }\end{array}$ & $\begin{array}{c}\text { Nocentini et al., } 2012 \\
\text { Reginensi et al., } 2015 \\
\text { Su et al., } 2007\end{array}$ & NgR & $\begin{array}{l}\text { Nocentini et al., } 2012 \\
\text { Su et al., } 2007 \\
\text { Woodhall et al., } 2003\end{array}$ \\
\hline & - & - & TIMP2 & Pastrana et al., 2006 \\
\hline & Ephrin A1 & Pastrana et al., 2006 & - & - \\
\hline & $\begin{array}{l}\text { Slit-2 (migration inhibitor for } \\
\text { OEG) }\end{array}$ & $\begin{array}{c}\text { Huang et al., } 2011 \\
\text { Wang and Huang, } 2012\end{array}$ & Robo receptors & $\begin{array}{c}\text { Huang et al., } 2011 \\
\text { Wang and Huang, } 2012 \\
\end{array}$ \\
\hline & Fibulin-3 & Vukovic et al., $2009 \mathrm{~b}$ & & \\
\hline
\end{tabular}




\begin{tabular}{|c|c|c|c|c|}
\hline & \multicolumn{4}{|c|}{ TABLE 2. Factors secreted by OECs } \\
\hline & \multicolumn{2}{|c|}{ Pro-regenerative Factors } & \multicolumn{2}{|c|}{ Inhibitory Factors } \\
\hline & Factors & References & Factors & References \\
\hline \multirow{4}{*}{ 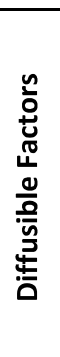 } & Neuregulins (NRG) & Boruch et al., 2001 & \multirow{2}{*}{ Semaphorin $3 \mathrm{~A}$} & \multirow{2}{*}{ Schwarting et al., 2000} \\
\hline & $\begin{array}{l}\text { Nerve Growth Factor } \\
\text { (NGF) } \\
\text { Brain Derived } \\
\text { Neurotrophic Factor } \\
\text { (BDNF) } \\
\end{array}$ & $\begin{array}{l}\text { Pastrana et al., 2007; } \\
\text { Woodhall et al., } 2001\end{array}$ & & \\
\hline & MMP2 y MMP9 & Pastrana et al., 2006 & & \\
\hline & Serpine-1 & Simon et al., 2011 & & \\
\hline
\end{tabular}




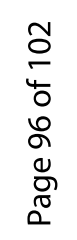

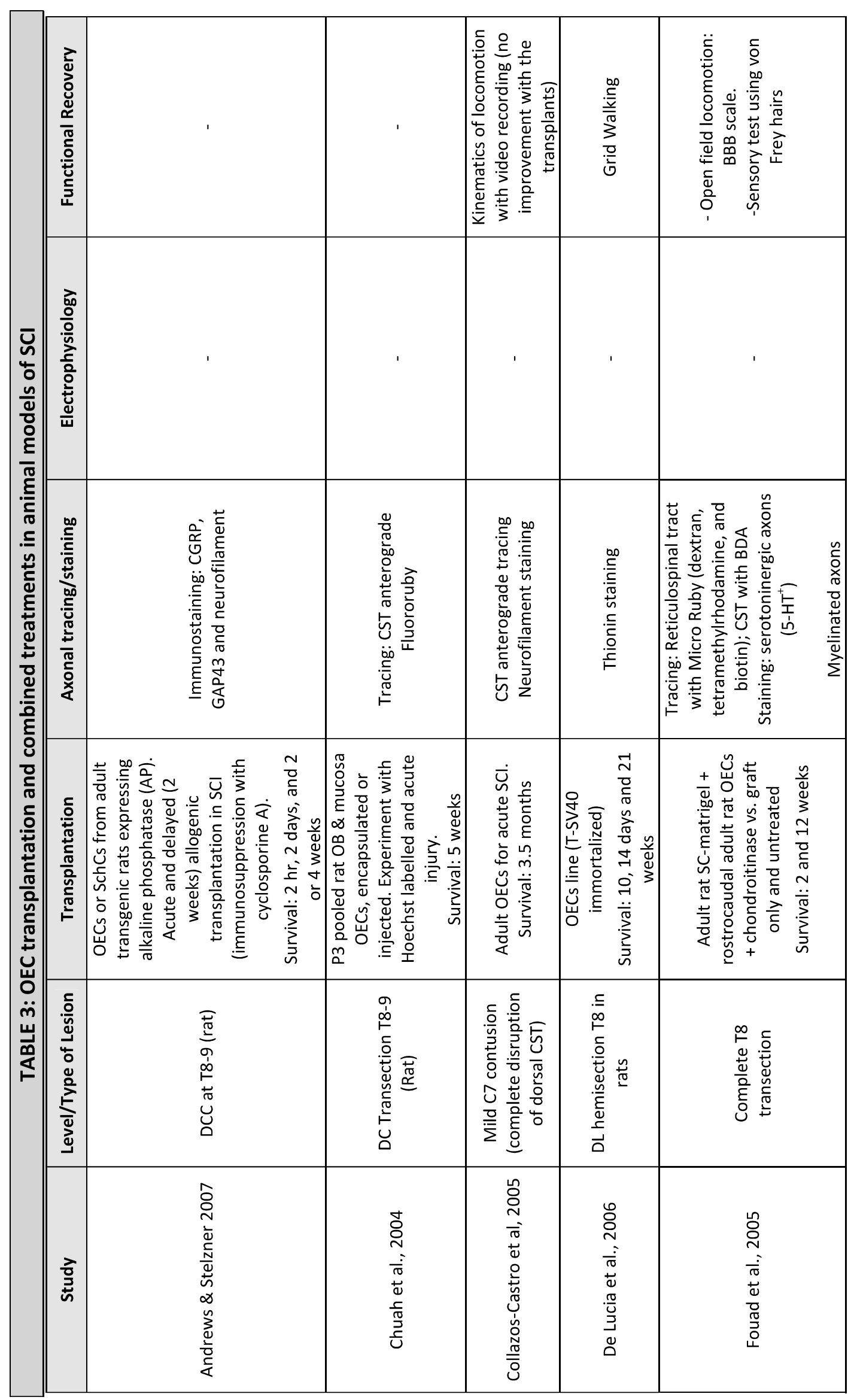




\begin{tabular}{|c|c|c|c|c|}
\hline 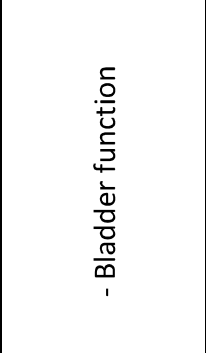 & 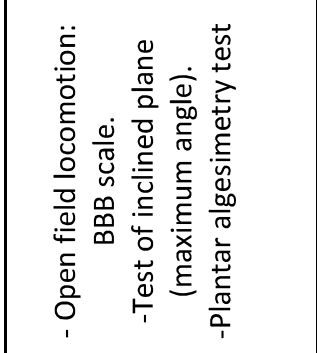 & 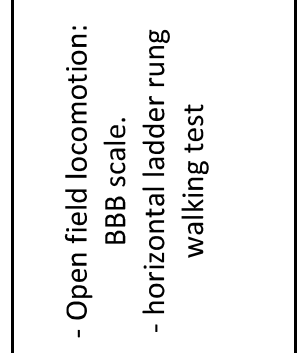 & 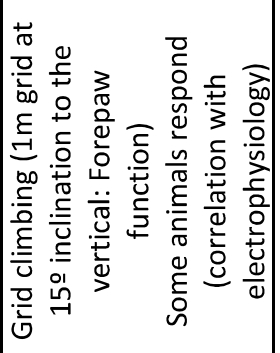 & 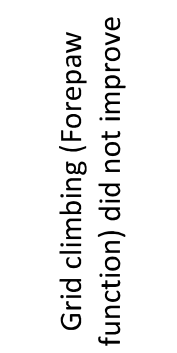 \\
\hline ' & 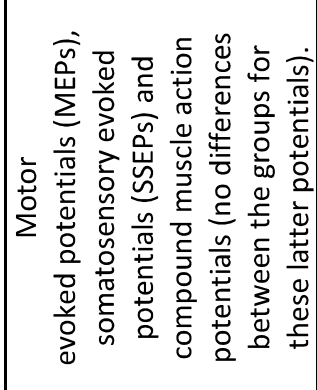 & גו & 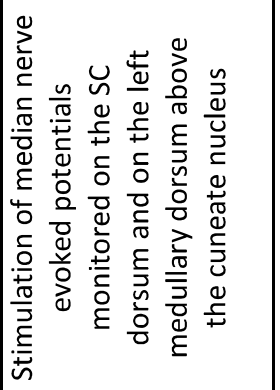 & ' \\
\hline 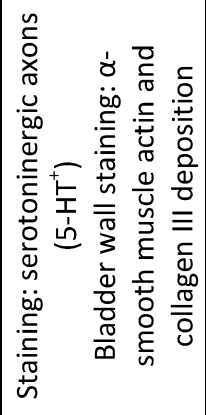 & 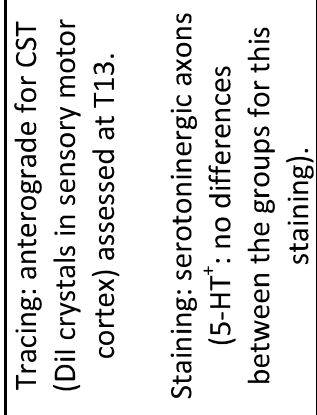 & 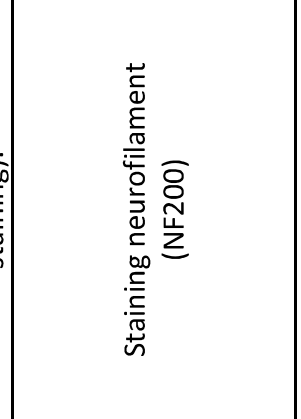 & 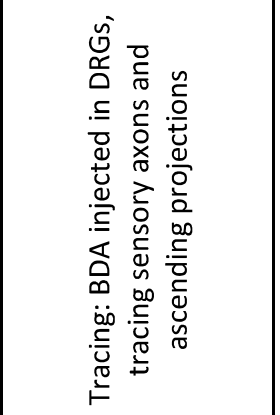 & 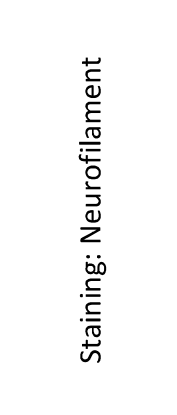 \\
\hline 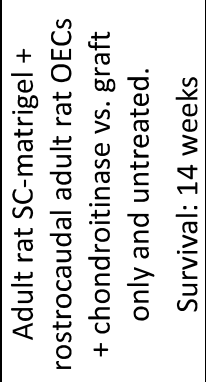 & 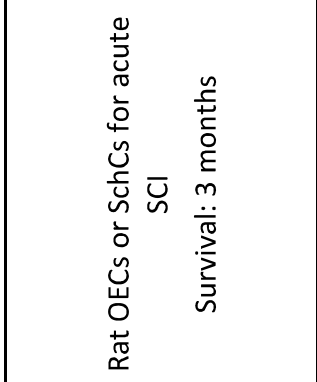 & 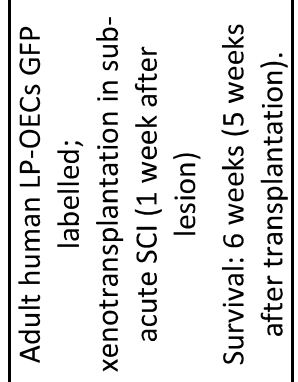 & 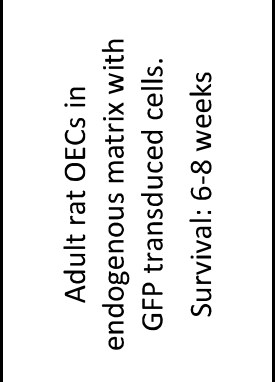 & 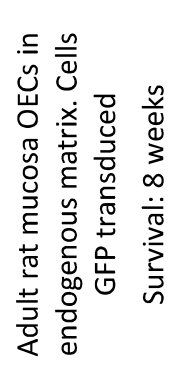 \\
\hline 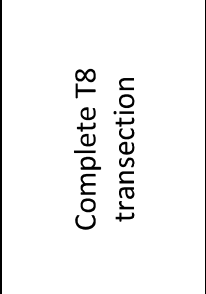 & 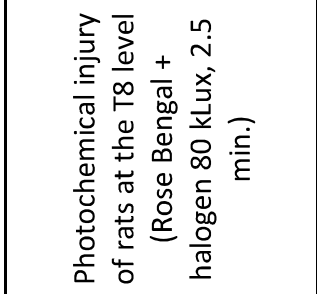 & 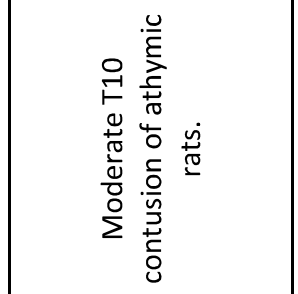 & 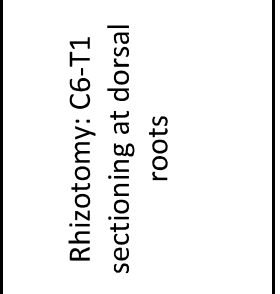 & 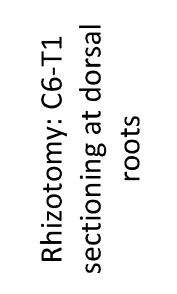 \\
\hline 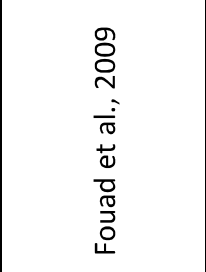 & 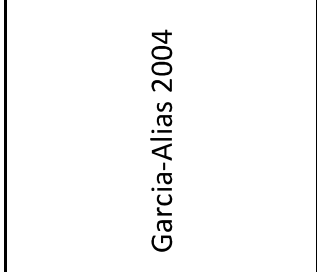 & 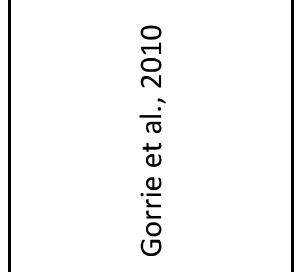 & 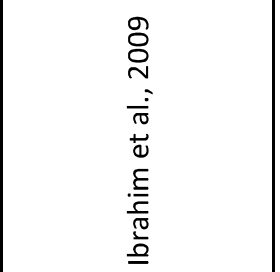 & 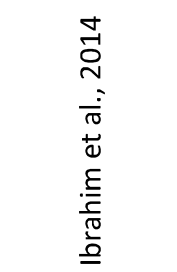 \\
\hline
\end{tabular}




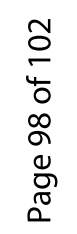

\begin{tabular}{|c|c|c|c|c|c|c|}
\hline ' & ' & 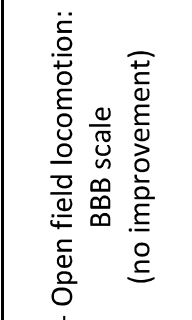 & & & 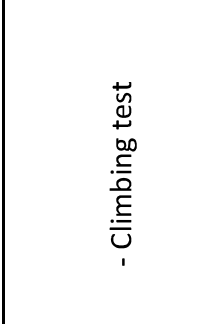 & 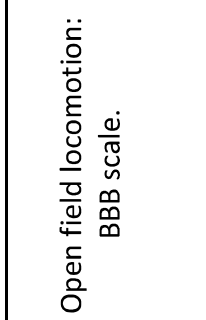 \\
\hline 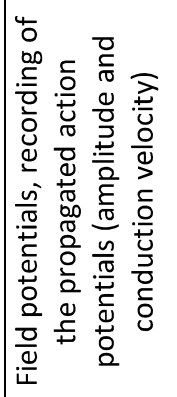 & 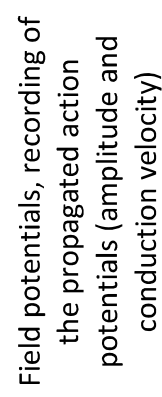 & ' & ' & ' & 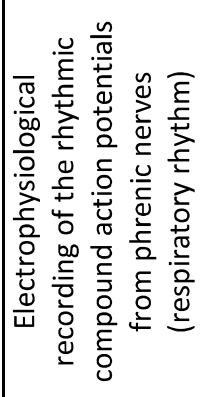 & 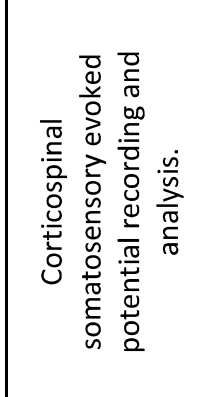 \\
\hline 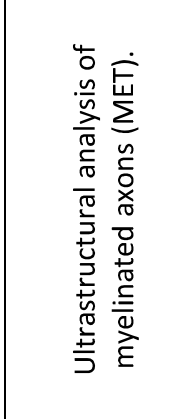 & 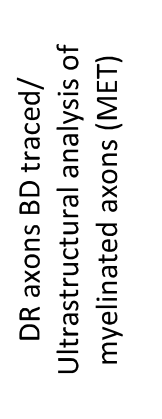 & 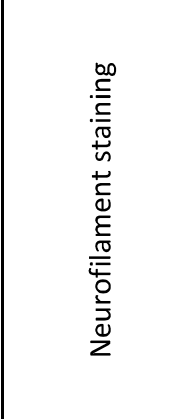 & 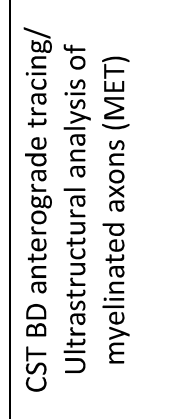 & 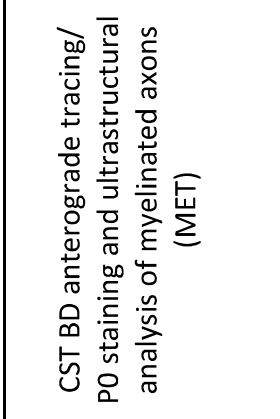 & 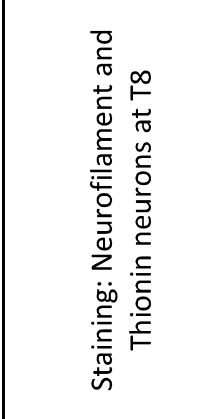 & 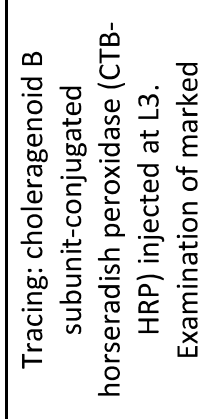 \\
\hline 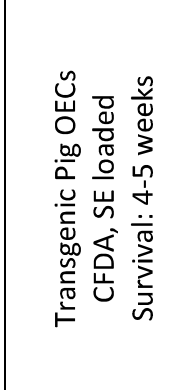 & 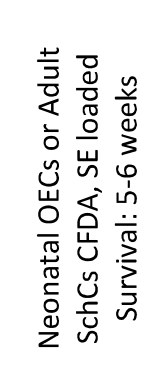 & 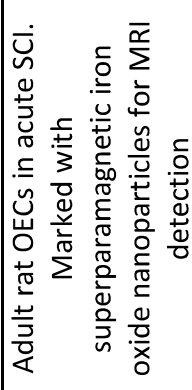 & 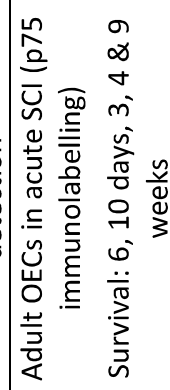 & 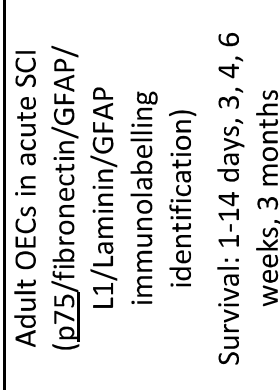 & 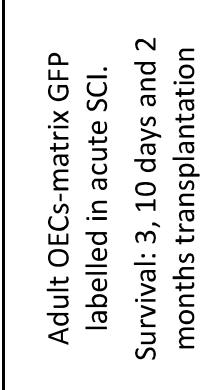 & 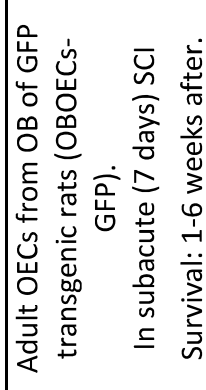 \\
\hline 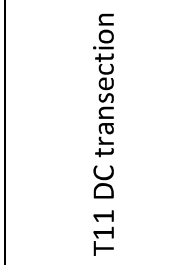 & 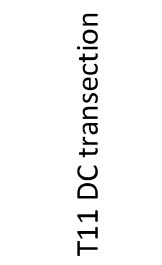 & 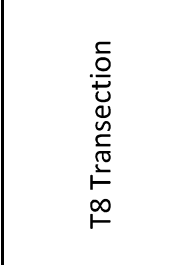 & 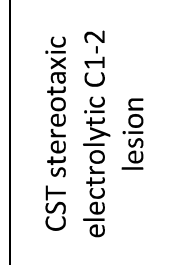 & 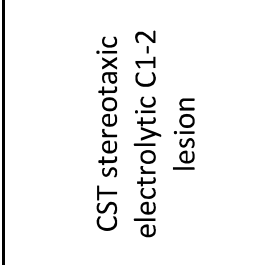 & 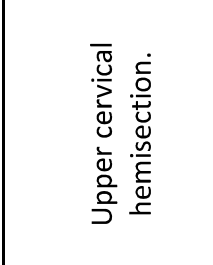 & 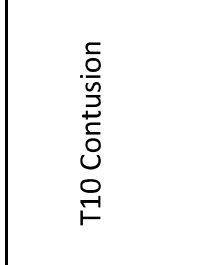 \\
\hline 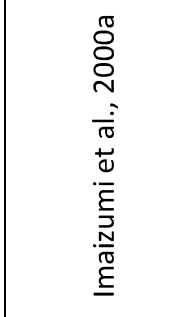 & 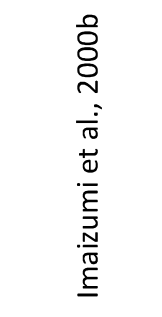 & 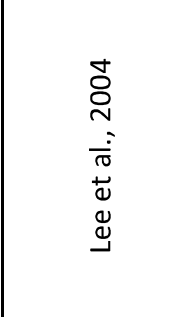 & 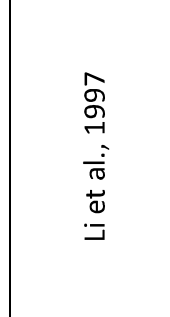 & 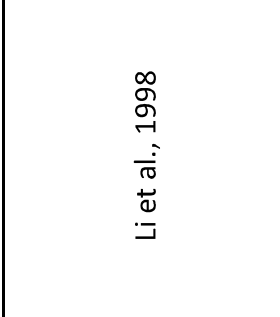 & 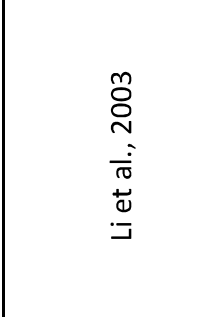 & 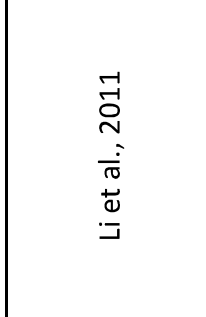 \\
\hline
\end{tabular}




\begin{tabular}{|c|c|c|c|c|}
\hline 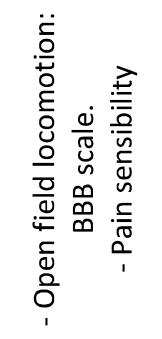 & 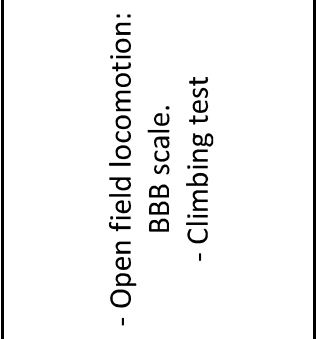 & 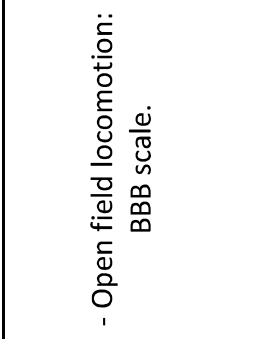 & 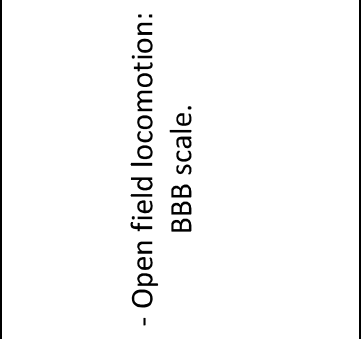 & 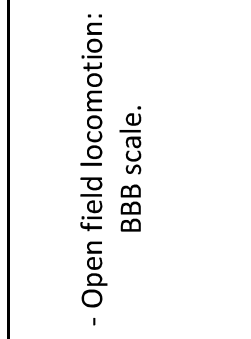 \\
\hline 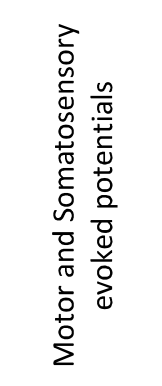 & 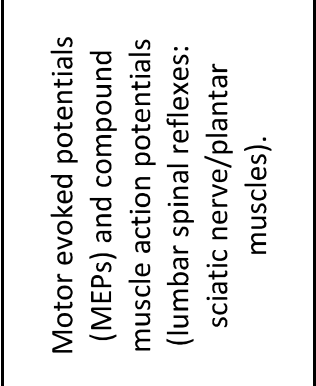 & 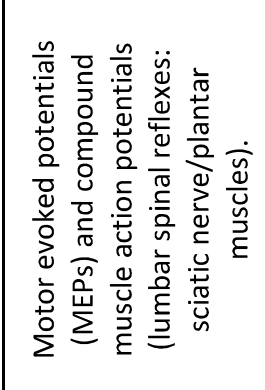 & 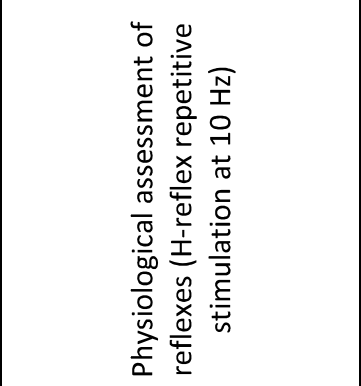 & \\
\hline 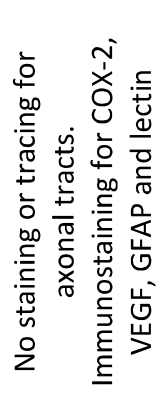 & 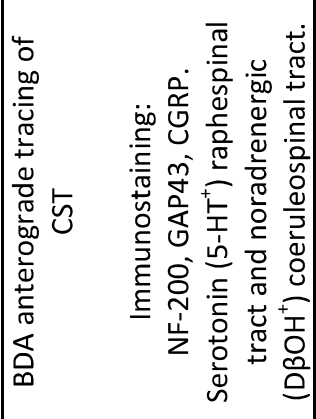 & 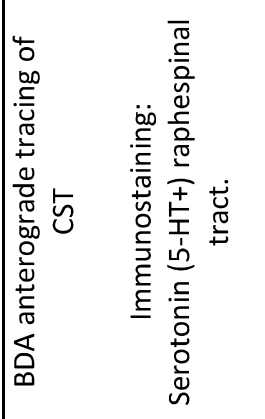 & 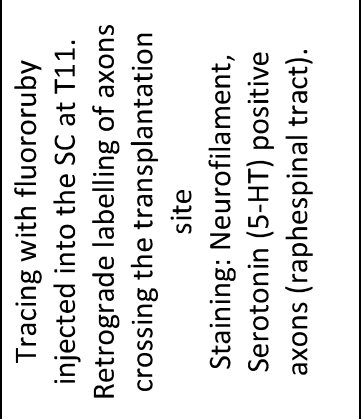 & 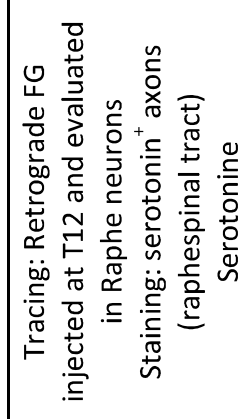 \\
\hline 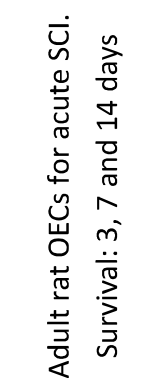 & 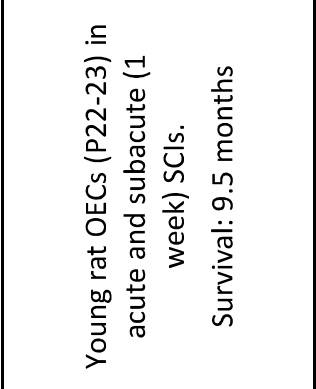 & 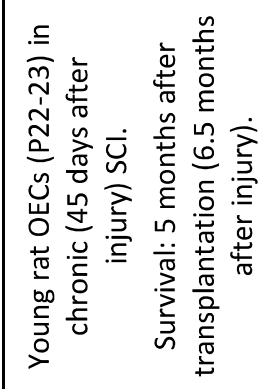 & 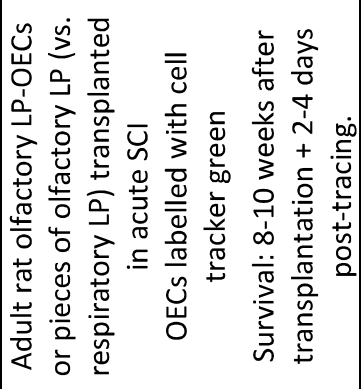 & 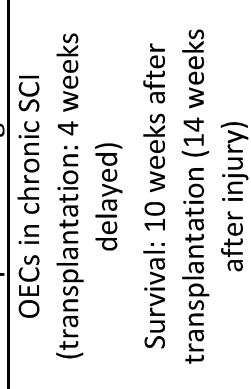 \\
\hline 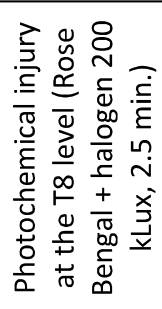 & 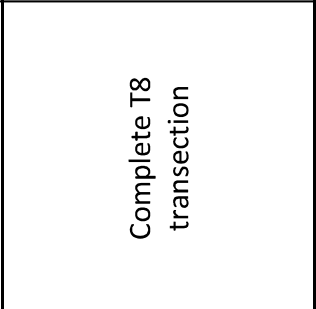 & 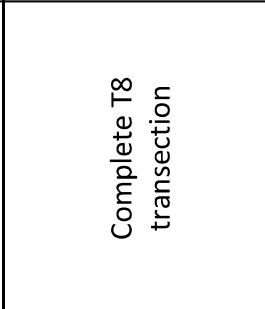 & 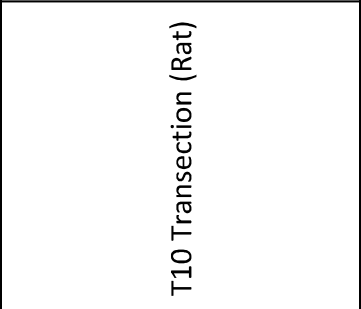 & 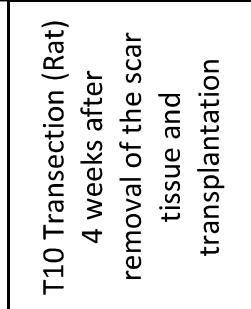 \\
\hline 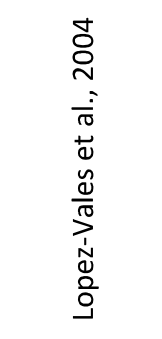 & 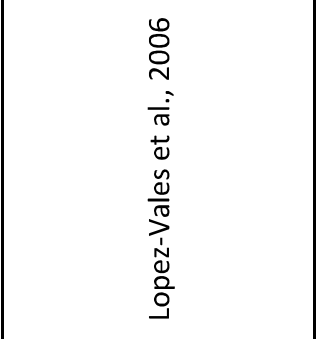 & 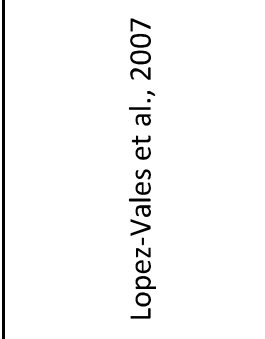 & 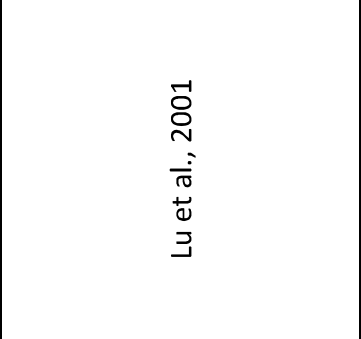 & 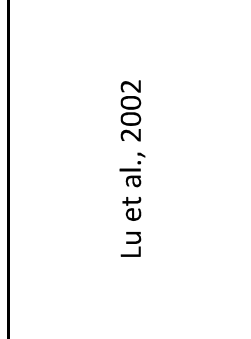 \\
\hline
\end{tabular}




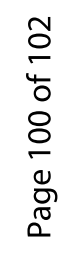

\begin{tabular}{|c|c|c|c|c|c|c|}
\hline 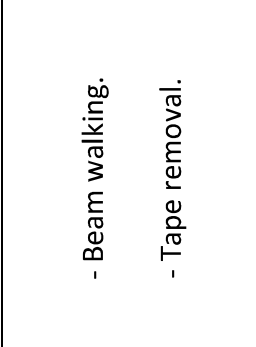 & 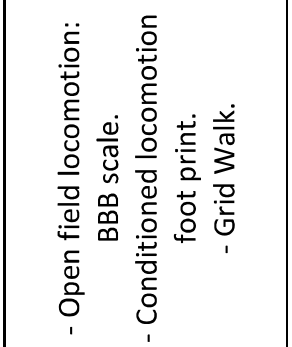 & 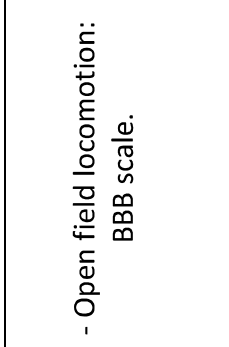 & ' & & & 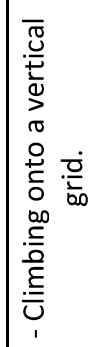 \\
\hline & 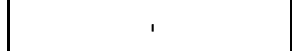 & & ' & & & ' \\
\hline 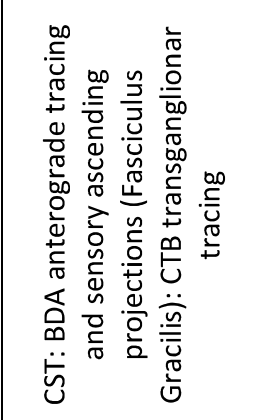 & 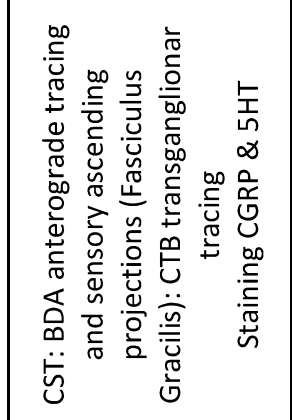 & 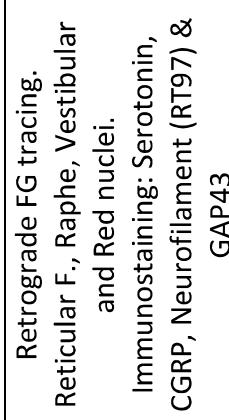 & 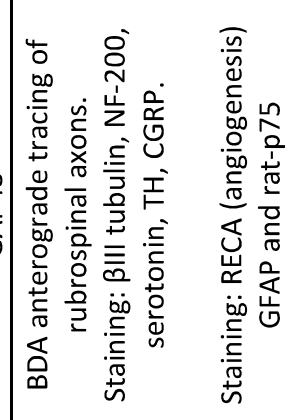 & 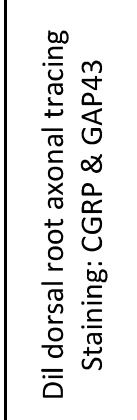 & 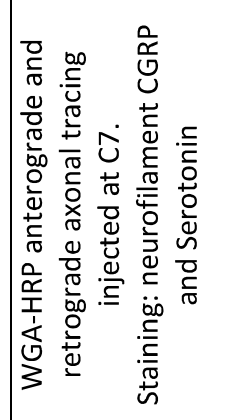 & 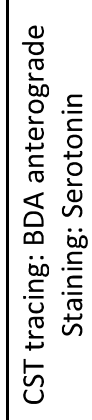 \\
\hline 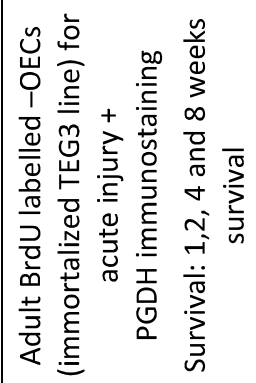 & 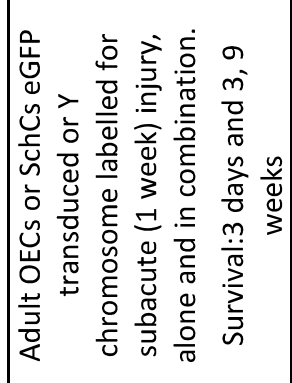 & 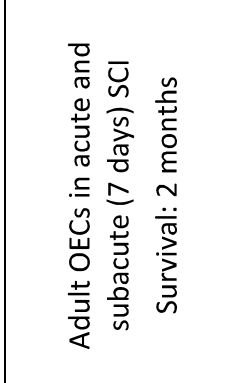 & 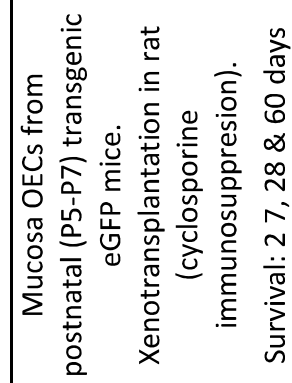 & 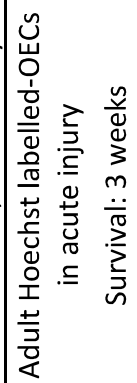 & 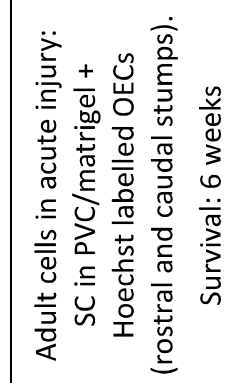 & 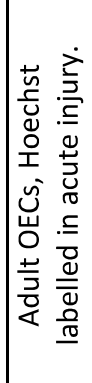 \\
\hline $\begin{array}{l}\frac{1}{5} \\
\text { ỹ } \\
0 \\
0 \\
u \\
0\end{array}$ & 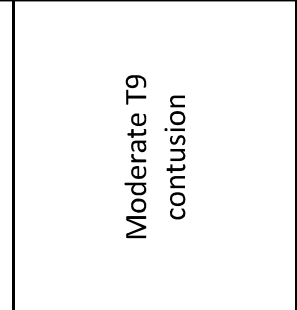 & 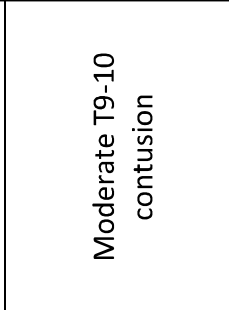 & 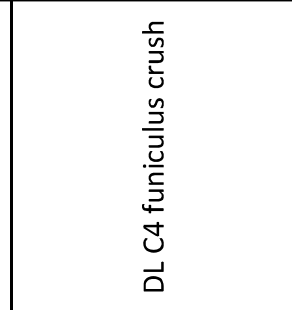 & 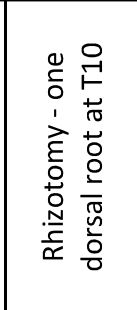 & 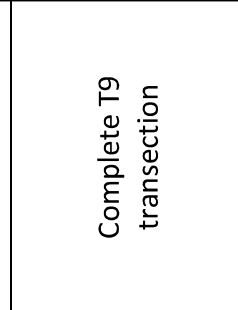 & 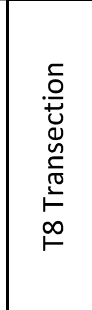 \\
\hline 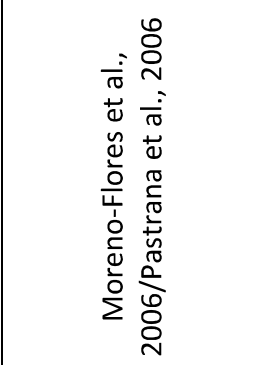 & 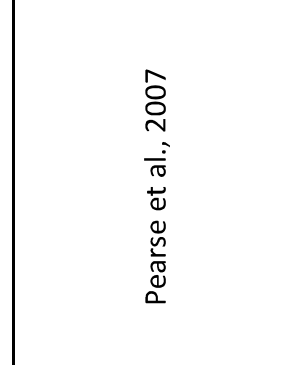 & 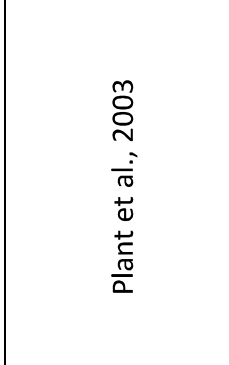 & 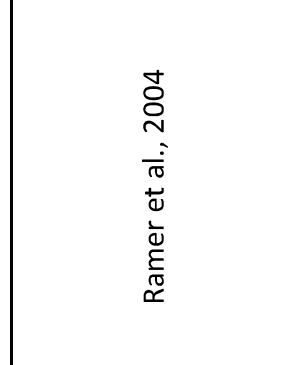 & 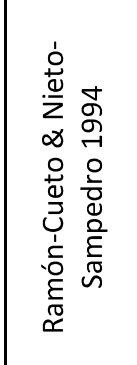 & 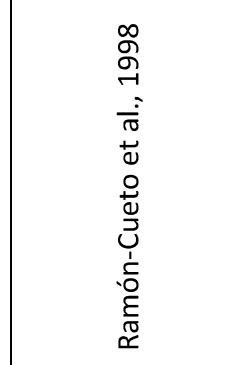 & 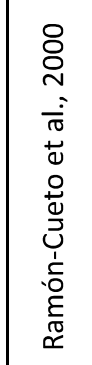 \\
\hline
\end{tabular}




\begin{tabular}{|c|c|c|c|c|c|}
\hline \multirow[t]{2}{*}{ 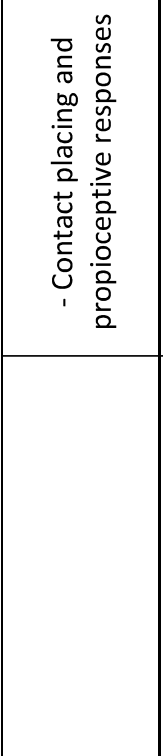 } & 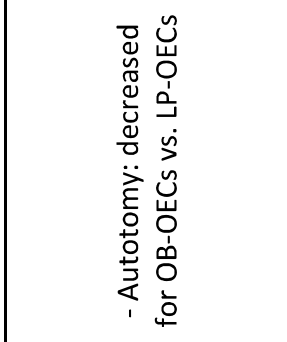 & 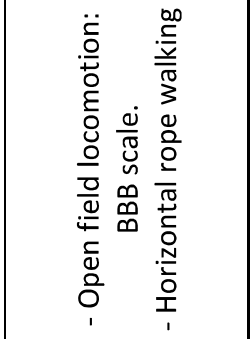 & 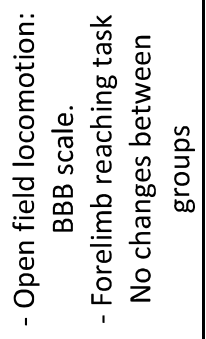 & 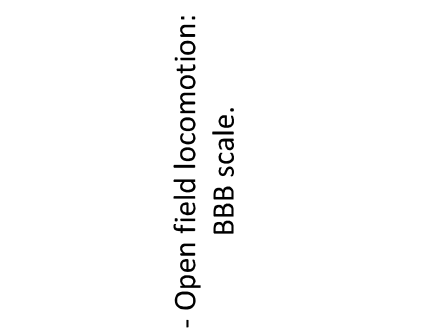 & ' \\
\hline & ' & 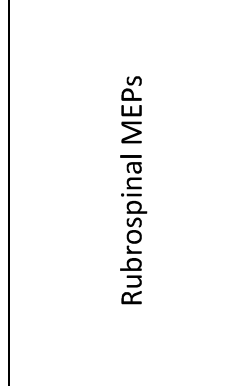 & & & 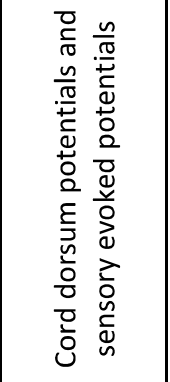 \\
\hline 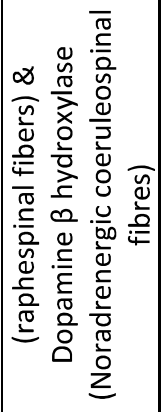 & 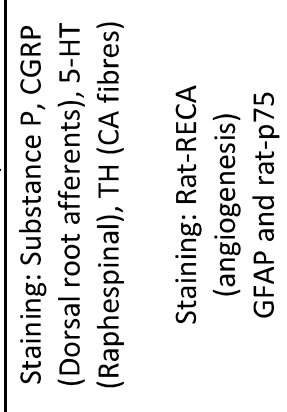 & 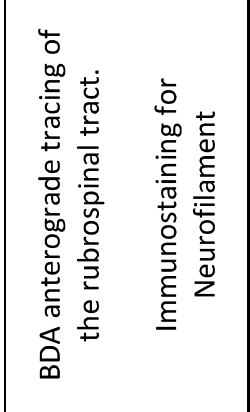 & 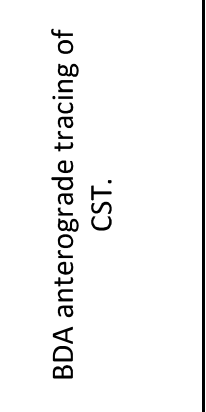 & 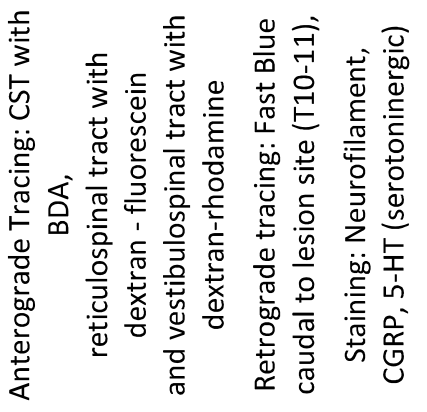 & 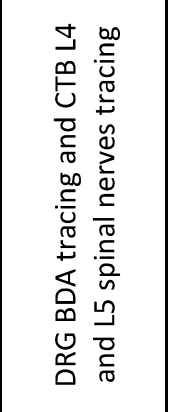 \\
\hline \multirow[t]{3}{*}{ 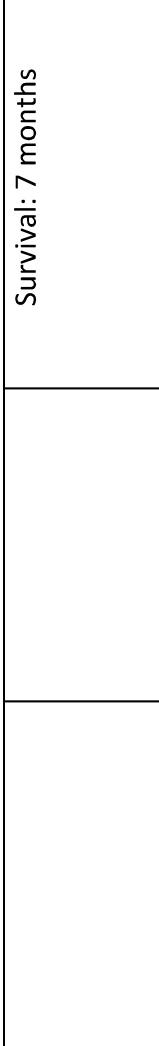 } & 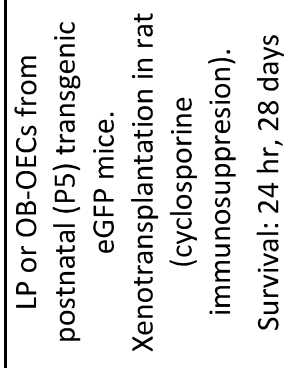 & 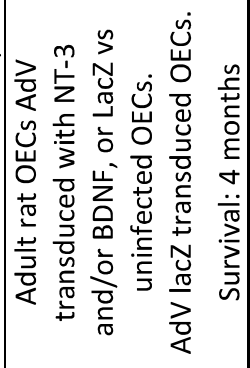 & 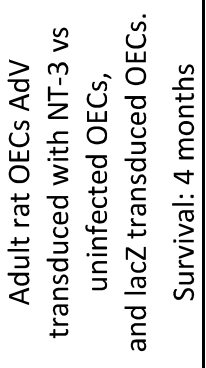 & 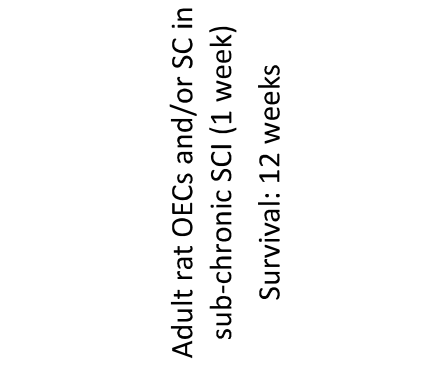 & 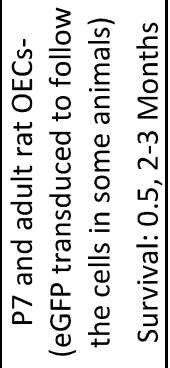 \\
\hline & 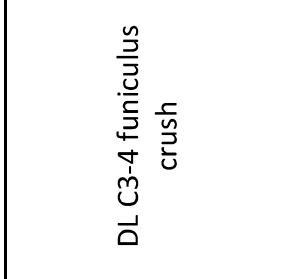 & 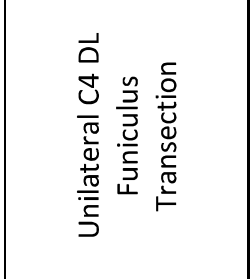 & 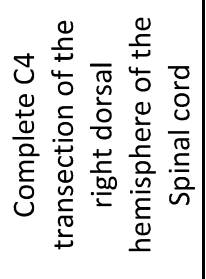 & 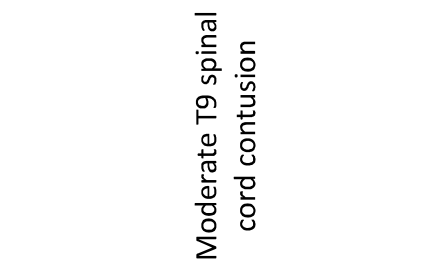 & 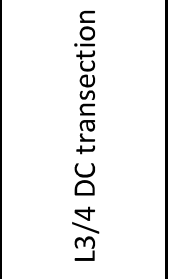 \\
\hline & 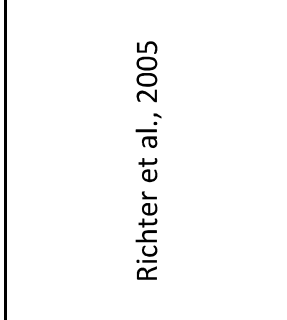 & 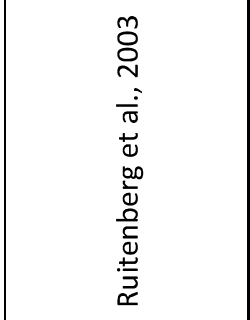 & 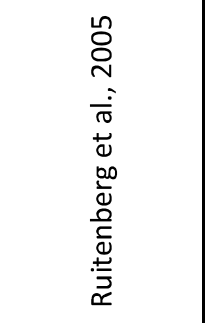 & 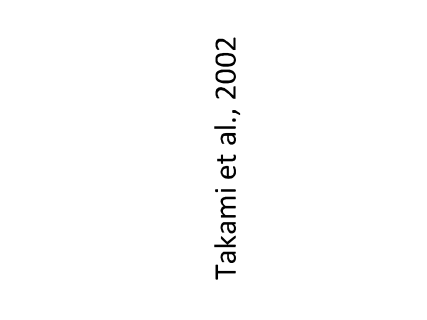 & 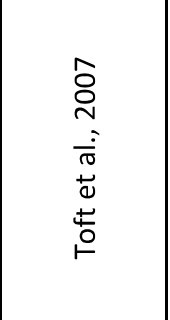 \\
\hline
\end{tabular}




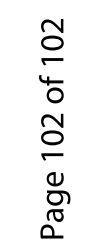

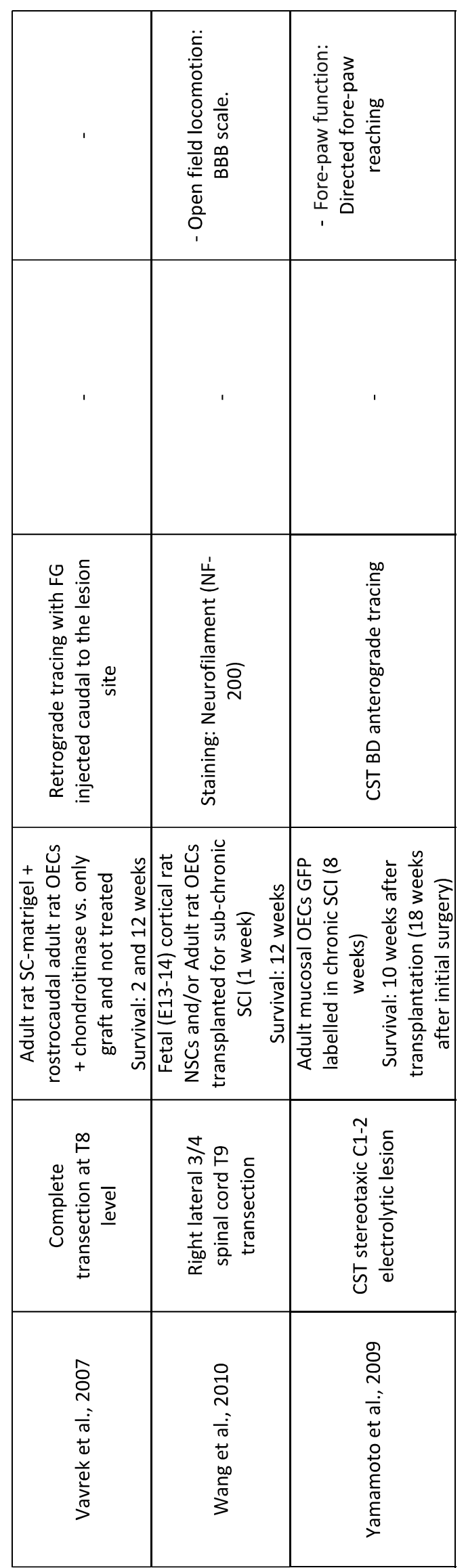

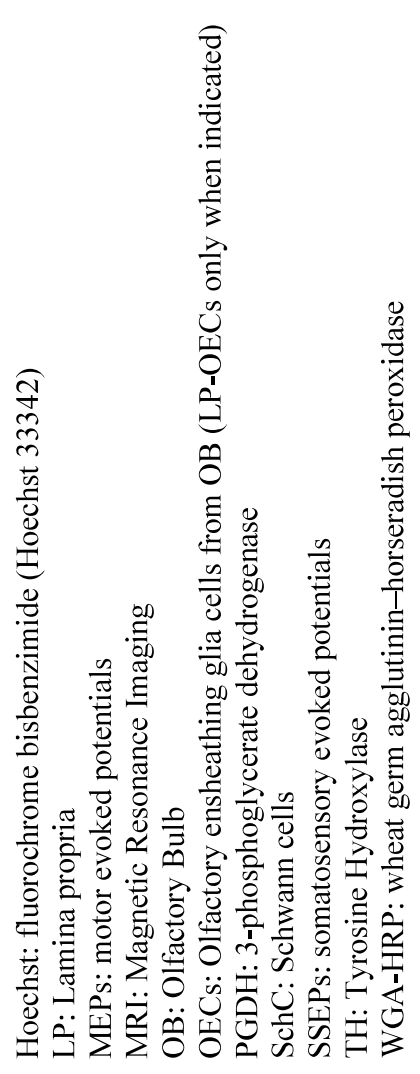

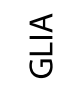

